University of Louisville

ThinkIR: The University of Louisville's Institutional Repository

Electronic Theses and Dissertations

$5-2017$

\title{
Characterization of a mutant oncolytic adenovirus and the role of jnk in enhancing virotherapy.
}

Stephen L. Wechman

University of Louisville

Follow this and additional works at: https://ir.library.louisville.edu/etd

Part of the Medical Pharmacology Commons, and the Medical Toxicology Commons

\section{Recommended Citation}

Wechman, Stephen L., "Characterization of a mutant oncolytic adenovirus and the role of jnk in enhancing virotherapy." (2017). Electronic Theses and Dissertations. Paper 2734.

https://doi.org/10.18297/etd/2734

This Doctoral Dissertation is brought to you for free and open access by ThinkIR: The University of Louisville's Institutional Repository. It has been accepted for inclusion in Electronic Theses and Dissertations by an authorized administrator of ThinkIR: The University of Louisville's Institutional Repository. This title appears here courtesy of the author, who has retained all other copyrights. For more information, please contact thinkir@louisville.edu. 


\title{
CHARACTERIZATION OF A MUTANT ONCOLYTIC ADENOVIRUS AND THE ROLE OF JNK IN ENHANCING VIROTHERAPY
}

\author{
By \\ Stephen L. Wechman \\ B.S., Georgetown College, 2011 \\ M.S., University of Louisville, 2015

\begin{abstract}
A Dissertation
Submitted to the Graduate Faculty of the University of Louisville School of Medicine in Partial Fulfillment of the Requirements for the degree of
\end{abstract} \\ Doctor of Philosophy \\ in Pharmacology and Toxicology \\ Department of Pharmacology and Toxicology \\ University of Louisville \\ Louisville, Kentucky
}

May 2017 



\title{
CHARACTERIZATION OF A MUTANT ONCOLYTIC ADENOVIRUS AND THE ROLE OF JNK IN ENHANCING VIROTHERAPY
}

\author{
By \\ Stephen L. Wechman \\ B.S., Georgetown College, 2011 \\ M.S., University of Louisville 2015
}

A Dissertation Approved on

February $8^{\text {th }}, 2017$

by the following Dissertation Committee:

Kelly M. McMasters, M.D., Ph.D.

Heshan Sam Zhou, Ph.D.

J. Christopher States, Ph.D.

Kenneth E. Palmer, Ph.D.

Wolfgang Zacharias, Ph.D. 


\section{DEDICATION}

I dedicate this thesis to my beloved daughter,

Eleanor Elizabeth Wechman,

who has shown me the true value of curiosity and determination. 


\section{ACKNOWLEDGEMENTS}

It is impossible for me to properly acknowledge everyone who has helped me along my graduate school career these 5 years and 6 months; however, please know that even if you are not mentioned here I have cherished our time together. First, I would like to acknowledge my mentor, Dr. Kelly McMasters. It was a pleasure to work with you and to gain experience in the field of oncolytic virotherapy, which I have been very interested in ever since I was an undergraduate. It was truly an honor and a privilege to be a part of your laboratory. To Dr. Sam Zhou, over the years I have learned how to properly design my experiments as well as write scientifically due to your guidance. Any success I have achieved stems directly from your hard work and advice. I am very grateful for everything that you and Dr. McMasters have done for me.

I would also like to posthumously acknowledge the contributions of my former committee member and friend, Dr. Steven Myers (1956 - 2016). Dr. Myers and I started working together 4 years ago to teach his introduction to pharmacology course while I served as his teaching assistant in the spring of 2013. We continued working and teaching together until he died (December $4^{\text {th }}$, 2016). It is truly impossible for me to state how much Dr. Myers helped me progress my career. To give just one example, I asked if he could send my teaching evaluations to Virginia Commonwealth University (VCU) just a few weeks prior to his hospitalization and death. Dr. Myers sent these documents to 
VCU to support my application for a postdoctoral fellowship requiring skilled instructors. Two days before Dr. Myers died, I received my official offer letter for this position and its associated NIH-sponsored fellowship. I regret that I was not able to share this exciting news with him. This position represents the logical next step in my career and should bring me closer to achieving my dreams. Without Dr. Myers, I would not have been qualified for this position. I had the pleasure of meeting his son, Alex Myers, on many occasions. I extend my deepest love and support to his family which has lost more than I can imagine. Dr. Myers was a great man. I miss him greatly and I wish I could express my gratitude to him personally.

I would also like to acknowledge my other committee members: Dr. Chris States, Dr. Kenneth Palmer, and Dr. Wolfgang Zacharias. Dr. States and Dr. Palmer were also a part of my master's thesis committee, and with their advice, I was able to significantly improve my scientific writing to which I owe them a great debt of gratitude. Dr. Zacharias has joined our committee after the sudden passing of Dr. Myers. I am very glad to welcome him to my committee, and I appreciate his willingness to serve. Dr. Zacharias has collaborated with the Dr. McMasters laboratory in the past, and I am thrilled to be working with him again. Critical support was also provided by Dr. Shesh Rai and Ms. Margaret Abby. Dr. Rai consulted on the statistical analysis for and Ms. Abby professionally edited this dissertation.

The completion of this dissertation would have been impossible without the support of my friends and family. My daughter Eleanor Elizabeth Wechman 
was born (On July $\left.9^{\text {th }}, 2015\right)$ around the time I received my master's degree. She has been a delight, and I have treasured my time with her. Both sides of Eleanor's family live nearby and have helped my wife and I care for Eleanor, allowing me and my wife to continue developing our careers. With deepest gratitude, I would like to thank all of you. Without your help I would not have been able to pursue my dreams and complete this dissertation. 


\section{ABSTRACT \\ CHARACTERIZATION OF A MUTANT ONCOLYTIC ADENOVIRUS AND THE \\ ROLE OF JNK IN ENHANCING VIROTHERAPY \\ Stephen L. Wechman \\ February 8, 2017}

Oncolytic adenoviruses (Ads) have great therapeutic potential for lung cancer treatment. Cancer selective E1b-deleted Ads are safe; however, their clinical cancer therapeutic efficacy remains limited. The limited efficacy of Ad virotherapy is due to many factors including inefficient cancer cell lysis, Ad release and spread. Progress in overcoming these barriers to Ad virotherapy are hampered by limited knowledge of the genes associated with enhanced Ad release and spread and the dearth of understanding of the mechanisms by which E1bdeleted Ads cause cancer cell lysis. The role of c-JNK n- terminal kinase (JNK) phosphorylation in this process remains unknown. By uncovering the molecular aspects that enhance Ad spread and oncolysis, this dissertation has addressed critical gaps in the oncolytic Ad field. In chapter II, the novel oncolytic Ad mutant, AdUV, was developed. AdUV displayed enhanced oncolytic effects, release, and spread in A549 cells. AdUV also induced autophagy more effectively than the parental strain Ad5. In chapter III, AdUV was subjected to DNA sequence analysis to determine which AdUV mutations may have induced these enhanced cancer therapeutic effects (spread, Ad release, and oncolysis). For example, 
mutations to the DNA-binding genes $52 K$ and $p V$ may have enhanced AdUV release. These mutations increased the number of encoded positively-charged amino acids in AdUV. Therefore, I hypothesized that these mutations may have increased AdUV's binding affinity for the negatively-charged DNA sugarphosphate backbone. In chapter IV, the mechanism of Ad-induced JNK phosphorylation was investigated to further characterize Ad oncolysis. These data indicated that Ads induce p-JNK via the expression of E1b-19K and E1a. Additionally, we have shown that the p-JNK inducer, etoposide, enhanced oncolytic effects, but not the replication of AdUV in vitro. This work has advanced the knowledge of Ad oncolysis and will lead to further progress in the field of oncolytic virotherapy. 


\section{TABLE OF CONTENTS}

PAGE

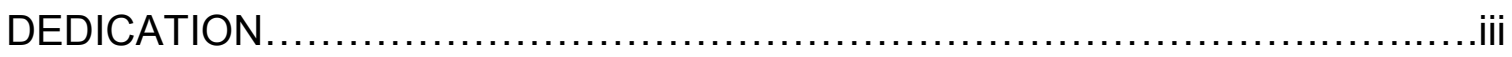

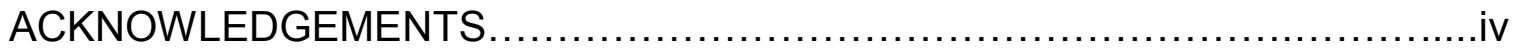

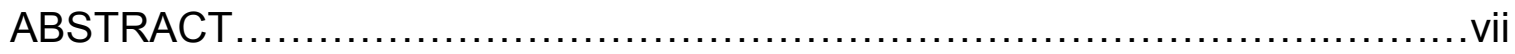

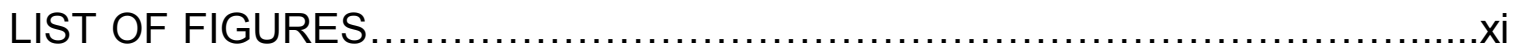

CHAPTERS: PAGE

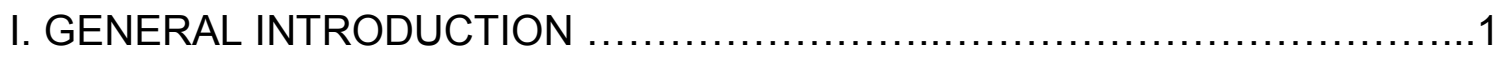

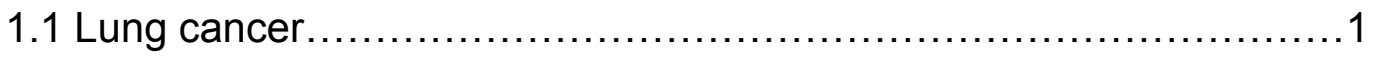

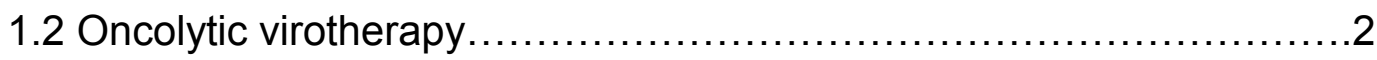

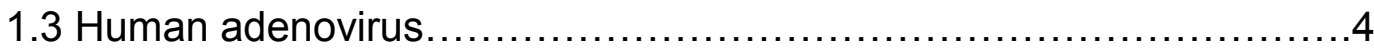

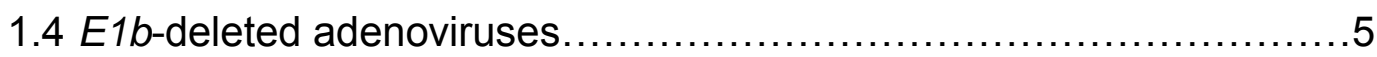

1.5 Oncolytic adenoviruses as lung cancer therapeutics...................

1.6 Repeated cancer selection enhances oncolytic adenovirus efficacy....8

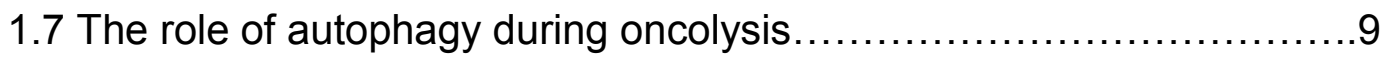

$1.8 \mathrm{E} 1 \mathrm{~b}$ and its effects upon Ad oncolysis........................... 10

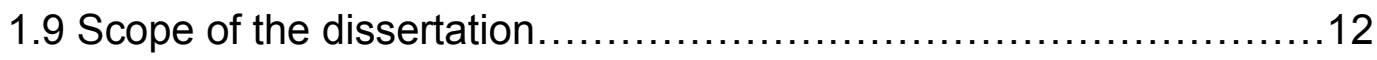

II. DEVELOPMENT OF AN ONCOLYTIC ADENOVIRUS WITH ENHANCED SPREAD ABILITY THROUGH REPEATED UV IRRADIATION AND CANCER SELECTION (Wechman et al. Viruses, 2016)..............................15 


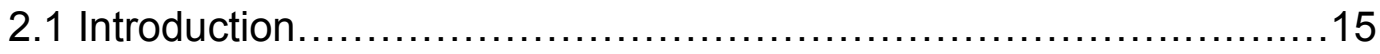

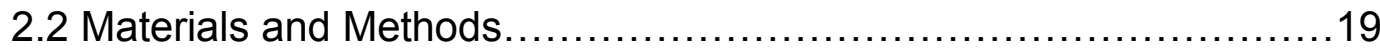

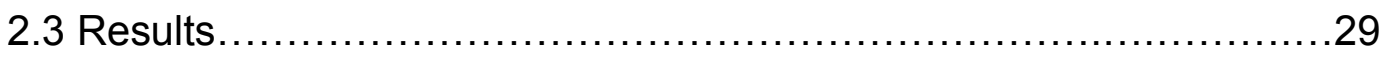

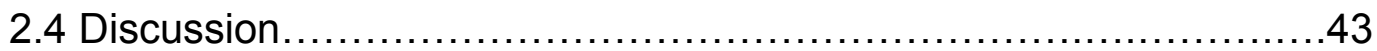

III. ADENOVIRUS WITH DNA PACKAGING GENE MUTATIONS INCREASED VIRUS RELEASE (Wechman et al. Viruses, 2016)................................48

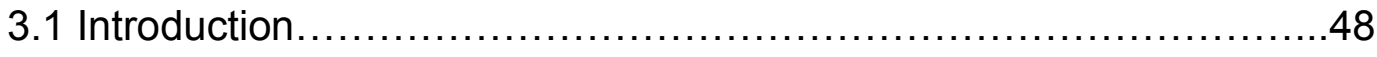

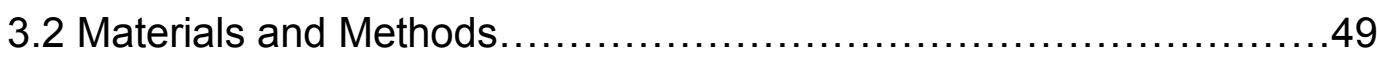

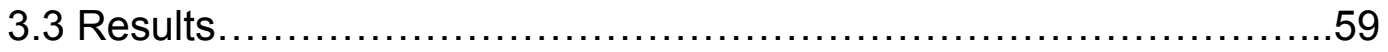

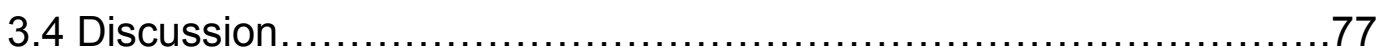

IV. THE ROLE OF JNK PHOSPHORYLATION AS A MOLECULAR TARGET TO ENHANCE ADENOVIRUS REPLICATION, ONCOLYSIS AND CANCER

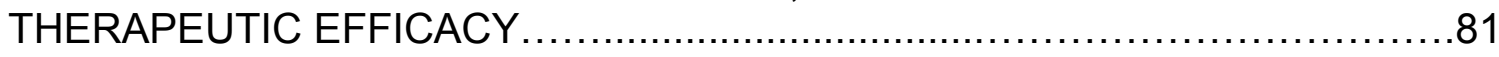

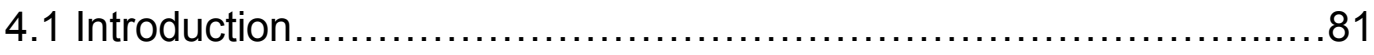

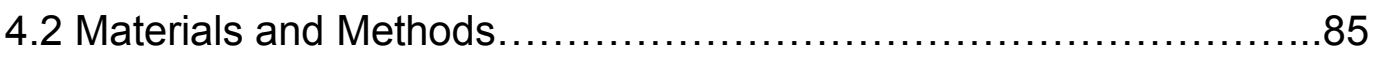

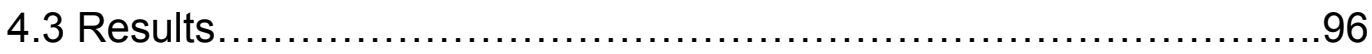

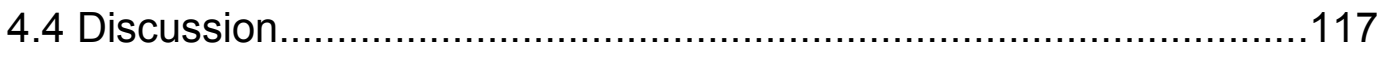

V.SUMMARY AND FUTURE PERSPECTIVES ..................................121

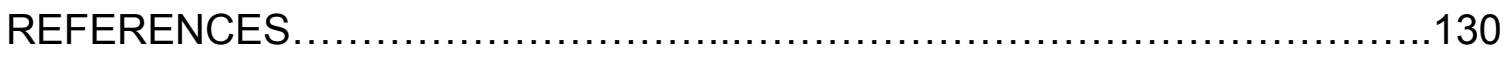

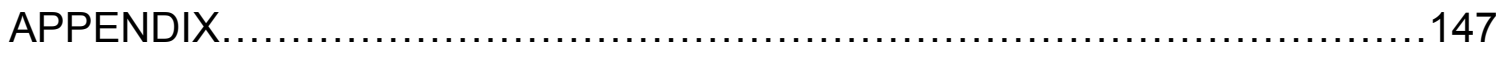

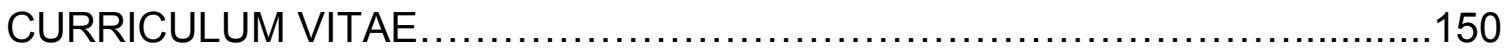




\section{LIST OF FIGURES}

PAGE

Figure 1. The repeated UV irradiation and cancer selection of AdUV .............23

Figure 2. AdUV is released from and lyses A549 cells more efficiently than

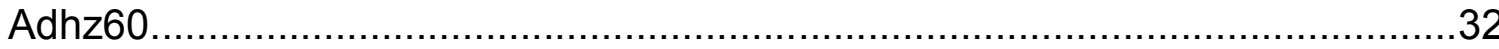

Figure 3. AdUV spread in A549 cells.............................................

Figure 4. AdUV virus replication in A549 lung cancer cells........................39

Figure 5. AdUV induces greater autophagy in A549 lung cancer cells............43

Figure 6. AdUV kills multiple cancer cell lines more effectively than Adhz60 in

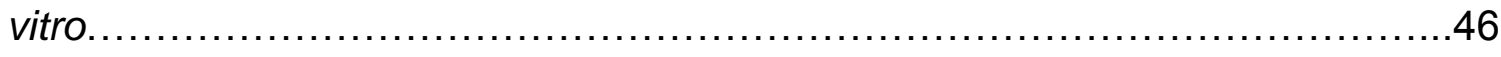

Figure 7. AdUV DNA mutation map ......................................... 51

Figure 8. DNA mutations contained in AdUV ...................................65

Table 1. Table of AdUV mutations, their location, and changes in their amino acid

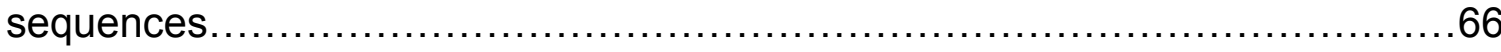

Figure 9. AdUV displays similar cancer selectivity to Adhz60 in A549 lung cancer cells relative to HBEC and MRC5 non-cancerous lung cells in vitro...............76

Figure 10. AdUV displays greater oncolysis than Ad5 and Adhz60 in A549 and Saos-2 cancer cells............................................................ 77

Figure 11. AdUV displays greater release than Ad5 and Adhz60 in A549 and Saos-2 cancer cells ........................................................... 79

Figure 12. The effect of AdUV upon A549 xenograft tumor growth and nude mice survival.

Figure 13. The effect of Ad5 upon p-JNK across time.........................105

Figure 14. The effect of selective E1b-deleted Ads upon p-JNK at $36 \mathrm{~h} \ldots \ldots \ldots \ldots . .109$

Figure 15. The effect of E1b-19K expression upon JNK phosphorylation.........111 
Figure 16. The effect of E1a expression upon JNK phosphorylation.................115

Figure 17. The effect of etoposide upon p-JNK and Ad oncolysis..................119

Figure 18. The effect of etoposide upon Ad replication and oncolysis..............121

Figure 19. The effect of JNK expression upon A549 cell oncolysis and oncolytic

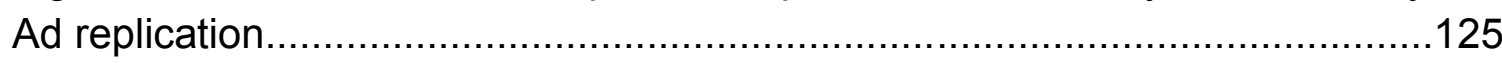




\section{CHAPTER I \\ GENERAL INTRODUCTION}

\section{1 - Lung cancer}

Lung cancer is the leading cause of death from malignancy. The number of lung cancer deaths $(158,140)$ in 2016 was comparable to the number of deaths $(157,548)$ from the next four leading cancers combined: colon, breast, pancreatic and prostate (American Cancer Society). The Surveillance Epidemiology and End Results (SEER) statistics indicate that the five-year survival rate of lung cancer patients improved from $11.4 \%$ in 1975 to $17.5 \%$ in 2006 . However, lung cancer will continue to be a leading cause of death from malignancy unless more effective treatments are developed.

Surgery remains the best treatment option for early stage (Stage I and II) lung cancer. Most stage I and II lung tumors are minimally invasive, therefore lobar resection is feasible for these patients. When primary lung tumors are resected, $85 \%$ of stage I and $77 \%$ of stage II cancer patients survive at least two years after diagnosis [1]. However, patient follow-up is necessary to observe for recurrent primary or metastatic tumor growth following resection. Surgically resected stage II lung cancer patients, but not 
stage I, are also frequently treated with adjuvant platinum-based chemotherapy [2].

For lung cancer patients with disease beyond stage II, the combination of surgery, intravenous (IV) chemotherapy, and radiation provides the best results [3-5]. Stage III lung tumors have regionally metastasized to the lymph nodes and often have invaded at least one of the tissues surrounding the lung, including the chest wall, pleura, or the main bronchus [6]. Stage IV lung tumors can be of any size however, distant metastasis are observed [6]. These distant metastases are often observed in the adrenal glands, bone, the opposite lung, liver or brain $[7,8]$. The majority $(57 \%)$ of lung cancer patients have distant metastases at the time of diagnosis. Therefore, most lung cancer patients are stage IV and are ineligible for surgery. Alternative treatments to surgery such as cancer chemotherapy have not significantly enhanced lung cancer patient survival despite the investigation of several different chemotherapeutic combinations [9-11]. To treat lung cancer patients more effectively, the development of novel cancer therapeutics is imperative.

\section{2 - Oncolytic Virotherapy}

The use of cancer selective viruses, or oncolytic virotherapy, is an emerging lung cancer treatment option with great therapeutic potential [12, 13]. Oncolytic virotherapy is unique because these viruses can spread within 
tumors following their initial infection of a small number of tumor cells [12, 14]. The cancer selective (oncolytic) adenovirus (Ad) d/1520 displayed favorable safety and induced anti-tumor responses during preclinical and clinical studies [15-17]. To date, two oncolytic viruses have been approved for the treatment of cancer. First, a virus very similar to d/1520, H101, was commercially approved in China for the treatment of head and neck cancers in combination with the PF chemotherapy regimen (cisplatin and fluorouracil) by the China Food and Drug Administration (CFDA) [18]. In a phase III trial, H101 increased the tumor response rate of head and neck cancer patients treated with the PF regimen from $39.6 \%$ to $78.8 \%$ [19]. Secondly, the United States Food and Drug Administration (FDA) approved the oncolytic herpes virus TVec, which expresses the immune stimulatory cytokine granulocyte macrophage colony stimulation factor (GMCSF) for the treatment of malignant melanoma [20]. Interestingly, both oncolytic virus replication and the expression of GMCSF contributed to T-Vec's cancer therapeutic efficacy [20]. Novel oncolytic Ads, such as ColoAd1, are also currently under investigation in a phase II clinical trials and have shown great cancer therapeutic potential [21]. Next generation ColoAd1 vectors feature Ad3/11 capsid chimeras which were shown to have the greatest cancer therapeutic activity and stability in human blood [22]. This next generation ColoAd1 vector expressing Ad3/11 
capsid proteins (Enadenotucirev) appears to be safe and effective following intravenous (IV) injection for the treatment of distant metastases [22].

\section{$\underline{1.3-\text { Human adenoviruses }}$}

The Ad genome is composed of linear, double-stranded DNA of approximately $36 \mathrm{~kb}$, which can be divided into early $(E)$ and late $(L)$ genes based upon their expression across the infection cycle $[23,24]$. The $L$ genes encode structural proteins, which package the viral DNA into the Ad virion during the final stages of replication. The $E$ genes include $E 1 a, E 1 b, E 2, E 3$, and E4 for regulation of viral replication. The proteins encoded by E1a are produced immediately after infection to modulate the cell cycle, recruit cellular proteins, and regulate the expression of cellular and viral genes [25]. The Ad E1b gene encodes two major polypeptides, termed 55K and 19K, which are 55 kilodaltons $(\mathrm{kDa})$ and $19 \mathrm{kDa}$, respectively. The expression of both E1b55K and E1b19K is required to transform rodent cells following viral transduction and DNA transfection $[26,27]$. Both E1B55K and E1B19K proteins protect infected cells from E1A-induced stabilization of TP53 and apoptosis [28]. E1B55K also enhances viral E1a expression [29], and is involved in the induction of cyclin E gene expression (which is required for efficient Ad replication) [30-35]. The Ad E1B19K protein is a putative B-cell lymphoma 2 protein (BCL-2) functional homolog and a strong inhibitor of 
apoptosis [36-38]. E1B19K prevents E1A-induced apoptosis by interfering with the actions of the pro-apoptotic proteins Bak and Bax [39]. E1B19K can also transactivate E1a during Ad infection [40]. Therefore, the actions of these E1b-encoded proteins are thought to maximize Ad replication.

\section{$1.4-E 1 b 55 \mathrm{~K}$-deleted adenoviruses}

The E1b-55K gene has been shown to bind promyelocytic leukemia protein nuclear bodies (PML-nb) and TP53 during Ad infection [41-43]. By interacting with PML-nbs and TP53, E1b-55K was shown to induce TP53 sumoylation as the overexpression of PML-nb and TP53 led to the polyubiqitination and proteolytic degradation of TP53 [44]. Dr. Arnold Berk applied this understanding of $E 1 b-55 \mathrm{~K}$ and TP53, to design the first $E 1 b 55 \mathrm{~K}-$ deleted oncolytic Ad, d/1520 in collaboration with Dr. Douglas Barker [26].

This adenovirus, d/1520, was E1b55K-deleted and was hypothesized to be replication-deficient in primary cells expressing TP53 [45]. TP53 is the most commonly inactivated tumor suppressor as a result of oncogenic transformation. TP53 is mutated or deleted in approximately $50 \%$ of all human tumors [46]. This dependence upon TP53 inactivation appeared to have led to cancer selective cell lysis in vitro. However, Harada and Berk then tested the dependence of d/1520 upon TP53 inactivation to induce its oncolytic effects. Using H1299 (Tp53-deficient) lung cancer cells with inducible TP53 
expression via a temperature-sensitive promotor (H1299-tsp53), d/1520induced H1299 CPE did not correlate with the expression of TP53 [47]. These data suggested that the cancer selectivity of dl1520 follows a TP53independent mechanism of action.

Recent studies have indicated that E1b55K-deleted Ads can only replicate in S-phase synchronized cancer cells [31]. E1b-55K has been previously shown to induce cyclin E production and cyclin dependent kinase 2 (CDK2) phosphorylation [33]. Cyclin E overexpression is occurs in more than $90 \%$ of lung, liver, and gastrointestinal cancers, and in more than $80 \%$ of glioma/blastoma, bone, and breast cancers respectively [48]. Interestingly, E1b-deleted oncolytic Ads were only shown to induce cyclin E and p-CDK2 in malignant cells. These data indicated that the oncogenic transformation(s) may have led to the production of E1b55K-like factors which appear to have recovered the attenuated CDK2/cyclin E axis activation observed by $E 1 b 55 \mathrm{~K}-$ deleted Ads [29]. Furthermore, these data and additional studies also suggest that dysregulated cyclin E production may contribute to the mechanism of E1b55K-deleted Ad cancer selectivity [30].

While the true mechanism of E1b55K-deleted oncolytic Ad cancer selectivity remains unknown, $d / 1520$ was safely utilized to treat several hundred cancer patients during several phase I and II clinical trials [49]. 
However, while d/1520 progressed to phase III clinical trials in combination with cancer chemotherapy, the trial was suspended due to the limited cancer therapeutic effects [18]. While E1b-deleted Ads, such as d/1520, were less successful than expected clinically, these trials indicated that oncolytic viruses were safe and an attractive drug platform for the development of cancer therapeutics in the future.

\section{5 - Oncolytic adenoviruses as lung cancer therapeutics}

Ads are especially promising for the treatment of lung cancer. Ads have respiratory tropism, allowing them to very efficiently infect and spread throughout the lung to produce their cancer therapeutic effects [50]. Early stage (phase I) Ad lung cancer clinical trials indicated that high doses of replication deficient Ads were well tolerated by lung cancer patients. Some examples include the administration of a TP53-expressing Ad by bronchoalveolar lavage (BAL) [51] and another L523S-expressing Ad given by intramuscular injection (IM) [52].

In a phase II clinical trial, Nemunaitis et al. administered d/1520 IV at increasing doses to metastatic lung cancer patients [53]. Their research revealed that $d / 1520$ could infect and replicate within the patients' lung cancer tumors following IV injection with no serious side effects [53]. Furthermore, E1b-deleted Ads interact synergistically with cancer chemotherapy, as shown 
in primary lung cancer tissue in vitro and lung cancer xenograft models in vivo $[16,54-56]$. These studies suggest that oncolytic adenovirus therapy is safe for the treatment of lung cancer and displays synergistic interactions in combination with many cancer chemotherapeutics.

\section{6 - Repeated cancer selection enhances oncolytic adenovirus efficacy}

Most oncolytic Ads are constructed with E1b deletions and/or E1a regulated by cancer-selective promoters. Oncolytic Ads have achieved some success in human clinical trials however, their efficacy has been disappointing $[15,18,57-59]$. It is possible that the rational design of the E1 gene (E1a and E1b) modified Ads is not sufficient to induce profound cancer therapeutic responses. Rationally designed Ads are dependent upon a nearly complete understanding of Ad's virus-host interactions. Therefore, it is necessary to explore new approaches for the development of more effective oncolytic Ads. One such approach entails the use of directed evolution. Using this approach, Ads are exposed to DNA mutagenic agents to generate the genetic diversity required for directed evolution and the selection of Ads with enhanced oncolytic effects. Therefore, directed evolution may be capable of generating Ads with greater anti-cancer activity without requiring a complete understanding of all the virus-host interactions your Ad construct and cancer cells of interest [30,60-62]. In this experiment, the E1 wild-type Ad, d/309, 
was UV-irradiated prior to the selection of more effective therapeutic Ads in cancer cells. After 72 cycles of repeated UV-irradiation and cancer selection AdUV was isolated by plaque purification. AdUV displayed enhanced release and spread between A549 cells. AdUV displayed greater anti-cancer efficacy than the oncolytic Ad control, Adhz60, in all cancer cell lines tested. AdUV also induced autophagy more effectively than either Ad5 or Adhz60 in A549 cells. AdUV also displayed increased virus release and oncolysis in Soas-2 cells (AdUV was selected in these cells). In addition, AdUV significantly suppressed the growth of A549 xenograft tumors and prolonged the survival of athymic nu/nu mice. These studies suggest that AdUV has potential as a lung cancer therapeutic agent.

\section{7 - The role of autophagy during Ad oncolysis}

Oncolytic Ads have been shown to induce several cell death pathways during infection such as apoptosis [63], necrosis [64] and autophagy [65, 66]. Autophagy represents an alternative form of programmed cell death, distinct from apoptosis and necrosis $[67,68]$. Autophagy leads to the sequestration of organelles and long-lived proteins into autophagosomes, which then fuse with the lysosomes forming the autophagolysosome to recycle cellular components $[69,70]$. During autophagolysosome formation, microtubuleassociated protein 1 light chain 3 (LC3) matures from LC3-I (18 kDa) to LC3-II 
(16 kDa) [71]. Therefore, the LC3-II/LC3-I protein ratio correlates with the abundance of autophagosomes and indicates the relative level of autophagy induction $[72,73]$.

Autophagy is activated by cell stresses such as cell starvation [74], DNA damage [75], chemotherapy treatment [76] and Ad infection [66]. Ads have been shown to induce autophagy in glioma, ovarian and lung cancer cells $[66,77]$. Furthermore, the autophagy inhibitors 3-methyladenine (3MA) and bafilomycin A1 (Baf-A1) were shown to protect cancer cells from Ad oncolysis [66, 78]. Autophagy induction has also been shown to support Ad replication [66]. These studies indicate that autophagy is crucial for Ad cancer therapy; however, the effects of many adenovirus genes upon autophagy remain unknown.

\section{$1.8-E 1 b$ and its effects upon Ad oncolysis}

Despite decades of pre-clinical and clinical studies, adenovirologists have not emphasized the investigation of the mechanism of E1b-deleted $\mathrm{Ad}$ oncolysis. Furthermore, the role of autophagy mediators such as c-JUN nterminal kinase (JNK) during E1b-deleted Ad oncolysis remains unclear. The JNKs originate from 3 genes that yield 10 isoforms via alternative mRNA splicing: JNK1 $\alpha 1, \mathrm{JNK} 1 \beta 1, \mathrm{JNK} 2 \alpha 1, \mathrm{JNK} 2 \beta 1$ and JNK3a1 which represent the $46 \mathrm{kDa}$ isoforms; and JNK1 2 2, JNK1 $\beta 2$, JNK2 $\alpha 2$, JNK2 $\beta 2$ and JNK3 $\beta 2$ 
which represent the $54 \mathrm{kDa}$ isoforms respectively [79]. The first publication, to my knowledge, to demonstrate an interaction between $E 1 b$ and JNK was published by See and Shi in 1998. However, this report did not indicate if JNK had an effect upon adenovirus replication or oncolysis [80]. Klein et al. reported in 2015 that JNK expression was essential for E1b wild-type Ad oncolysis [81]. However, their focus was upon the necessity of JNK expression for Ad oncolysis and not the study of JNK phosphorylation by E1b and E1a or the effect of p-JNK upon Ad replication. While Klein et al. did not ascertain the relationship between JNK and Ad replication specifically, they did report co-localization of hexon and p-JNK by immunofluorescence in Adinfected tumor sections, indicating that Ad replication maybe associated with p-JNK production within tumors in vivo [81].

Other reports have suggested that autophagy induction by $E 1 b$ wildtype Ads occurs independently of the molecular target of rapamycin (mTOR) cell starvation pathway $[77,81]$. Studies have demonstrated that rapamycin treatment induced autophagy and enhanced E1b-deleted Ad replication [55, 66]. However autophagy induction by Ads appears to occur via the MKK $7 / p$ JNK/BECLIN-1 axis, perhaps due to the expression of E1b-19K [80].

I hypothesized that E1b-deleted Ads display less efficient virus replication and oncolysis, at least in part, due to attenuated p-JNK production in cancer cells. Previous reports and data from chapter II of this dissertation 
show that $E 1 b$-deleted Ads induce autophagy less efficiently than $E 1 b$ wildtype Ads, indicating that autophagy signaling is likely induced by $E 1 b$ [66, 82]; however this phenomenon has remained uncharacterized. This dissertation determined the effects of E1a and E1b upon JNK using Ads with selective E1a overexpression or bearing E1b-deletions.

The JNK pathway is driven by the mitogen activated protein kinase (MAPK) pathway, which interacts with a wide array of intracellular processes [79]. Due to this complexity, very limited tools are available to selectively induce p-JNK production selectively. Therefore, cancer chemotherapeutic drugs which have been reported to induce $\mathrm{p}$-JNK production were utilized: etoposide [83], cytarabine [84], cycloheximide [85], and paclitaxel [86]. To determine the selective effects of JNK upon Ad replication and oncolysis, JNK1/2-siRNAs were utilized. By the completion of these studies, this dissertation demonstrated for the first time that p-JNK production supports not only Ad oncolysis, but also Ad replication.

\section{$1.9-$ Scope of the dissertation}

d/1520, the first E1b55K-deleted virus, was initially developed and tested in the United States. Once E1b-deleted Ads were shown to have limited cancer therapeutic efficacy in several clinical trials, their clinical applications were aborted in the United States [15, 18, 57-59]. However, a 
similar E1b55K-deleted Ad (H101) was approved for the treatment of head and neck cancer patients in China [87]. Despite the success of the E1b55Kdeleted Ads, such as d/1520 and H101, the development of cancer selective Ads with greater cancer therapeutic efficacy is necessary.

The work contained within this dissertation is focused upon enhancing the efficacy of oncolytic Ads using multiple approaches. First, the novel Ad mutant (AdUV) was generated using a directed evolution approach entailing repeated UV-irradiation and cancer selection. In chapter II, AdUV displayed enhanced autophagy induction, virus release and spread. Second, the AdUV genome was sequenced to determine which mutations might have enhanced its oncolytic efficiency. In chapter III, several AdUV mutations were found in genes encoding Ad DNA packaging functions. These mutations were hypothesized to enhance the DNA packaging efficiency of AdUV by the inclusion of more positively-charged amino acids in these DNA binding proteins. These mutations may have facilitated greater binding to the negatively-charged DNA sugar-phosphate backbone. AdUV was also shown to replicate within and suppress the growth of A549 tumor xenografts while remaining non-lethal to AdUV-treated mice.

While Ads have been extensively researched, the mechanism of Adinduced oncolysis and which cell death pathways should be targeted to 
enhance Ad therapy remain unknown. Therefore the third approach in this dissertation to enhance Ad therapy, I expanded upon the literature's description of Ad induced JNK phosphorylation and determined if $p$-JNK production enhanced Ad oncolysis $[80,88]$. In chapter IV, E1b-deleted Ads displayed less p-JNK, which appeared to be induced by E1b-19K. These data indicated that E1a led to increased $\mathrm{p}$-JNK production. The cancer chemotherapeutic, etoposide, was shown to induce p-JNK and enhance Ad oncolysis. JNK1/2-targeting siRNA confirmed that JNK was essential for Ad replication and A549 cell oncolysis.

Ultimately, by uncovering Ad genes associated with increased Ad spread and understanding how Ads interact with the JNK pathway may help to overcome the limitations facing Ad oncolytic virotherapy and lead to development of more effective oncolytic Ads. 


\section{CHAPTER II}

DEVELOPMENT OF AN ONCOLYTIC ADENOVIRUS WITH ENHANCED SPREAD ABILITY THROUGH REPEATED UV IRRADIATION AND CANCER SELECTION

\section{1 - Introduction}

Human Ads have been modified to selectively replicate and lyse cancer cells [89]. Ads exhibit their favorable safety profile because they only cause negligible flu-like symptoms and cannot integrate their genomes into the host cell chromosomes [23]. The therapeutic effects of oncolytic Ads are initiated from a small number of infected cancer cells from which the progeny viruses are released to infect adjacent cancer cells further within tumors [12, 14]. However, preclinical and clinical studies have suggested that Ad spread is restricted in large tumors, limiting their therapeutic efficacy.

The development of oncolytic Ads has focused primarily upon the genetic manipulation of $E 1 a$ and $E 1 b$. At least two approaches have been applied for the development of oncolytic Ads to date. One approach is to delete or attenuate $E 1 b$, the expression of which is not essential for virus replication in cancer cells. For example, dl1520 (ONYX-015) is a geneattenuated oncolytic virus with an 827-bp deletion and a nonsense point 
mutation in the $E 1 b$ region which generates a premature stop codon, preventing the complete translation of the E1B55K protein; therefore, d/1520 is functionally E1b55K-deleted [15, 26, 90]. Several hundred cancer patients were treated with d/1520 via various routes of administration in phase I and II clinical trials [49]. However, during a phase III clinical trial when d/1520 was combined with cancer chemotherapy to treat head and neck squamous cell carcinoma patients, the trial was suspended due to the limited therapeutic effects [18].

Another approach to develop cancer selective Ads is to regulate the transcription of essential viral genes, such as E1a, with tumor-specific promoters to restrict the expression of viral regulatory genes and oncolytic Ads within tumors rather than normal tissue [14, 91]. Ad-cycE was recently developed and expresses E1a under the control of the cyclinE promoter to produce cancer selective oncolytic effects $[34,35,55]$. Furthermore, the replication of Ad-cycE is further stimulated by Ad infection, augmenting the oncolytic efficacy of Ad-cycE [30, 31]. Ad-cycE can selectively replicate in a diverse range of cancer cells and was shown to significantly repress tumor growth, prolonging the survival of xenograft tumor bearing mice $[34,55]$. Other examples of oncolytic Ads with cancer-selective promoters include, OBP-301 (Telomelysin $®$ ) which expresses E1a under the control of the human telomerase reverse transcriptase (hTERT) promoter [92], and CV706 
which expresses E1a under the control of the prostate-specific antigen (PSA) promoter [93]. Both Telomelysin $\AA$ and CV706 have progressed to human clinical trials but have shown limited cancer therapeutic efficacy.

Although Ads with E1b deletions and/or E1a regulated by cancerselective promoters have achieved some success in human clinical trials, the efficacy of oncolytic Ad virotherapy overall has been disappointing [15, 18, 5759]. Oncolytic Ads were previously shown efficiently inhibit the growth of only small tumors in vivo following intratumoral (IT) injection [59]. This phenomenon was also observed during clinical studies, as the direct injection of d/1520 did not inhibit the growth of larger tumors clinically [15, 58]. Restricted virus spread in larger tumors likely presents a significant barrier to the efficacy of Ad virotherapy [94]. It appears that extensive genetic manipulation of E1a and/or E1b is not sufficient to overcome these Ad therapeutic barriers. Therefore, it is necessary to explore new approaches to develop more effective oncolytic Ads.

In this study, the E1 wild-type d/309 (Ad5) was UV irradiated, followed by repeated selection in Soas-2 cancer cells. These treatments were repeated for total 72 cycles to select for Ads which can efficiently release from and spread between cancer cells. This approach targeted the entire genome rather than focusing upon the E1 region exclusively. Using this approach, the 
oncolytic virus AdUV was isolated. AdUV displayed the properties of enhanced oncolytic replication and spread in vitro. 


\section{2 - Materials and Methods}

\section{Cell Lines and Culture Conditions}

HEK293 (ATCC no. CRL-1573) human embryonic kidney cells, MRC5 (ATTCC no. CCL-171) human non-cancerous fibroblasts, HBEC (ATTCC no. CRL-4051) human non-cancerous epithelial cells, A549 (ATCC no. CCL-185) human lung carcinoma cells, H1299 (ATCC no. CRL-5803) metastatic human lung carcinoma cells isolated from lymph nodes, H441 (ATCC no. HTB-174) human lung papillary adenocarcinoma cells, MCF-7 (ATCC no. HTB-22) human breast adenocarcinoma cells, and Saos-2 human bone osteosarcoma cells (ATTCC no. HTB-85) were obtained from the American Type Culture Collection (Rockville, MD, USA). A549, MCF-7, MRC5, and HEK293 cells were maintained in DMEM. H1299 and H441 cells were cultured in RPMI 1640 medium. Saos-2 cells were maintained in McCoy's 5A media. HBEC cells were maintained in keratinocyte serum-free medium containing bovine pituitary extract and recombinant epidermal growth factor (Invitrogen, Waltham, MA, USA). All cell culture media were supplemented with $10 \%$ fetal bovine serum, $5 \%$ L-glutamine, and $5 \%$ penicillin/streptomycin $(100 \mathrm{U} / \mathrm{mL})$ unless indicated otherwise. All cells were cultured and maintained in humidified $5 \% \mathrm{CO}_{2}$ incubators at $37^{\circ} \mathrm{C}$. All other cell culture reagents were obtained from VWR (VWR, Radnor, PA, USA) unless indicated otherwise. 


\section{Adenoviral Vectors}

Ad5, d/309, is E1 wild-type virus [95] and was used as a non-selective Ad control. Adhz60 with a deletion of the entire E1b gene was used as a cancer selective Ad control [96]. AdGFP is an Ad vector with the entire E1 gene ( $E 1 a$ and $E 1 b)$ deleted, expressing GFP driven by the cytomegalovirus (CMV) promoter. AdGFP, as a negative control, does not replicate nor induce CPE. All Ads used in this study are based on the Ad5 backbone sequence.

To select for Ads with increased spread, cell culture media containing Ad5 d/309 was UV-irradiated for 5 min using a UV-light germicidal lamp, inactivating approximately $90 \%$ of virus particles. The UV-light source was a germicidal lamp, USEG30T3 (Sylvania, Danvers, MA, USA), fitted with a 30 watt G30T8 UV-light bulb (Philips, Amsterdam, The Netherlands), which produces UV type-C irradiation. UV irradiation was measured with a $25 X$ UVX radiometer (Fisher Scientific, Pittsburgh, PA, USA). Using these conditions, $213 \mu \mathrm{W} / \mathrm{cm}^{2}$ UV type-C was produced, generating a total UV dose of $639 \mathrm{~J} / \mathrm{m}^{2}$ after 5 min exposure. Irradiated viruses were then used to infect Saos-2 cancer cells, in which Ads cannot efficiently replicate [31]. Four $h$ after infection, extracellular virus particles were removed by washing the cells with fresh media. The cell culture media were collected at the first sign of CPE, generally at $24 \mathrm{~h}$ after infection, to harvest viruses that might replicate and release from the infected cancer cells more efficenctly. The harvested viruses were then amplified in 293 cells before being used for another cycle of UVirradiation. These treatments were repeated for total 72 cycles and AdUV, that formed a large plaque on Saos-2 cells, was isolated (Figure 1). 


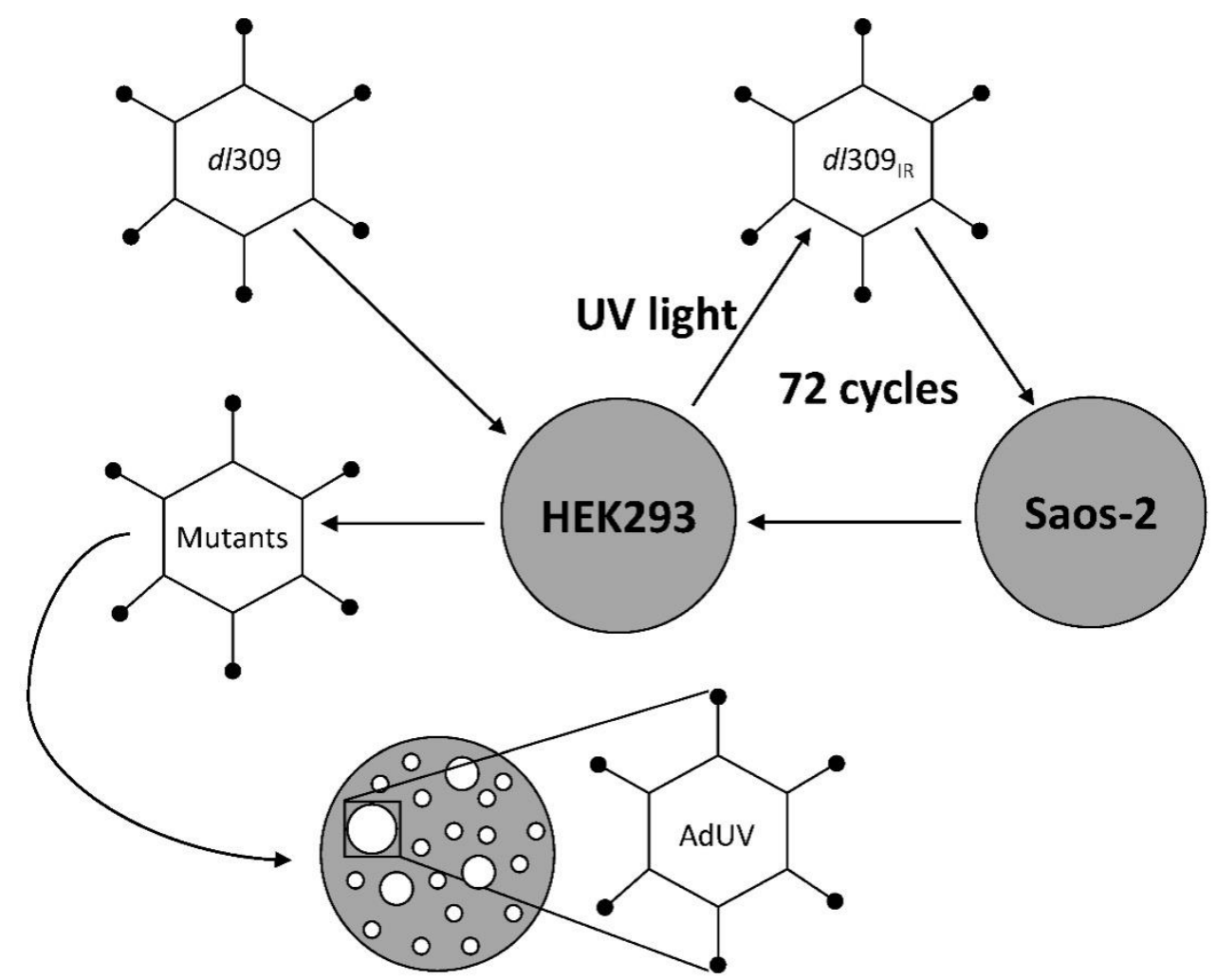

Reprinted with permission: Wechman et al., Viruses, 2016

Figure 1. The repeated UV irradiation and cancer selection of AdUV. Ad5 d/309 was initially amplified in HEK293 cells prior to UVirradiation. Irradiated viruses $\left(d / 309_{\mathrm{IR}}\right)$ were then selected in Saos-2 cancer cells. Viruses were then harvested from Saos-2 cells and amplified in HEK293 cells before subsequent cycles of UV irradiation. After 72 cycles of UV irradiation and cancer selection, AdUV was isolated by plaque purification from a large plaque formed upon Saos2 cells. 


\section{Virus Titration and Release}

Virus titer was determined using the TCID50 method as described previously [33]. HEK293 cells were seeded overnight onto 96-well plates at a density of $1 \times 10^{3}$ cells per well and infected with virus samples serially diluted 10 fold. The presence or absence of CPE in HEK293 cells was then recorded after a minimum of 7 days to calculate the virus titer.

To determine the release kinetics of AdUV, A549 cells were seeded onto 12-well plates at a density of $1 \times 10^{5}$ cells per well. A549 cells were then infected with Ad5, Adhz60 or AdUV at an MOI of 1. Samples were collected at $6,24,36,48$, and $72 \mathrm{~h}$ after infection. The cells and cell culture media were separated by centrifugation at 2000 RPM (350 RCF) at $4{ }^{\circ} \mathrm{C}$ for 5 min using a micromax RF refrigerated microcentrifuge equipped with an IEC 851 rotor (Thermo Fisher Scientific, Waltham, MA, USA). Cell pellets were then resuspended in $1 \mathrm{~mL}$ of sterile phosphate buffered saline (PBS) and subjected to 3 freeze-thaw cycles to release viruses contained within cells prior to titration. Cell free media samples were titered to detect viruses released from cells. For studies focusing upon virus titer in the media alone, cells were infected at $1 \mathrm{MOI}$ and media samples $(20 \mu \mathrm{L})$ were collected daily for 5 days. 


\section{Western Blot Analysis}

A549 cells were seeded onto $60 \mathrm{~mm}$ dishes at a density of $6 \times 10^{5}$ cells per dish incubated overnight. Cells were collected and centrifuged at 1500 RPM (453 RCF) at $4{ }^{\circ} \mathrm{C}$ for 5 min using an Eppendorf 15 amp $5810 \mathrm{R}$ refrigerated centrifuge equipped with a A-4-62 rotor (Eppendorf, Hamburg, Germany). The cell pellets were then washed with PBS prior to lysis with radio immunoprecipitation assay (RIPA) buffer containing $50 \mathrm{mM}$ Tris- $\mathrm{HCl}, 150 \mathrm{mM}$ $\mathrm{NaCl}, 1 \% \mathrm{NP}-40,0.5 \%$ sodium deoxycholate, and $0.1 \%$ sodium docecyl sulfate (SDS) with a protease inhibitor (PI) cocktail containing 4-(2aminoethyl)-benzenesulfonyl fluoride (AEBSF), pepstatin A, transepoxysuccinyl-L-leucylamido-(4-guanidino)butane (E-64), bestatin, leupeptin, and aprotinin (10 mL / $1 \times 10^{6}$ cells; Sigma, St. Louis, MO, USA). The cell lysates were then incubated on ice in PI containing RIPA buffer for 30 min and homogenized every $10 \mathrm{~min}$ using a vortex-genie 2 (Scientific Industries, Bohemia, NY, USA). These lysates were then centrifuged at 14,500 RPM $(196,000 \mathrm{RCF})$ at $4{ }^{\circ} \mathrm{C}$ for $10 \mathrm{~min}$ using a micromax RF microcentrifuge equipped with an IEC 851 rotor to pellet cell debris formed during lysate preparation (Thermo Fisher Scientific, Waltham, MA, USA). The pellet was discarded and the supernatant was stored at $-80{ }^{\circ} \mathrm{C}$ for further experimentation. Protein concentrations were determined using the Pierce BCA protein assay kit according to the manufacturer's instructions (Thermo Fisher Scientific, Waltham, MA, USA). Equal amounts of cellular protein were resolved by electrophoresis through $8 \%$ (E1A, hexon, penton, protein $\mathrm{V}$, protein VI, protein VII) or 12\% (LC3-I and LC3-II) SDS-polyacrylamide gels prior to transfer to methanol activated PVDF membranes (GE healthcare, 
Little Chalfont, UK) using a semi-dry transfer apparatus (BIO-RAD, Hercules, CA, USA). Membranes were then blocked using 5\% nonfat milk prepared in TBST for $1 \mathrm{~h}$ at room temperature. To detect protein expression, membranes were incubated with the following primary antibodies: rabbit-anti-adenovirus type 5 (1:10,000; Abcam, Cambridge, UK), rabbit-anti-human-LC3 (1:3000; Novus Biologicals, Littleton, CO, USA), rabbit-anti-human-actin (1:2000; Sigma, St. Louis, MO, USA) or mouse-anti-adenovirus-E1A antibody (1:1000; BD Pharmagen, San Jose, CA, USA) at $4{ }^{\circ} \mathrm{C}$ overnight on a lab-line thermal rocker (Thermo Fisher Scientific, Waltham, MA, USA). Primary antibody binding was detected by the incubation with the horseradish peroxidase (HRP) linked anti-mouse or anti-rabbit immunoglobulin (Ig) diluted 1:5000 for $1 \mathrm{~h}$ at room temperature (Amersham, Piscataway, NJ, USA). All antibodies were diluted in TBST. Enhanced chemiluminescence (ECL) reagents were used to detect HRP-linked secondary antibody binding according to the manufacturer's instructions (Amersham, Piscataway, NJ, USA). 


\section{Plaque Formation Assay}

A549 cells were seeded onto 6 -well plates at a density of $3 \times 10^{5}$ cells per well. Cells were then infected with Ad5, Adhz60 and AdUV at an MOI of 0.01 . The cell culture media were removed after $6 \mathrm{~h}$ and replaced with $5 \mathrm{~mL}$ of sterile DMEM, $1 \%$ agarose heated gell per well. This gell overlay was then allowed to become solid at RT. Images were taken 6 days post-infection with an EVOS FL microscope (Life Technologies, Carlsbad, CA, USA) at $4 \times$ total magnification. The pixels contained within 10 representative plaques per Ad5, Adhz60, and AdUV treatment groups were quantified with the area density tool using Gel-pro analyzer 4.0 software according to the manufacturer's tutorial (Media Cybernetics, Rockville, MD, USA). The total number of pixels for each plaque was converted to millimeters squared $\left(\mathrm{mm}^{2}\right)$ by dividing the number of pixels per plaque by the number of pixels per $1 \mathrm{~mm}^{2}(261,100$ pixels) or squared pixel length of the 1000 micrometer $(\mu \mathrm{m})$ scale bar $(510$ pixels). 


\section{Quantification of Band Intensity}

Band intensities were quantified by Gel-pro analyzer 4.0 software in accordance with the manufacturer's tutorial (Media Cybernetics, Rockville, MD, USA). Densitometric values were expressed as the absolute integrated optical density (IOD) of each band normalized to actin expression as described previously [55]. Mock treated cells were represented as 1 fold LC3II/LC3-I production for each experiment. 


\section{Cytotoxicity Assay}

Cells were seeded overnight at a density of $2 \times 10^{4}(\mathrm{H} 1299), 2.5 \times 10^{4}$ (MRC5), $3 \times 10^{4}$ (HBEC), $3 \times 10^{4}$ (A549), $4 \times 10^{4}$ (MCF-7), or $6 \times 10^{4}(\mathrm{H} 441)$ cells per well in 24-well plates. Cytotoxicity was assessed by crystal violet staining [97]. Suspended cells were removed by aspiration, the remaining adherent cells were then fixed with $3.7 \%$ formaldehyde for 20 min at room temperature. The excess formaldehyde was washed off with PBS; the cells were then stained using $1 \%$ crystal violet at room temperature for $30 \mathrm{~min}$. Excess crystal violet was washed away with water. Plates were then scanned using an HP Scanjet 4070 scanner (HP, Palo Alto, CA, USA). The remaining crystal violet was then solubilized with a $2 \%$ SDS solution and the sample absorbances (OD) were measured at $590 \mathrm{~nm}$ using a Synergy HT Multi-Mode Microplate Reader (Bio-Tek, Winooski, VT, USA). The OD values of each treatment were then normalized to mock-treated cells converting each sample OD into the percent $(\%)$ of cell viability according to the formula, cell viability $\%=(O D$ of treated cells $/ O D$ of mock-treated cells $) \times 100 \%$. A549 cells displaying CPE were photographed at 200x magnification using an Olympus BX53 microscope (Olympus, Center Valley, PA, USA). 


\section{Statistical Analysis}

All experiments were repeated at least 3 times. Quantification of results was reported as means of 3 independent experiments plus or minus $( \pm)$ the standard deviation. The Pearson correlation coefficient $(r)$ was used to evaluate the accuracy of equations used to calculate sample protein concentrations with the Pierce BCA protein assay kit. Statistical significance was assessed using analysis of variance analysis (ANOVA) for parametric data and the Kruskal-Wallis test for non-parametric data. Multiple comparisons of ANOVA tests were corrected using Bonferroni's method. Multiple comparisons of Kruskal-Wallis one-way analyses were corrected by Dunnett's test. All statistical tests were conducted using GraphPad PRISM 6 software (Microsoft, Redmond, WA, USA). 


\section{3 - Results}

\section{AdUV Displays More Efficient Release and Cancer Cell Lysis}

AdUV was generated as illustrated in Figure 1. Briefly, AdUV was isolated from a pool of $d / 309$ (Ad5) viral particles that were repeatedly treated with UV irradiation and selected in cancer cells for 72 cycles. To evaluate the potency of AdUV in lung cancer cells, A549 cells were infected with the increasing MOls of AdGFP, Ad5, Adhz60, or AdUV for 5 days (Figure 2A). The differences among treatment groups were greatest at an $\mathrm{MOI}$ of 3; these cancer cell viabilities were 20,60 , and $90 \%$ after treatment with AdUV, Ad5, or Adhz60, respectively (Figure 2B). Morphologically, AdUV induced greater cell rounding, consistent with CPE relative to A549 cells treated with Adhz60, Ad5 (Figure 2C). These data indicated that AdUV efficiently destroyed A549 human lung cancer cells. 
A

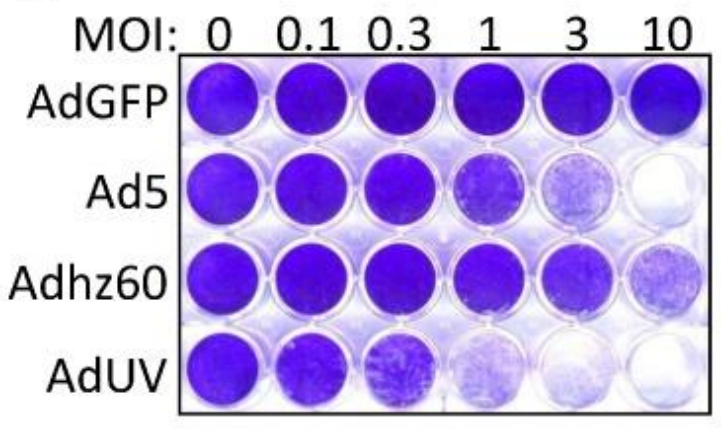

B

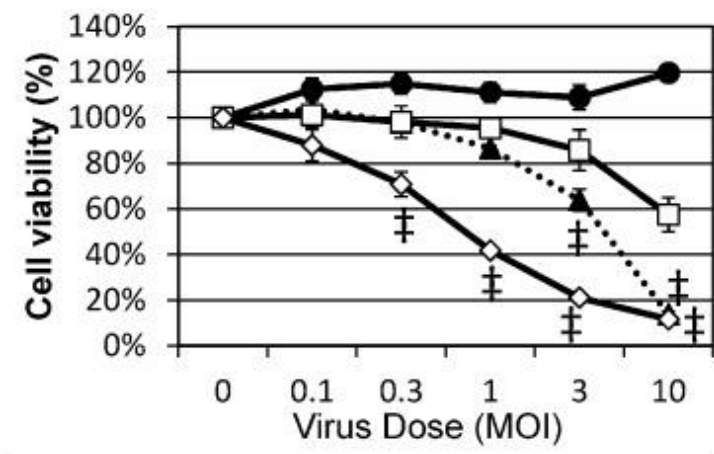

$\longrightarrow$ AdGFP ...A.. Ad5 $-\square-A d h z 60 \multimap$ AdUV

C

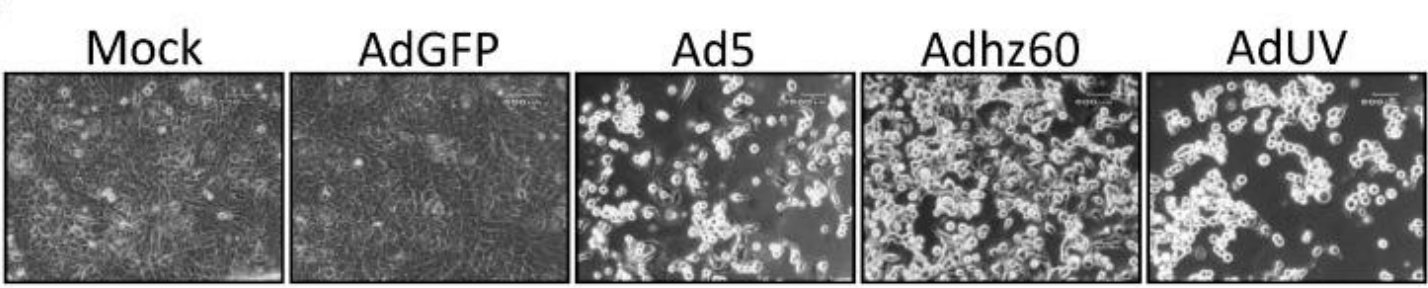

D
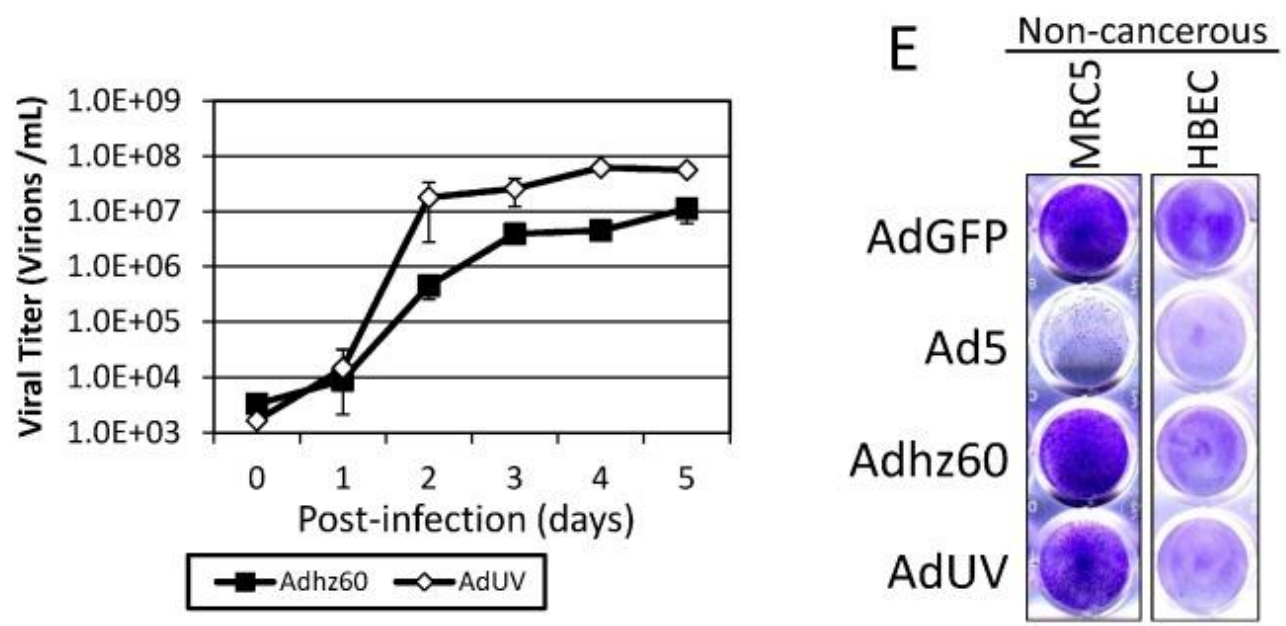

Reprinted with permission: Wechman et al., Viruses, 2016

Figure 2. AdUV is released from and lyses A549 cells more efficiently than Adhz60. (A) A549 cells stained with crystal violet after five days' treatment with the indicated Ads and MOls; (B) Quantification of A549 cells stained with crystal violet expressed at the percent (\%) viability; (C) CPE in A549 cells treated at an MOI of 1 for the indicated Ads were photographed at $200 \times$ total magnification 
five days post-infection; (D) A549 cells were infected with at an MOI of 1 with Adhz60 and AdUV and media samples were collected daily until day 5. Ad titer was determined via the TCID50 method using HEK293 cells. Day 0 represents samples collected at $6 \mathrm{~h}$ postinfection; (E) Crystal violet staining of non-cancerous lung fibroblasts (MRC5) and epithelial (HBEC) cell lines treated at an MOI of 10 for 3 days. Quantified data are shown \pm the standard deviation (SD) of 3 independent replicates. Statistical significance was assessed relative to the oncolytic Ad control Adhz60 via two-way ANOVA relative to Adhz60 treated cells with multiple comparisons corrected for by Bonferroni's method. $\neq_{\text {indicates }} p$-value $<0.001$.

The enhanced lysis of A549 cells by AdUV prompted additional studies to determine if AdUV was released from cells more efficiently. To determine the release kinetics of AdUV, A549 cells were infected with AdUV and Adhz60 and media samples were then collected at $0,1,2,3,4$, and 5 days postinfection (Figure 2D). Viral titers were then determined to quantify the number of virus particles released into culture media at each time-point. The titers for both viruses within the cell culture media increased with time; however, AdUV media titers were greater at each time-point than Adhz60. At day 2, AdUV titer $\left(3 \times 10^{7}\right)$ was 40.5 fold greater than Adhz60 $\left(7.4 \times 10^{5}\right)$ in the cell culture media (Figure 2D). To evaluate the cancer selectivity of AdUV, MRC5 and HBEC non-cancerous cells were infected with negative control AdGFP, the cancer non-selective Ad5, and the cancer-selective Adhz60 and AdUV at an 
MOI of 10. These data indicated that AdUV lysed MRC5 and HBEC noncancerous cells less efficiently than the cancer non-selective Ad5 however, AdUV lysed more non-cancerous cells than the cancer selective Adhz60; indicating that AdUV is at least partially cancer selective (Figure 2E).

To verify the enhanced release and spread of AdUV, plaque assays were conducted. The plaque assay is based on the ability of a single infectious viral unit (IFU) to replicate in cells and release a large number of progeny that can infect neighboring cancer cells, finally forming a macroscopic area of cytopathology, or plaque, on a monolayer of cultured cells. Viruses that can efficiently replicate and release a greater number of viral particles will presumably form larger plaques. In this study, nearly confluent (70\%) A549 cells were infected with Ad5, Adhz60, or AdUV. Initial plaque formation was observed 4 to 5 days post-infection. At day 6 postinfection, at least 10 plaques formed by each virus were studied. The average size of plaques formed by Ad5, Adhz60, and AdUV were $0.883,0.534$, and $1.680 \mathrm{~mm}^{2}$, respectively; plaques formed by AdUV were $314 \%$ larger than those plaques formed by Adhz60 and 190\% larger than those of Ad5 (Figure $3 A, B ; 2$ representative plaques per treatment are shown). These differences were shown to be statistically significant. These studies taken together indicate that AdUV is released and spreads more effectively than Ad5 and Adhz60 in A549 lung cancer cells. 
A

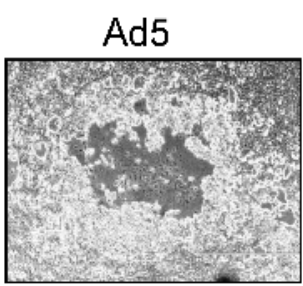

Adhz60

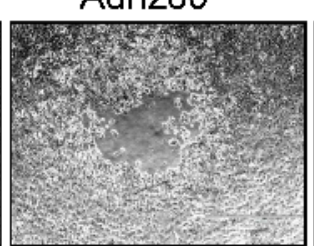

AdUV

$0.807 \mathrm{~mm}^{2}$

$0.549 \mathrm{~mm}^{2}$

$1.305 \mathrm{~mm}^{2}$
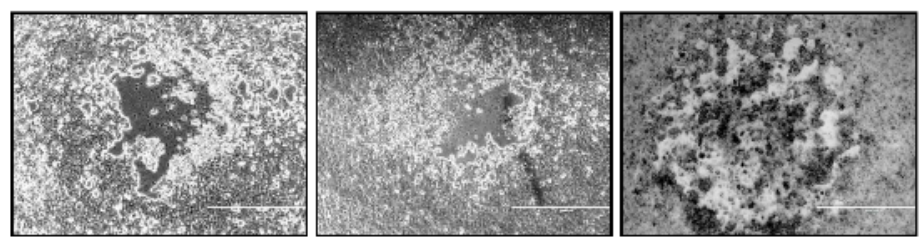

$0.575 \mathrm{~mm}^{2}$

$0.609 \mathrm{~mm}^{2}$

$2.191 \mathrm{~mm}^{2}$

B

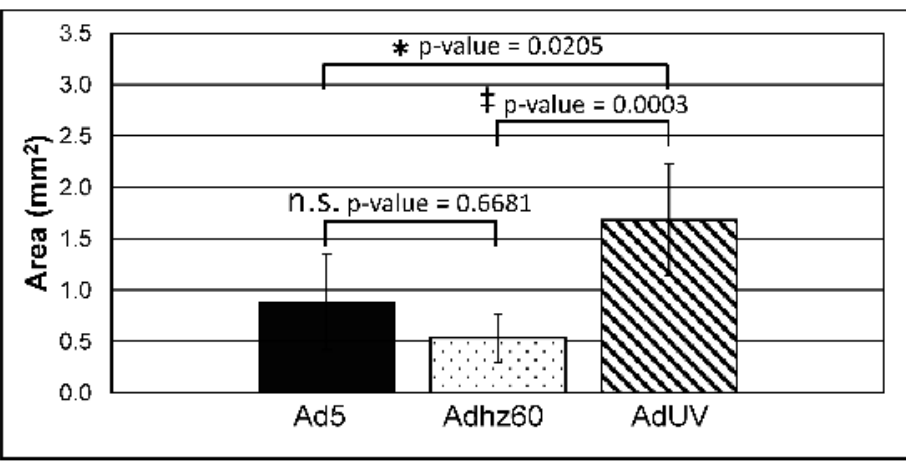

Reprinted with permission: Wechman et al., Viruses, 2016

Figure 3. AdUV spread in A549 cells. (A) Two representative plaques of Ad5, Adhz60 and AdUV treated A549 cells are shown at $4 \times$ magnifications; (B) Using the $1000 \mu \mathrm{M}$ scale (or $1 \mathrm{mM}$ ), the number of pixels contained within each plaque was calculated by dividing by the number of pixels contained within each plaque by the number of pixels per $1 \mathrm{~mm}^{2}$ to determine the size of each plaque in square millimeters $\left(\mathrm{mm}^{2}\right)$. These data were then plotted as the average \pm the SD of these 10 quantified plaques. Statistical significance was assessed using the Kruskal-Wallis test. Adjusted $p$ values were reported for multiple comparisons via Tukey's test. n.s. 
indicates $p$-value $<0.05,{ }^{*}$ indicates $p$-value $<0.05,{ }^{\ddagger}$ indicates $p$-value $<0.001$. 


\section{Improved AdUV Replication in Cancer Cells}

To investigate whether the large plaque formation phenotype of AdUV was related to increased virus replication, viral early (regulative) and late (structural) protein production was studied in A549 cells by Western blot analysis. The E1b-deleted Adhz60 produced much less E1A than the E1b wild-type Ad5 in A549 cells at $48 \mathrm{~h}$ (Figure 4A). This result was expected because E1b expression has been supports E1A production during $\mathrm{Ad}$ infection [29]. At $48 \mathrm{~h}$, AdUV induced peak E1A production. The level of AdUV E1A production was even greater than the cancer non-selective wild-type Ad Ad5 (Figure 4A). At $72 \mathrm{~h}$, the production of E1A by AdUV decreased, while Adhz60-mediated E1A production increased (Figure 4A). Following the rapid expression of E1A proteins by AdUV, late protein production was also shown to increase to levels much greater than Adhz60 and comparable to Ad5 at 72 h (Figure 4A). 


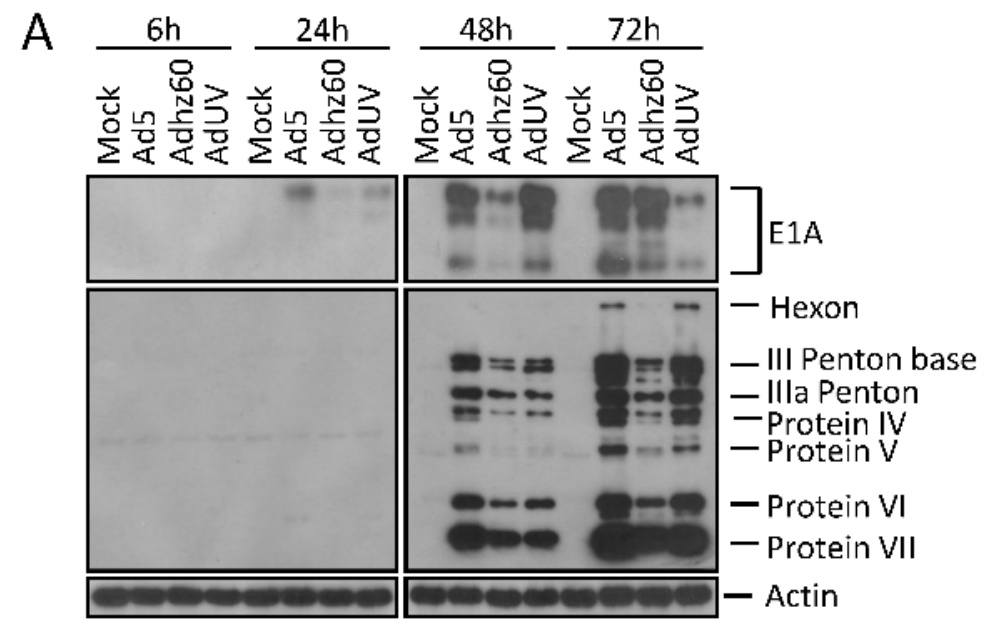

B

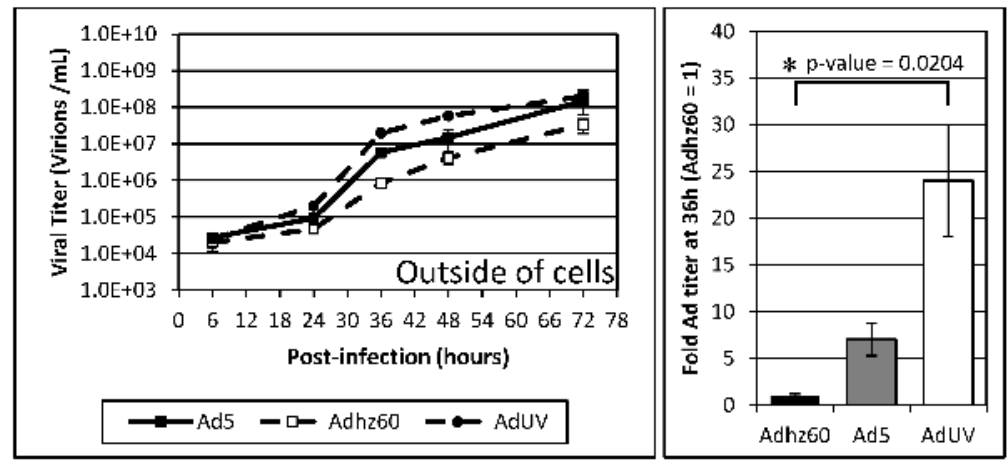

C

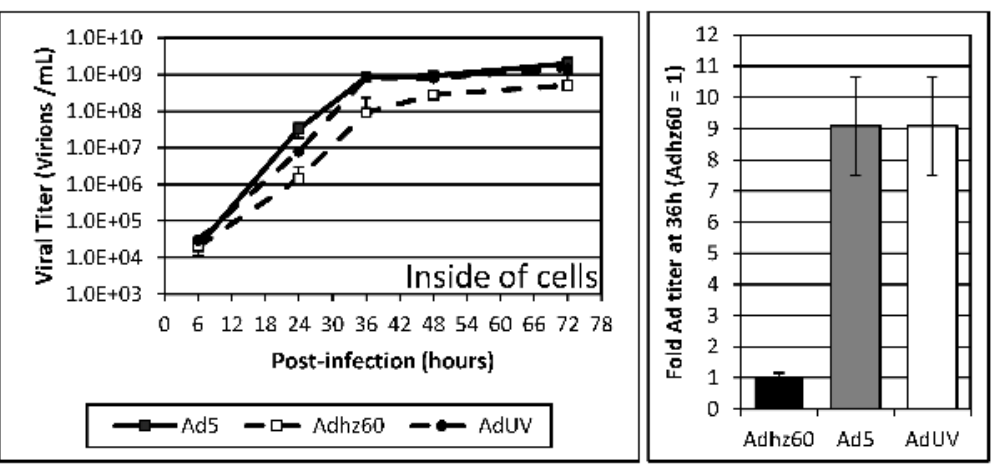

Reprinted with permission: Wechman et al., Viruses, 2016

Figure 4. AdUV virus replication in A549 lung cancer cells. (A) The expression of the Ad E1A and late genes were observed in A549 cells treated with the indicated Ads at an MOI of 1 following $6 \mathrm{~h}, 24 \mathrm{~h}$, $48 \mathrm{~h}$, and $72 \mathrm{~h}$ infection; (B) Virus titer outside of A549 cells treated with the indicated Ads at an $\mathrm{MOI}$ of 1 . Samples were collected at the indicated time-points. At $36 \mathrm{~h}$, the number of virions of released in the 
cell culture media was 7 fold for Ad5 and 24 fold for AdUV when normalized to Adhz60 titer; (C) Virus titer inside of infected A549 cells treated with the indicated Ads at an $\mathrm{MOI}$ of 1 . Samples were collected at the indicated time-points. At $36 \mathrm{~h}$, the titers of both AdUV and Ad5 inside of cells were 9 fold greater than Adhz60. Data is presented as the average titer \pm SD of 3 independent replicates. Significance was determined via the Kruskal-Wallis test. Adjusted $p$-values were reported for multiple comparisons via Dunnett's test. $\mathrm{h}$ indicates hours, ${ }^{*}$ indicates $p$-value $<0.05$

To study the oncolytic replication and release of AdUV further, A549 cells were infected with AdUV, Ad5, or Adhz60 at an MOI of 1 . In this experiment, the cell culture media and total cells were collected at $6,24,36$, 48, and $72 \mathrm{~h}$ post-infection. The cells and culture media were separated via centrifugation to determine the titers of Ads within cells and of viruses released into the culture media. The titers of AdUV released into the cell culture media were $5 \times 10^{6}$ at $36 \mathrm{~h}$ which was greater than both Ad5 (1.5 $\times$ $\left.10^{6}\right)$ and Adhz60 (1.5 $\times 10^{5} ;$ Figure 4B, left $)$. When these data were normalized to Adhz60 titer, AdUV was 24 fold while Ad5 titer was 7 fold greater than Adhz60 (Figure 4B, right). The viral titers of AdUV and Ad5 within cancer cells were similar; the titers of both AdUV and Ad5 were consistently 5 to 10 fold greater than Adhz60 from 24 to $72 \mathrm{~h}$ within A549 cells and were 9 fold greater than Adhz60 at $36 \mathrm{~h}$ (Figure 4C). These data indicate that AdUV replicates and is released more rapidly from A549 cells than Adhz60. It is likely that the rapid release of AdUV supports its ability to form large plaques in A549 cells. 


\section{AdUV is a Greater Autophagy Inducer}

Ads have been shown to induce autophagy to enhance virus replication [66]. Autophagy leads to the sequestration of organelles and long lived proteins into autophagosomes, which then fuse with lysosomes, forming the autophagolysosome to recycle cellular components [69]. During autophagolysosome formation, microtubule-associated protein 1 light chain 3 (LC3) matures from LC3-I (18 kDa) to LC3-II (16 kDa) [71]. Therefore, the LC3-II/LC3-I protein ratio can be used to estimate the abundance of autophagosomes and indicate the relative levels of cellular autophagy induction $[72,73]$.

To study autophagy induction by AdUV, A549 cells were treated with AdGFP, Ad5, Adhz60, or AdUV at an MOI of 1. Large vesicles were observed in the cytoplasm of A549 cells treated with Ad5 and AdUV, but not with AdGFP or Adhz60 (Figure 5A, arrowheads). The presence of such vesicles is

a morphological marker of autophagy induction. Autophagy induction was evaluated further via the observation of LC3 production via Western blot analysis. Relative to mock, the LC3-II/LC3-I expression ratio increased to 30.9, 12.2, and 7.8 fold for AdUV, Ad5, and Adhz60, respectively (Figure 5B). AdUV treatment displayed the greatest LC3-II/LC3-I fold expression ratio. According to these data, AdUV induced autophagy much more effectively than either Ad5 or Adhz60 in A549 cells. 


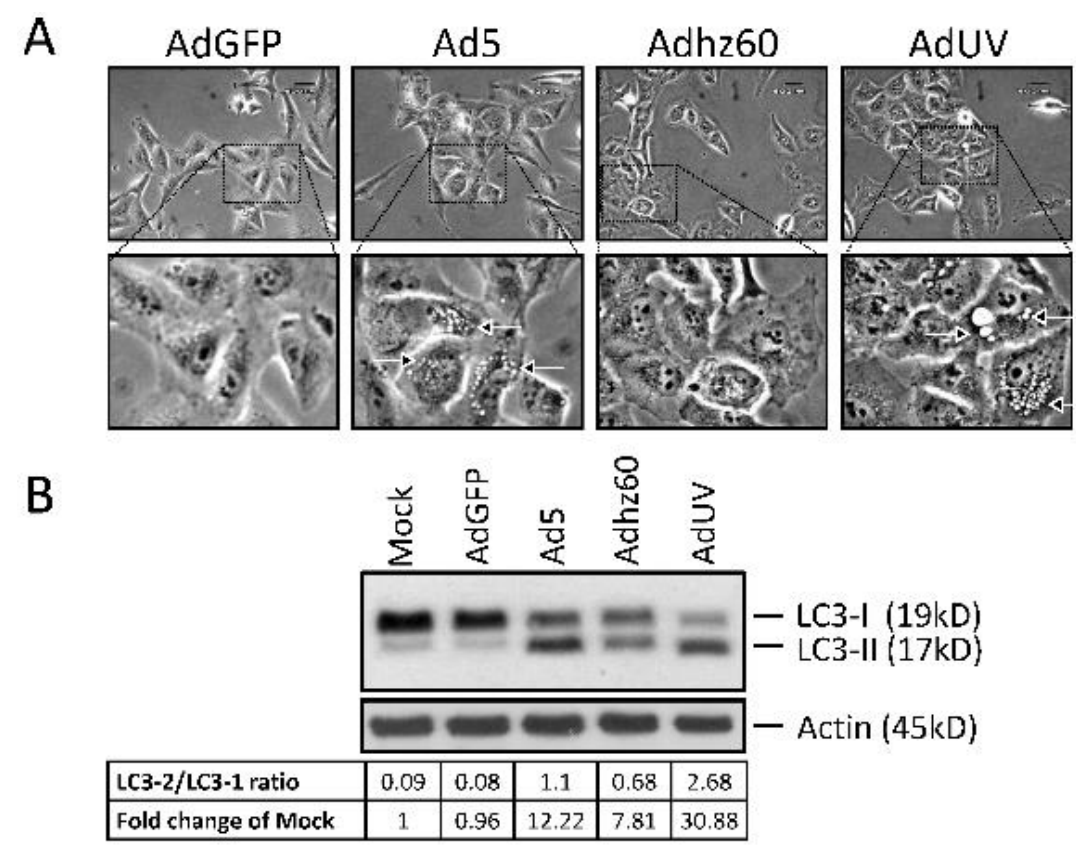

Reprinted with permission: Wechman et al., Viruses, 2016

Figure 5. AdUV induces greater autophagy in A549 cells. (A) Pictures of A549 cells (400x total magnifications) treated with the indicated Ads at an MOI of 1 for 3 days. Boxes indicate the magnified ( $\sim 9.3 \times$ total magnifications) to emphasize the presence or absence of vesicle formation in the cytoplasm. Arrows were used to indicate these vesicles. Scale bar (top right) is indicative of $600 \mu \mathrm{m}$; (B) A549 cells were treated with the indicated Ads at an MOI of 1 for 5 days and observed for LC3 expression by Western blot analysis. Densitometric analysis of LC3-II to LC3-I and actin were performed using Gel-pro analyzer 4.0 software. LC3 expression was normalized to actin expression. 


\section{AdUV Kills a Variety of Cancer Cell Lines}

To study the oncolytic effects of AdUV upon other cancer cell lines, A549, H1299, and H441 lung cancer cells, as well as MCF-7 breast cancer cells were treated with increasing MOls of AdGFP, Ad5, Adhz60, or AdUV for 5 days. Cell viability was assessed via crystal violet staining and normalized to mock-treated cancer cells (Figure 6A). The negative control AdGFP did not alter treated cell viability while treatment with the positive control Ad5 was shown to efficiently lyse all cancer cell lines tested. AdUV lysed A549 cells with significantly greater efficiently than both Ad5 ( $p$-value $=0.005$ ) and Adhz60 $(p$-value $=0.0002)$ at $0.3 \mathrm{MOI}($ Figure 6A). AdUV killed H1299 lung cancer cells $64 \%$, comparing with $8 \%$ of Adhz60 and $18 \%$ of Ad5 treatment at the same condition (0.3 MOI). Compared with the E1b-deleted Ad Adhz60, AdUV also efficiently destroyed H441 lung cancer cells and MCF-7 breast cancer cells (Figure 6A). The EC50s of AdUV were 0.99, 1.12, 1.12, and 1.76 for A549, H1299, H441 and MCF-7, respectively (Figure 6B). Adjusted pvalues for multiple comparisons indicated that statistically significant differences were observed between the AdUV and Adhz60 treatment groups in all cancer cell lines treated at an MOI of 1 except MCF-7 (Figure 6C). Therefore, AdUV induced the oncolysis of multiple cancer cell lines much more effectively than Adhz60. 

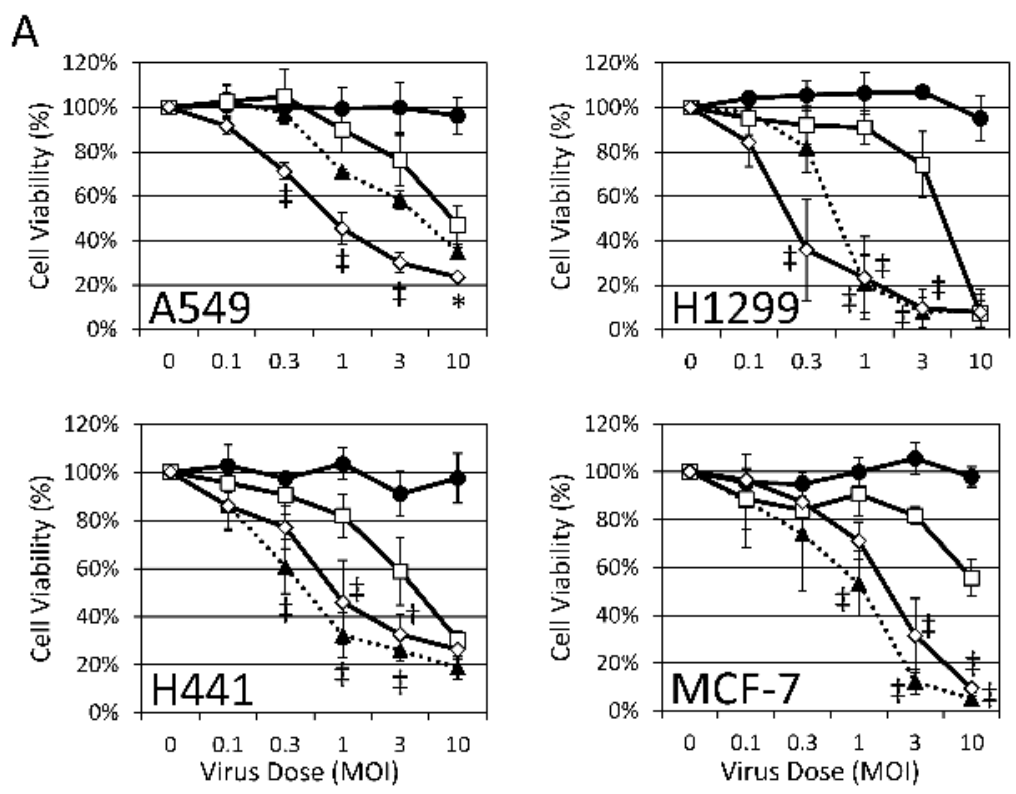

$\rightarrow$ AdGFP $\quad \cdots \cdots \cdot$ Ad5

$\rightarrow \square-A d h z 60 \quad \approx$ AdUV

B

\begin{tabular}{|c|c|c|c|c|}
\hline & \multicolumn{4}{|c|}{ EC50 (MOI) } \\
\hline Virus & A549 & H1299 & H441 & MCF-7 \\
\hline Ad5 & 4.11 & 0.58 & 0.58 & 0.84 \\
\hline Adhz60 & 9.05 & 4.29 & 4.29 & d.n.e. \\
\hline AdUV & 0.99 & 1.12 & 1.12 & 1.76 \\
\hline
\end{tabular}

C

\begin{tabular}{|c|c|c|c|c|}
\hline & \multicolumn{4}{|c|}{1 MOI p-values } \\
\hline virus & A549 & H1299 & H441 & MCF-7 \\
\hline AdGFP vs. Ad5 & n.S. & $\ddagger$ & $\ddagger$ & $\ddagger$ \\
\hline AdGFP vs. Adhz60 & n.S. & n.S. & n.S. & n.S. \\
\hline AdGFP vs. AdUV & $\ddagger$ & $\ddagger$ & $\ddagger$ & $*$ \\
\hline Ad5 vs. Adhz60 & n.S. & $\ddagger$ & $\ddagger$ & $\dagger$ \\
\hline Adhz60 vs. AdUv & $\ddagger$ & $\ddagger$ & $†$ & n.S. \\
\hline Ad5 vs. AdUv & n.S. & n.S. & n.S. & n.S. \\
\hline
\end{tabular}

Reprinted with permission: Wechman et al., Viruses, 2016

\section{Figure 6. AdUV kills multiple cancer cell lines more effectively} than Adhz60 in vitro. (A) A549, H1299, H441 lung cancer cells and MCF-7 breast cancer cells were treated with the indicated MOls and Ads for 5 days prior to staining with crystal violet. The amount of crystal violet staining was quantified and expressed as the percent (\%) viability of treated cells relative to non-treated cells \pm the standard deviation of 3 independent experiments; (B) EC50 values were determined using GraphPad PRISM software; (C) Two-way ANOVA with multiple comparisons were conducted between all Ad treatments across all cancer cell lines at an $\mathrm{MOI}$ of 1 . Adjusted $\mathrm{p}$-values were 
reported for multiple comparisons via Bonferroni's method. d.n.e. indicates that the EC50 does not exist, ${ }^{*}$ Indicates a $p$-value $<0.05,{ }^{\dagger}$ indicates a $p$-value $<0.01, \ddagger$ indicates a $p$-value $<0.001$. 


\section{4 - Discussion}

All clinical studies have shown that the efficacy of Ad virotherapy, specifically d/1520/ONYX-015 and H101, has remained low $[15,17,18,57$, 58, 98-100]. Ad spread within solid tumors was limited to cancer cells in the immediate vicinity of the injection site in clusters of $5-20$ cells during clinical studies [101-103]. In the Dr. McMasters lab, intratumorally (IT) injected Ads localized within capsule-like structures in syngenic xenograft bearing mice [35]; the formation of these capsules likely prevented Ad spread throughout the entire tumor mass, limiting its therapeutic outcomes. These data indicated that Ad spread is restricted in tumors and may have antagonized the efficacy of Ad virotherapy [94].

The development of Ad vectors with increased spread would likely lead to enhanced cancer therapeutic efficacy for the treatment of solid tumors. Most Ads used clinically are E1 gene modified. E1-modified Ads have been the focus of clinical studies primarily because the functions of $E 1$ are well characterized relative to many of the other Ad genes, whose effects upon Ad replication in cancer cells are not understood. Therefore, it is difficult to predict the biological consequences resulting from the genetic manipulation of nonE1 Ad genes. An alternative strategy to develop oncolytic Ads is to use random mutagenesis to introduce changes to the viral genome and then select for mutant Ads with the desired properties. Such directed evolution has 
been shown to enhance the oncolytic efficacy of other viruses such as the recombinant Newcastle disease virus MTH87 [62] and Ad5 [60, 61]. In this study, d/309 (Ad5) was treated with UV irradiation and then selected from the pool of the UV-irradiated viruses for efficient replication in and release from cancer cells. This approach differs from previous reports as Ad particles were treated with DNA-damaging agent a total of 72 times throughout the cancer selection process. After 72 cycles of UV irradiation and cancer selection, AdUV was isolated. AdUV formed larger plaques than both Adhz60 and Ad5 in cancer cells, indicating greater viral spread. Furthermore, AdUV displayed greater anti-cancer potency and efficacy in all cancer cell lines tested. These studies demonstrated the efficacy of AdUV in vitro.

Previously, Ad infection was shown to increase the conversion of LC3-I to LC3-II, inducing autophagy, which positively correlates with enhanced viral replication and oncolytic cell death. This suggests that autophagy may generate macromolecules to support Ad assembly and replication [66]. Results presented in chapter II have shown that AdUV induced LC3-II conversion more effectively than either Ad5 or Adhz60 in cancer cells. Furthermore, the autophagy inducer verapamil, an L-type $\mathrm{Ca}^{2+}$ channel antagonist, has been shown to increase Ad spread between cancer cells in vitro [104], indicating that increased autophagy induction by AdUV may have led to its large plaque formation phenotype in addition the increased release 
of AdUV. The autophagy inhibitor 3MA, a phosphatidylinositol 3-kinase (PI3K) and autophagosome formation inhibitor, was shown to inhibit the replication and oncolysis of Ad infected cancer cells validating these findings [66]. Ad-mediated cancer cell lysis may also be related to the induction of apoptotic [36] and necrotic [64] cancer cell death pathways. Conflicting reports also indicate that wild-type serotype 5 Ads (Ad5) kill cancer cells independently of caspase activation and TP53 expression $[64,105]$. While the molecular mechanism of enhanced AdUV cytolysis remains unclear, enhanced autophagy induction appears to play an important role.

One limitation of this approach is that multiple mutations may be introduced into the viral genome. Ascertaining the effects of an individual mutation upon virotherapy from mutagenesis and cancer selection is complex. To determine which mutation or combination of mutations has the greatest effect upon this enhanced oncolysis phenotype, additional in vitro and in vivo studies are necessary to characterize these mutations and is the subject of future investigation. 


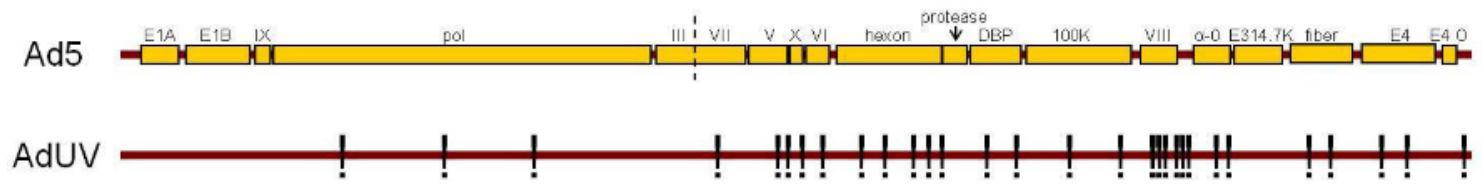

Reprinted with permission: Wechman et al., Viruses, 2016

Figure 7. AdUV DNA mutation map. 30 mutations were detected in the AdUV genome in total, relative to the Ad serotype 5 (Ad5) reference sequences. No mutations were present in the early genes. The majority of these mutations were contained in Ad late genes. Mutations are indicated by exclamation points. Data was collected via ION torrent DNA sequencing and viewed with open source IGV software. 
In this study, these data indicated that AdUV, developed through repeated mutagenesis and selection in cancer cells, has displayed many favorable characteristics and has substantial potential as a cancer therapeutic platform. The enhanced cancer cell lysis by AdUV appears to be related to the increased viral replication and release from infected cancer cells, as well as increased autophagy induction. This study has also indicated the utility of this approach for the development of other oncolytic viruses with designated therapeutic properties. 


\section{CHAPTER III \\ ADENOVIRUS WITH DNA PACKAGING GENE MUTATIONS INCREASED VIRUS RELEASE}

\section{1 - Introduction}

In the preceding chapter, AdUV was isolated from a pool of the Ad serotype 5 d/309 (Ad5) viral particles which were repeatedly treated with UV type-C irradiation and selected for rapid cancer cell lysis. AdUV was shown to lyse cancer cells very effectively and form large viral plaques on cancer cell monolayers [82]. In this chapter, we extended the description of AdUV in Chapter II to identify AdUV genome mutations. No mutations were observed in the early genes $(E 1, E 4)$ in AdUV, but several mutations were found within the late genes encoding Ad structural proteins involved in viral DNA packaging. AdUV was shown to effectively lyse cancer cells while safely and efficiently suppressing tumor growth using an athymic nude mouse ( $\mathrm{NCr}$ nu/nu) xenograft model. 


\section{$\underline{3.2-\text { Materials and Methods }}$}

\section{Cell Lines and Culture Conditions}

HEK293 (ATCC no. CRL-1573) human embryonic kidney, MRC5 (ATCC no. CCL-171) human non-cancerous lung fibroblast, HBEC (ATCC no. CRL-4051) human non-cancerous human bronchial epithelial cells, A549 (ATCC no. CCL-185) human lung carcinoma and Saos-2 (ATCC no. HTB-85) human osteosarcoma cells were all purchased from the ATCC (Rockville, MD, USA). A549, MRC5 and HEK293 cells were maintained in Dulbecco's Modified Eagle's Medium (DMEM). Saos-2 cells were maintained in McCoy's 5A media. DMEM and McCoy's 5A media were supplemented with $10 \%$ fetal bovine serum, L-glutamine, and penicillin/streptomycin (100 U/mL). HBEC cells were cultured in airway epithelial cell basal medium (ATCC PCS-300030) supplemented with bronchial epithelial cell growth kit (ATCC PCS-300040). All cells were cultured and maintained in humidified $5 \% \mathrm{CO}_{2}$ incubators at $37^{\circ} \mathrm{C}$. 


\section{Adenoviral Vectors}

Ad5 d/309 is E1 wild-type [95] and was used as a non-selective Ad control. This virus also contains deletions in E3, preventing the expression of E3B10.4K, 14.6K, and $14.7 K$, but not the E3A glycoprotein (gp) $19 \mathrm{~K}$ gene [95]. Adhz60 is an E1b-deleted vector similar to d/1520 and $\mathrm{H} 101$ and was used as a cancer selective control in these studies [96]. AdGFP is E1 (E1a and $E 1 b$ ) deleted, with green fluorescent protein (GFP) expression driven by the CMV promoter [55]. AdGFP, as a negative control, does not replicate nor induce CPE [34, 35]. All Ads used in this study express E1 and E4 unless otherwise specified, and are based upon Ad5 backbone sequences (GENEID\# AC_000008.1).

To select Ads with increased spread, Ad5 d/309 was treated with UV irradiation for $5 \mathrm{~min}$, inactivating approximately $90 \%$ of virus particles. The UV-light source was a germicidal lamp, USEG30T3 (Sylvania, Danvers, MA, USA), fitted with a 30 watt G30T8 UV-light bulb (Philips, Amsterdam, The Netherlands), which produces UV type-C irradiation. UV irradiation was measured with a model 25X UVX radiometer (Fisher Scientific, Pittsburgh, PA, USA). Using these conditions, $213 \mu \mathrm{W} / \mathrm{cm}^{2}$ UV type-C was produced, generating a total UV dose of $639 \mathrm{~J} / \mathrm{m}^{2}$ after $5 \mathrm{~min}$ exposure. Irradiated viruses were then used to infect Saos-2 cancer cells, in which Ads cannot replicate as well as in HEK293 and A549 cells [31]. Four h after infection, virus particles in the medium were removed by washing the cells with fresh media. Medium from infected monolayer cultures was collected at the first sign of CPE, generally at $24 \mathrm{~h}$ after infection, to harvest viruses that might 
replicate more efficiently in and release from the infected cancer cells. The harvested viruses were then amplified in HEK293 cells before subsequent cycles of UV-light treatment. These treatments were repeated for 72 cycles. AdUV was then isolated from a mixture of viruses by plaque purification and selection for those Ads forming large plaques on Saos-2 cells as previously described [82]. 


\section{Virus Titration and Release}

Virus titer was determined using the median tissue culture infective dose (TCID50) method [33, 59, 106]. HEK293 cells were seeded overnight onto 96-well plates at a density of $1 \times 10^{3}$ cells per well and infected with virus samples serially diluted 10 fold. The presence or absence of CPE in HEK293 cells was recorded, after a minimum of 7 days, to calculate Ad titer.

To determine the release kinetics of AdUV, A549 and Saos-2 cells were seeded onto 12-well plates at a density of $1 \times 10^{5}$ and $1.5 \times 10^{5}$ cells per well, respectively. A549 cells were then infected with Ad5, Adhz60 or AdUV at an $\mathrm{MOI}$ of 1 . The cells and cell culture samples were then collected at 6,24 , $36,48,72,96$ and $120 \mathrm{~h}$ post-infection. The cells were separated from the cell culture media and discarded from each sample following centrifugation at 2000 RPM (350 RCF) at $4{ }^{\circ} \mathrm{C}$ for 5 min using a micromax RF refrigerated microcentrifuge equipped with an IEC 851 rotor (Thermo Fisher Scientific, Waltham, MA, USA). The cell fraction was resuspended in PBS and subjected to 3 freeze and thaw cycles to release all Ads from the infected cancer cells. Cell free media samples and lysed cell samples were titered to detect the concentrations of Ads within each fraction respectively. 


\section{Cytotoxicity Assay}

Cells were seeded at a density of $3 \times 10^{4}$ (A549) or $4.5 \times 10^{4}$ (Saos-2) cells per well onto 24-well plates and allowed to adhere overnight. Cytotoxicity was assessed by crystal violet staining after 5 days [97]. Suspended cells were aspirated and the adherent cells were then fixed via incubation with $3.7 \%$ formaldehyde for $25 \mathrm{~min}$ at room temperature (RT). Excess formaldehyde was washed away using PBS. Cells were then stained using $1 \%$ crystal violet for 30 min at RT. Excess crystal violet was washed away with water. These crystal violet stained wells were then scanned using an HP Scanjet 4070 scanner (HP, Palo Alto, CA, USA). The remaining crystal violet was then solubilized with a $2 \%$ SDS solution and the sample ODs were measured at $590 \mathrm{~nm}$ using a Synergy HT Multi-Mode Microplate Reader (BioTek, Winooski, VT, USA). These OD values were then normalized to mocktreated cells converting each sample OD into the percent (\%) cell viability by the formula, cell viability $\%=(O D$ of treated cells $/ O D$ of mock-treated cells $) \times$ 100. 


\section{DNA Sequencing}

DNA sequencing was performed at the University of Louisville (Louisville, KY, USA) Genomics Facility using lon Torrent PGM Sequencing 200 kit v2 and Ion Torrent PGM system. An lon 314 v2 Chip was used for loading the enriched Ion One Touch 200 ISP samples. Open source integrated genomics viewer (IGV) software was downloaded to view these DNA sequencing data. Mutations with low DNA sequencing error rates are listed in Table 1. 


\section{Lung Cancer Xenograft}

Female athymic nude mice ( $\mathrm{NCr}-\mathrm{nu} / \mathrm{nu})$ were obtained from the National Cancer Institute (Bethesda, MD, USA). Tumors were formed following the subcutaneous injection (SC) of $5 \times 10^{6}$ A549 lung cancer cells into the right flanks of $\mathrm{NCr}$-nu/nu mice at 6 weeks of age. Ads were titrated on HEK293 cells using the plaque assay to determine the plaque forming units (PFU) for AdUV and AdGFP prior to intratumoral injection as described previously [107]. Once palpable tumors were established and reached 30 $\mathrm{mm}^{3}$, mice were randomized into 2 treatment groups to receive $5 \times 10^{8} \mathrm{PFU}$ of AdGFP ( $n=8)$ or AdUV $(n=7)$ suspended in $50 \mu \mathrm{L}$ PBS every 3 days for a total of 4 treatments $\left(2 \times 10^{9} \mathrm{PFU}\right)$ from days 6 to 15 . Tumor volumes were determined by externally measuring these tumors in 2 dimensions with a caliper and calculated based upon the following equation, $V=\left(L \times W^{2}\right) / 2$, where $L$ is length and $W$ is the width of the tumor as described previously [34, 35]. Eight mice were treated with AdGFP and 7 mice were treated with AdUV. Animal experiments were performed according to the institutional guidelines approved by the University of Louisville Institutional Animal Care and Use Committee (IACUC, protocol \# 11079, Louisville, KY, USA). 


\section{Immunohistochemistry}

Tumors were harvested 7 days following the fourth treatment and embedded in optimal cutting compound (OTC; Sakura Finetek, Torrance, CA, USA), and stored at $-20{ }^{\circ} \mathrm{C}$. Briefly, slides were air-dried and fixed in ice-cold methanol at $4{ }^{\circ} \mathrm{C}$ for $20 \mathrm{~min}$. The endogenous tissue peroxidase activity was blocked by incubation in a $0.3 \%$ hydrogen peroxide $3 \%$ methanol solution for 30 min according to the Vectastain $A B C$ protocol (Vector Laboratories, Burlingame, CA, USA). These tissues were then blocked in SuperBlock (Pierce Biotechnology, Rockford, IL, USA) for $45 \mathrm{~min}$ at RT. Sections were incubated with the goat-anti-hexon polyclonal antibody (Millipore, Billerica, MA, USA), diluted $1: 800$, overnight at $4{ }^{\circ} \mathrm{C}$. These signals were amplified by a biotinylated anti-goat lgG diluted 1:200 in conjunction with Vectastain avidinbiotin complex method kit (Vector Laboratories, Burlingame, CA, USA). Visualization was achieved using 3,3-diaminobenzidine-tetrahydrochloride (DAB) for 5 min at RT; DAB staining was terminated using water (ImmPACT DAB peroxidase substrate; Vector Laboratories, Burlingame, CA, USA). All antibodies were applied and diluted in SuperBlock. Slides were washed 3 times with PBS following the application of SuperBlock, primary antibody, secondary antibody and the $A B C$ reagent. Biotinylated secondary antibody and $A B C$ reagents were both applied to slides for $1 \mathrm{~h}$ at RT. Slides were counterstained with hematoxylin and photographed at $200 \times$ and $400 \times$ 
magnifications using an Olympus BX53 microscope (Olympus, Center Valley, PA, USA). 


\section{Statistical Analysis}

All experiments were repeated at least 3 times. Quantification of results were reported as the mean of 3 independent experiments plus or minus $( \pm)$ the SD. Statistical significance was set at $p$-value less than 0.05 . Statistical significance was assessed using two-way analysis of variance (ANOVA) test and the log-rank sum test. Multiple comparisons were corrected for by Bonferroni's method. Therefore, all $p$-values reported from two-way ANOVA were adjusted using this approach. Multiple comparisons were not made for the log-rank sum test, therefore this $p$-value was not adjusted. All statistical tests were conducted using GraphPad Prism 6 software (Microsoft, Redmond, WA, USA). 


\section{$\underline{3.3-\text { Results }}$}

\section{AdUV with Wild-type E1 and Mutated E3}

As described in Chapter II, AdUV was isolated following the repeated UV irradiation of d/309 (Ad5) which is an E1 wild-type, E3-deleted Ad [95, 108]. The irradiated viral progeny were then subsequently selected within cancer cells to isolate AdUV [82]. In order to determine the mutations that may be responsible for the improved cancer therapeutic efficacy of AdUV, viral DNA was purified and sequenced as described in the methods. The E1 and E3 sequences of AdUV were shown to match the Ad5 genome, validating Ad5 as the parental strain of AdUV. Twenty-five AdUV mutations with a low error rate of sequencing $(\leq 15 \%)$ are listed in Table 1 (GENEID\# AC_000008.1). Thirteen of these 25 mutations were either located within introns or did not alter the coded amino acid sequences of their respective genes. Therefore, this chapter will focus upon those 12 mutations which were shown to alter their respective coded amino acid sequences in the AdUV genome relative to Ad5 reference sequences (Table 1 and Figure 8). 

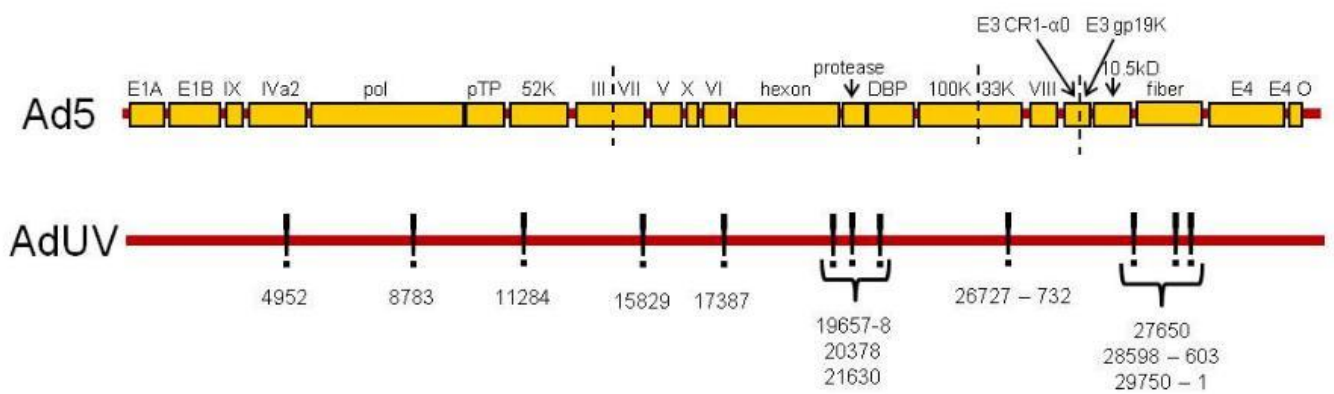

Reprinted with permission: Wechman et al., Viruses, 2016

Figure 8. DNA mutations contained in AdUV. Map of the 12 mutations in the AdUV genome which altered their respective encoded amino acids. Ads: adenoviruses; pTP: precursor terminal protein; DBP: DNA-binding protein. 


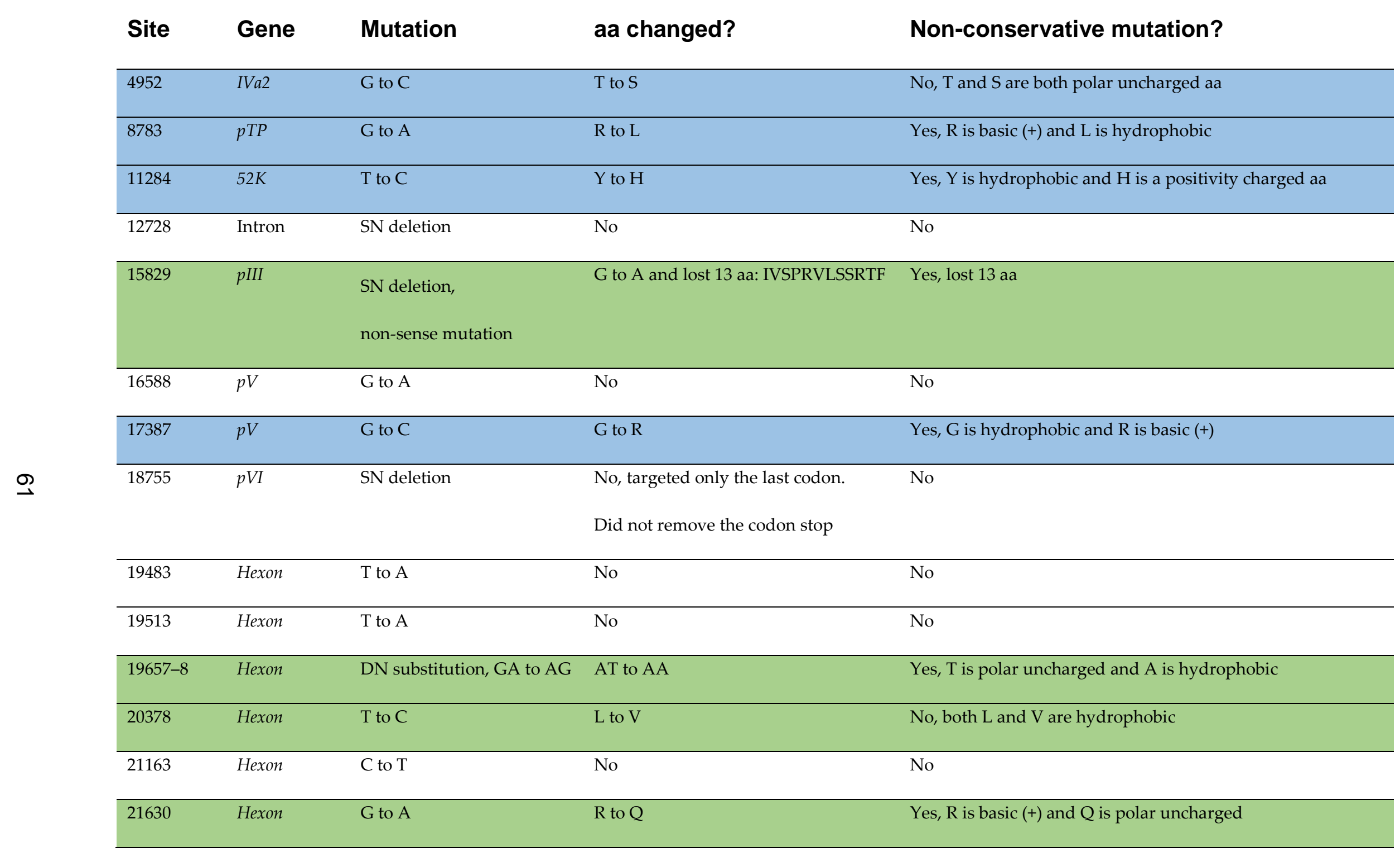




\begin{tabular}{|c|c|c|c|c|}
\hline 25995 & $100 \mathrm{~K}$ & A to $\mathrm{T}$ & No & No \\
\hline 26561 & Intron & G to $A$ & No & No \\
\hline $26727-32$ & $33 K$ & Six-nucleotide deletion & Lost 2 aa $\mathrm{A}$ and $\mathrm{A}$ & Yes, lost 2 aa \\
\hline 27161 & Intron & $\mathrm{C}$ to $\mathrm{T}$ & No & No \\
\hline 27314 & $p V I I I$ & $\mathrm{C}$ to $\mathrm{A}$ & No & No \\
\hline 27339 & $p V I I I$ & $\mathrm{~T}$ to $\mathrm{C}$ & No & No \\
\hline $27650-1$ & $p V I I I$ & DN substitution TC to CT & $\mathrm{RP}$ to RS & Yes, $\mathrm{P}$ is cyclic and $\mathrm{S}$ is polar uncharged \\
\hline 28120 & Intron & $\mathrm{T}$ to $\mathrm{C}$ & No & No \\
\hline $28596-601$ & E3 CR1- $\alpha 0$ & Six-nucleotide deletion & Lost 2 aa I and $G$ & Yes, lost 2 aa \\
\hline 29750 & $E 3 A 10.5 \mathrm{kD}$ & $\mathrm{T}$ to $\mathrm{G}$ & M to $R$ & Yes, $\mathrm{M}$ is hydrophobic and $\mathrm{R}$ is basic $(+)$ \\
\hline 35776 & Intron & A to $\mathrm{C}$ & No & No \\
\hline
\end{tabular}

Table 1. Table of AdUV mutations, their location, and changes in amino acid sequences. Conservative mutations are defined as changes to the encoded amino acids which have led to similar biochemical properties. We were interested in those non-conservative mutations in which DNA mutations altered the biochemical properties (charge, hydrophobicity and size) of these coded amino acids. Within the table, blue rows indicate mutations to DNA binding and packaging genes, green indicate mutations to Ad structural genes. White rows are indicative of mutations which were either conserved or occurred in genes which do not have functions related to Ad structure or DNA binding. These mutations were shown to have a low DNA sequencing error. The total Ad genome is 36 kilobases (kb). aa: amino acid; DN: double nucleotide; SN: single nucleotide. 


\section{Mutations That Affect Ad Packaging}

There are several mutations in genes associated with virus packaging (Figure 8 and Table 1, highlighted in blue). Mutation at position 4952 changed the encoded threonine amino acid to a serine in the IVa2 gene, which is associated with virus DNA packaging and the transcriptional activation of the major late Ad promoter $[109,110]$. AdUV was previously shown to rapidly transition from early to late gene expression [82]. While both threonine and serine serve very similar biochemical functions, the pivotal role of IVa2 to package the Ad genome indicates the potential relevance of this mutation. Since threonine and serine are both polar uncharged amino acids with very similar structures, this mutation is conservative. It is possible however that this mutation may have altered the tertiary or quaternary structure of IVa2 by replacing threonine with a smaller serine residue.

The Ad terminal protein or pTP was mutated at position 8783 (Table 1 and in Figure 8). The pTP peptide is the precursor form of the Ad terminal protein, which matures following protease cleavage [111]. pTP stabilizes the origins of Ad DNA replication, promoting DNA synthesis by the formation of a pTP/pol dimer and the recruitment of the transcription factors octamer-binding protein 1 (Oct-1) and nuclear factor I (NFI), which bind pTP and pol, respectively $[112,113]$. In AdUV, pTP is mutated at 8783 , changing an encoded arginine with a positive charge at physiological $\mathrm{pH}$ to a hydrophobic leucine.

A mutation at position 11284 to $52 \mathrm{~K}$ replaced a hydrophobic tyrosine residue with histidine, an amino acid with a positive charge at physiological $\mathrm{pH}$ 
(Table 1 and in Figure 8 ). The $52 \mathrm{~K}$ protein is a DNA binding protein $[114,115]$. Positively charged amino acids at residues 105, 106, and 107 were essential for $52 \mathrm{~K}$ function [116]. Therefore, it is possible that the addition of more positively charged amino acids may have further enhanced these functions.

In AdUV, the pV gene was mutated at 2 sites: 16588 (silent mutation) and 17387. The mutation at 17387 changed the endogenous glycine amino acid to an arginine residue (Table 1 and in Figure 8 ). Glycine has a single hydrogen atom as a side-chain, while arginine has a large, 6-carbon nitrogenous side-chain with a positive charge at physiological $\mathrm{pH}$. The endogenous function of $\mathrm{pV}$ is to form a shell surrounding the condensed Ad DNA during virion packaging onto the interior surface of the capsid during virion assembly by interaction with $p V I$ and $p 32$ [117-119]. The DNA binding functions of $\mathrm{pV}$ has been described as histonelike in infected cells [120]. There are 16 known pV DNA binding sites, however,

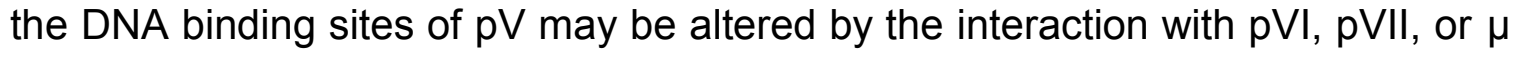
[121]. These $\mathrm{pV}$ peptide DNA binding sites were identified via PONDR-FIT, version VL-XT [122]. This mutation (17387) replaced the 281 glycine residue with an arginine which is not located in a known pV DNA binding site [120]. Therefore, the substitution of the glycine hydrogen atom side-chain for the positively charged arginine may have generated a novel site for $\mathrm{pV}$ to bind the negatively charged DNA sugar-phosphate backbone with greater affinity. This could promote viral packaging, leading to greater progeny production and increasing the oncolytic efficacy of AdUV. 
A mutation was also observed at 26727-32, which deleted 6 DNA nucleotides, removing 2 encoded alanine residues from 33K (Table 1 and in Figure 8). The $33 \mathrm{~K}$ protein is known to play a role to assist in Ad DNA packaging, the transactivation of IIIa and $p V I$, and to serve as an alternative RNA splicing factor $[123,124]$. Furthermore, mutant viruses with $33 \mathrm{~K}$ deleted were shown to produce empty Ad capsids devoid of Ad DNA, demonstrating the requirement of 33K expression to efficiently package Ad DNA [124]. 33K has also been shown to form a dimer with IVa2 to upregulate the transactivation of the major late $\mathrm{Ad}$ promoter, which helps to promote virion assembly and release [110, 125].

The effect of these mutations maybe to cooperate to bind and package Ad DNA more effectively and stimulate the rapid progression of AdUV from the early to late stages of $\mathrm{Ad}$ replication via enhanced $\mathrm{Ad}$ major late promoter transactivation. 


\section{Mutations Affecting Other Ad Structural Proteins}

There were also several mutations in other virus structural proteins (Table 1 and Figure 8, highlighted in green). A single nucleotide deletion in p/ll at 15829 resulted in a premature stop codon, preventing the translation of 12 amino acids (560-571, IVSPRVLSSRTF) into the plll peptide (Table 1). The plll gene has also been implicated for its role to package Ad DNA [126]. Once expressed, pIII binds with 4 other plll macromolecules to form the penton base, which is located at each of the 12 vertexes of the icosahedral Ad capsid [127]. Ad serotype 2 encoded plll peptide (98.6\% similarity to Ad5 by BLAST peptide analysis) was shown to be the most highly phosphorylated peptide in the Ad2 phosphatome with 12 total phosphorylation sites: one tyrosine, one threonine and 10 serine residues [128]. This truncated form of pIII expressed by AdUV may form smaller pllI pentamers (penton) with fewer phosphorylation sites.

Three of 6 mutations in hexon protein changed their respective amino acid sequences (Table 1 and Figure 8 ). The mutations at 19657-8 changed a polar uncharged threonine into an alanine, the mutation at 20378 changed a leucine to a valine, and the mutation at 21630 changed the positively charged arginine to a smaller, polar uncharged glutamine residue (Table 1 and Figure 8). Hexon is one of the principal components of the Ad capsid. Each facet of the Ad capsid contains 12 hexon trimers with hexon pentamers positioned at each vertex of the icosahedral capsid [129, 130]. In vivo, hexon is highly immunogenic [131] and contains many hypervariable regions (HVRs) which when bound by antibodies, neutralize the infectivity of Ads [132]. Hexon contains nine HVRs located in the 
DE1 and FG1 loops between the coded 126 and 461 amino acids [132]. The mutations located at 20378 and 21630 are not contained within 1 of these 9 HVRs. The 19657-8 mutation changed a threonine residue to an alanine at position 273; however, this mutation is also not located within any of these 9 hexon HVRs. Therefore, these mutations should not alter the coded amino acids of the hexon HVRs. However, these mutations effects upon hexon immunogenicity in vivo are unknown at this time.

One mutation in $p V I I I$ at $27650-1$ altered the endogenous hydrophobic, cyclic proline amino acid to a polar, uncharged serine residue (Table 1 and Figure 8). Proline is the only known cyclic amino acid. Therefore proline is required for the formation of sharp turns or kinks during polypeptide folding [133]. The capsid protein $\mathrm{pVIII}$ is known to interact with $\mathrm{pV}$ on the interior of the $\mathrm{Ad}$ capsid, which together with $\mathrm{pVI}$, helps to connect the Ad capsid vertexes to the interior of capsid and ultimately to the Ad DNA genome as virions are assembled [134]. The pVIII peptide contains several proline residues, from 37 to 90 , which forms a tight $\alpha$-helical structure which interacts with hexon [134]. There are also pVIII proline residues which contribute to the U-bend and a-helix structures [134]. This AdUV mutation substituted a proline for a serine at residue 160. However, this mutation did not occur within these crucial a-helical (37-90) and U-bend (6377) proline-rich domains. Therefore, this mutation may not have affected the polypeptide folding of $\mathrm{pVIII}$ as I expected. This mutation may have brought $\mathrm{pVIII,}$ $\mathrm{pV}$ and $\mathrm{pVI}$ into a more open conformation or increased the affinity of the capsid for Ad DNA, leading to greater oncolysis and spread in solid tumors. 


\section{AdUV Displayed Greater Oncolysis and Release from A549 and Saos-2 Cells}

As AdUV contains wild-type E1 region expression, therefore the ability of AdUV to lyse cancerous and non-cancerous cells was determined. MRC5 noncancerous lung fibroblasts, HBEC non-cancerous lung epithelial cells, and A549 lung cancer cells were treated with AdUV, the non-selective Ad5, and the cancer selective (E1b-deleted) Adhz60 at an MOI of 10. Cell viabilities were determined via crystal violet staining after $72 \mathrm{~h}$. Ad5 was shown to lyse MRC5 and HBEC non-cancerous lung cell lines more effectively than Adhz60 ( $p$-value $<0.001)$ and AdUV ( $p$-value < 0.001; Figure 9). While AdUV lysed significantly fewer HBEC cells than Ad5, AdUV may lyse normal lung tissue in vivo. It seems unlikely as that AdUV would lyse a significant number of lung cells, as Ad5-based oncolytic Ads have not been shown to induce pulmonary toxicity clinically. AdUV, like Ad5, lysed A549 lung cancer cells more effectively than Adhz60 ( $p$-value $<0.01$; Figure 9). Therefore, AdUV kills lung cancer cells efficiently, indicating that these AdUV mutations may have enhanced its oncolytic potential.

The effect of AdUV upon A549 and Saos-2 cancer cell viability was determined by crystal violet staining following treatment with the indicated Ads for 5 days. A549 cells support greater Ad replication relative to Saos-2 cells [31]. A549 cells displayed the greatest differences in cell viability at an $\mathrm{MOI}$ of 1 ; these viabilities were $91 \%, 40 \%, 67 \%$, and $10 \%$ for AdGFP, Ad5, Adhz60, and AdUV, respectively (Figure 10A). Saos-2 cells displayed the greatest differences in cell viability at an $\mathrm{MOI}$ of 3 : the viabilities were $100 \%, 74 \%, 87 \%, 57 \%$ for AdGFP, 
Ad5, Adhz60, and AdUV, respectively (Figure 10B). These data indicated that AdUV displayed enhanced lysis of both A549 and Soas-2 cells. The enhanced oncolytic effects of AdUV in Soas-2 cells, the cell line used to select AdUV, relative to the parental strain Ad5. 


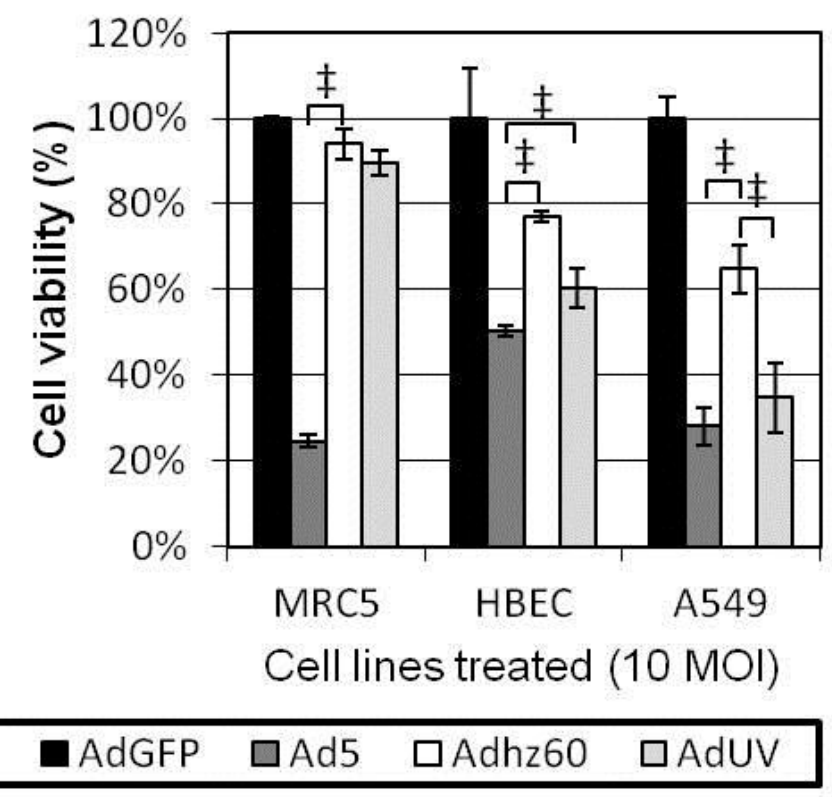

Reprinted with permission: Wechman et al., Viruses, 2016

Figure 9. AdUV displays similar cancer selectivity to Adhz60 in A549 lung cancer cells relative to HBEC and MRC5 non-cancerous lung cells in vitro. A549 lung adenocarcinoma, MCR5 non-cancerous lung fibroblast and HBEC non-cancerous lung epithelial cells were infected with the indicated Ads at a multiplicity of infection (MOI) of 10 for 3 days. They were then fixed with formaldehyde and stained using crystal violet. These results were then quantified and expressed as the percentage cell viability. Data were then analyzed using two-way ANOVA with multiple comparisons corrected for by Bonferroni's method. $\ddagger$, indicates $p$-value < 0.001 . 

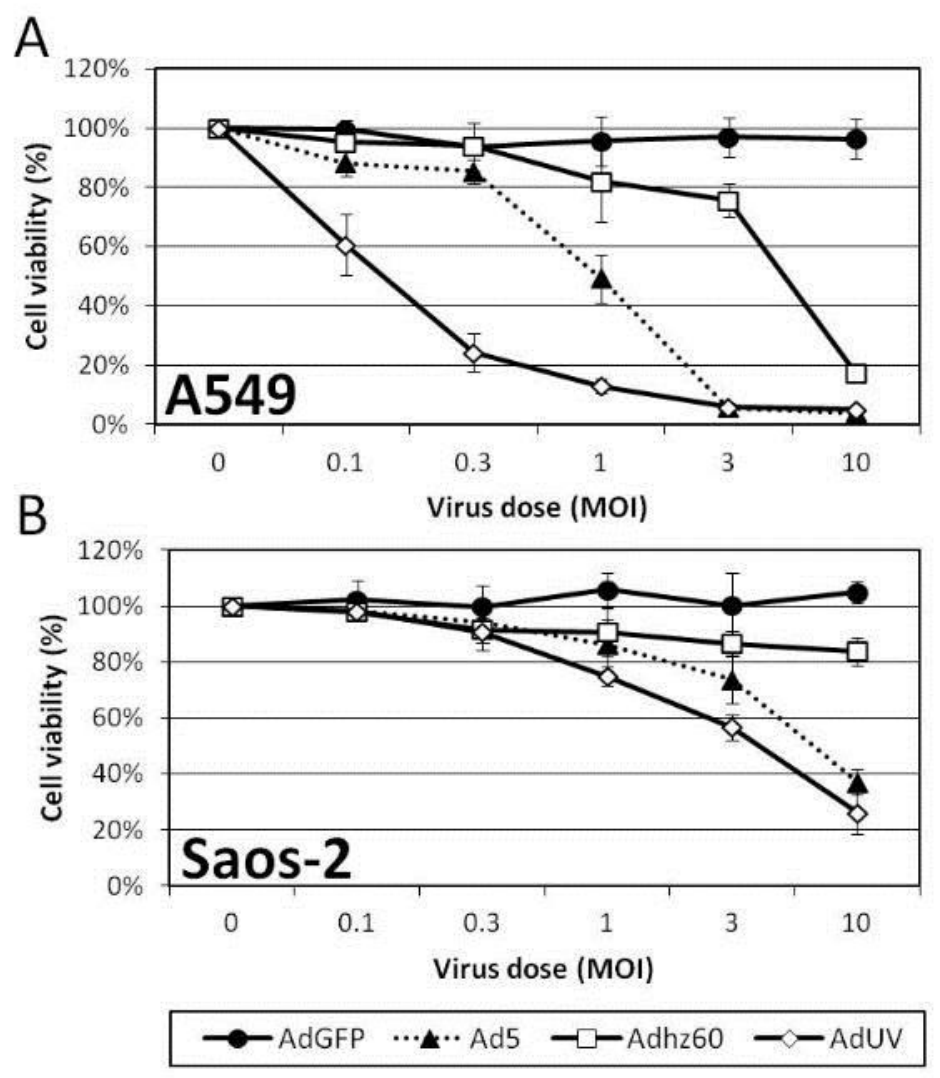

Reprinted with permission: Wechman et al., Viruses, 2016

Figure 10. AdUV displays greater oncolysis than Ad5 and Adhz60 in A549 and Saos-2 cancer cells. (A) A549 and (B) Saos-2 cells were infected with the indicated viruses and MOls for 5 days prior to crystal violet staining. The ODs of these treated cells were normalized relative to non-treated cells. 
To study AdUV release from cancer cells, A549 and Saos-2 cancer cells were infected with AdUV, Ad5, or Adhz60 at an MOI of 1. Six h after infection, these cells were washed with fresh culture media prior to collecting $25 \mu \mathrm{L}$ of the cell culture media every $24 \mathrm{~h}$ for 5 days. These samples were then titered on HEK293 cells using the TCID50 approach. The titer of each Ad was shown to increase with time in both A549 and Saos-2 cancer cell lines (Figure 11A,B). AdUV displayed higher viral titers than Ad5 and Adhz60 at each time point in A549 and Saos-2 cells. At $72 \mathrm{~h}$, Ad media titers were $5.9 \times 10^{8}, 8.73 \times 10^{7}, 2.18$ $\times 10^{7}$ for AdUV, Ad5, and Adhz60 treatments respectively (Figure 11A). At $72 \mathrm{~h}$, the titer of AdUV in the cell culture media was 10 fold greater than Ad5 and 30 fold greater than Adhz60. AdUV also displayed higher titers in Saos-2 cells than Ad5 and Adhz60. At $72 \mathrm{~h}$, AdUV titer was $2.28 \times 10^{6}$, while titers of Ad5 and Adhz60 titers were $5.60 \times 10^{5}$ and $2.19 \times 10^{5}$, respectively (Figure 11B). These data indicate that AdUV is released from both A549 and Soas-2 cancer cells much more rapidly than Ad5 and Adhz60. 


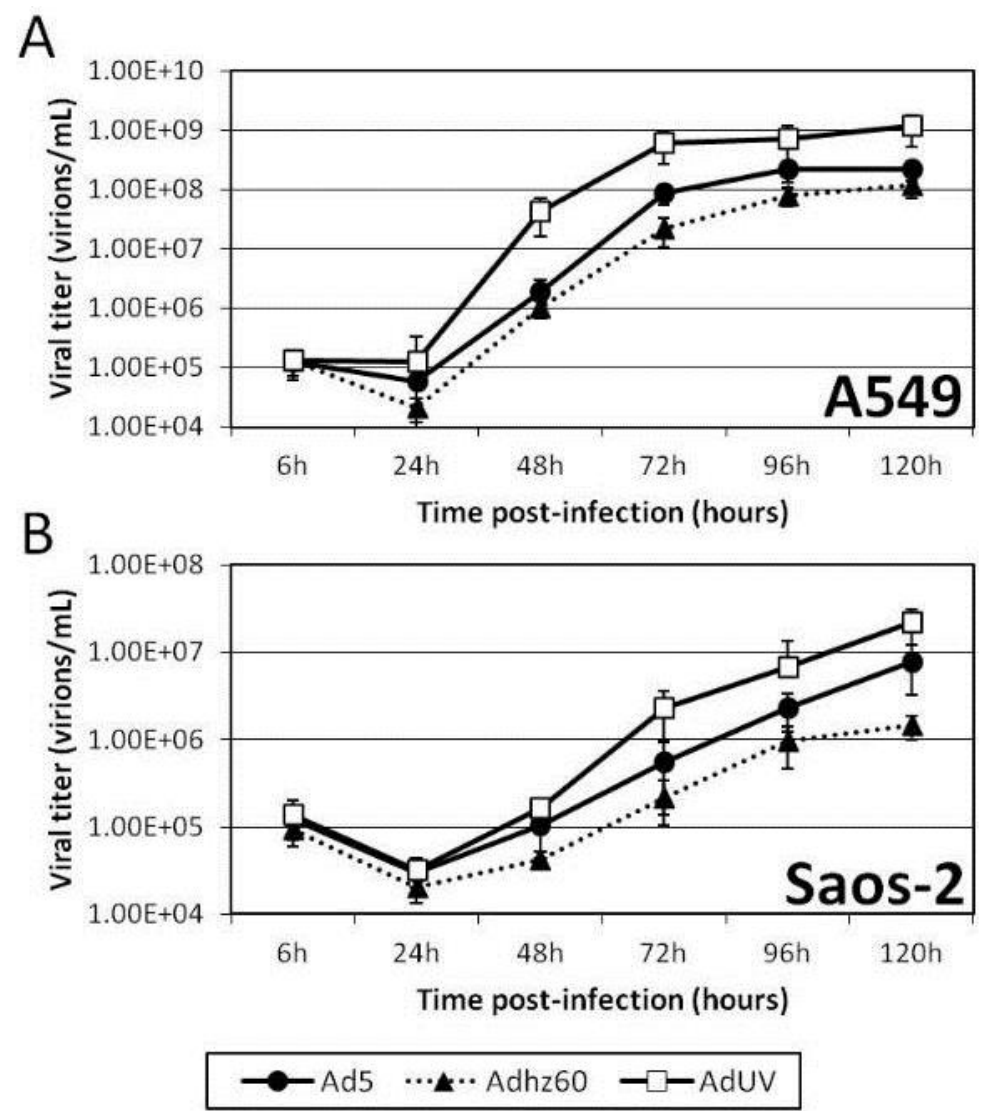

Reprinted with permission: Wechman et al., Viruses, 2016

Figure 11. AdUV displays greater release than Ad5 and Adhz60 in A549 and Saos-2 cancer cells. (A) A549 and (B) Saos-2 cells were infected with the indicated Ads at an $\mathrm{MOI}$ of 1 . Day 0 media samples were collected $6 \mathrm{~h}$ post-infection; after these samples were collected, cells were then washed with cell culture media to remove noninternalized Ad particles. Media samples were then collected every $24 \mathrm{~h}$ for 5 days. These samples were then titered on HEK293 cells using the median tissue culture infective dose (TCID50) method. 


\section{AdUV Inhibits Tumor Growth in Nude Mice}

The efficacy and safety of AdUV was further tested in vivo using an A549 subcutaneous athymic nude mouse (NCr-nu/nu) xenograft model. Once tumors grew to $30 \mathrm{~mm}^{3}$, mice were randomized and treated via intratumoral (IT) injection with $5 \times 10^{8}$ plaque forming units (PFU) of AdUV or the negative control AdGFP every 3 days for a total of 4 treatments (Figure 12A). The length and width of each tumor were measured using a caliper every 3 days. Mice treated with AdUV exhibited significantly suppressed tumor growth. AdUV with $94 \%$ reduction in mean tumor volume compared with mice treated with the control AdGFP vector at day 51 ( $p$-value $<0.001$, Figure 12A). Furthermore, all AdUV treated mice $(n=$ 7) survived until day $125(p$-value $=0.0005)$ while only 2 AdGFP treated mice $(n$ $=8$ ) survived to that time point (Figure 12B). Representative photographs were taken of mice treated with AdGFP or AdUV at day 51 to display the marked qualitative differences between the 2 treatment groups (Figure 12C). Furthermore, weight loss or lethargy was not observed following AdUV treatment. In addition, AdUV was shown to express the viral late protein, hexon, in A549 xenograft tumor sections 7 days after the final viral injection, which was not detected in tumors treated with AdGFP (Figure 12D). These results indicate that AdUV can be safely used in animals to suppress tumor growth. 

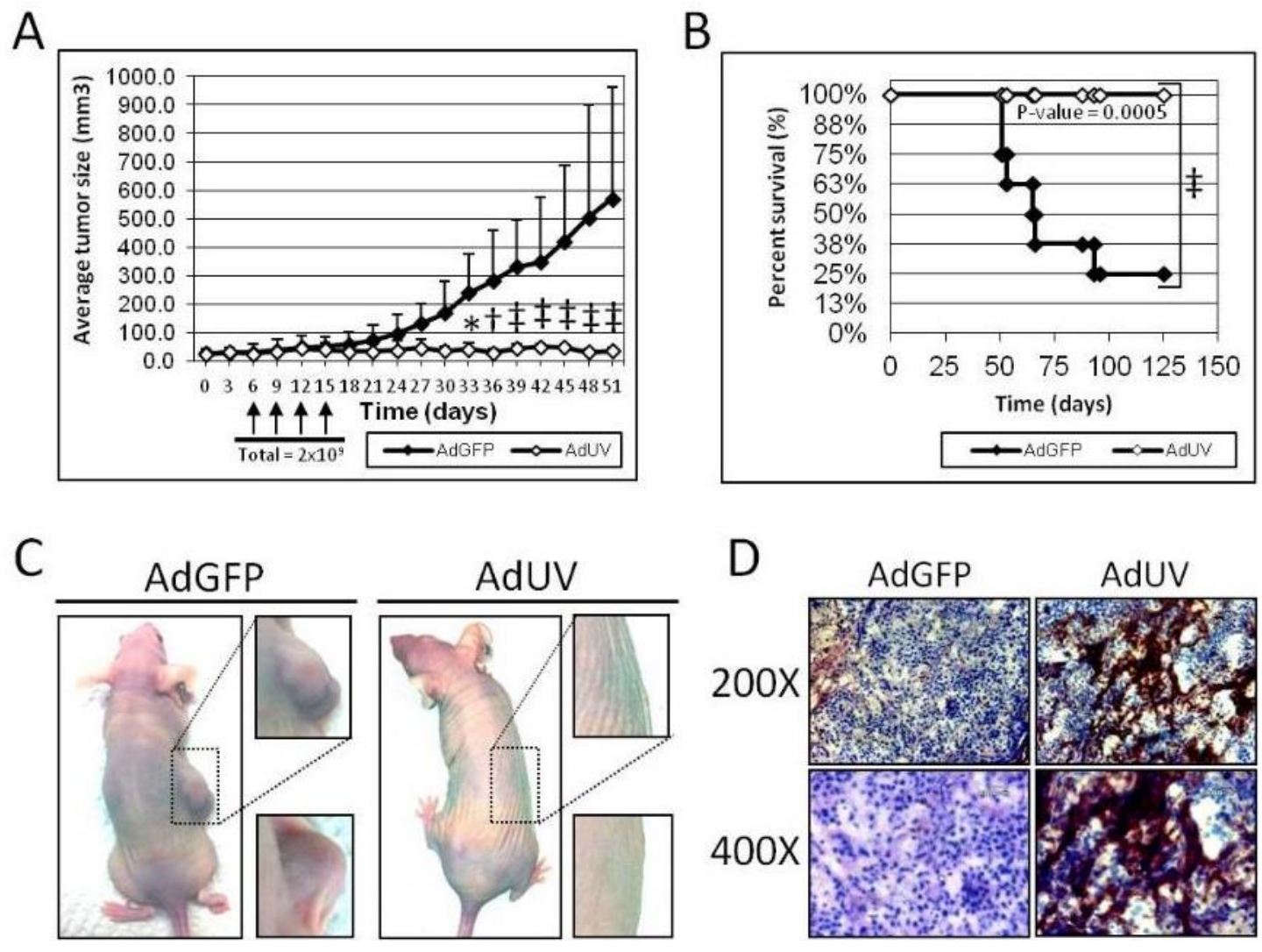

Reprinted with permission: Wechman et al., Viruses, 2016

Figure 12. The effect of AdUV upon A549 xenograft tumor growth and nude mice survival. Xenograft tumors were formed following the subcutaneous (SC) injection of $5 \times 10^{6}$ A549 cells into the right flank of athymic nude mice (NCr-nu/nu). (A) Tumors were then intratumorally (IT) injected with AdGFP or AdUV 4 times from day 6 until day 15 for a total dose of $2 \times 10^{9} \mathrm{PFU}$; (B) Mice were sacrificed once tumors were greater than $1000 \mathrm{~mm}^{3}$ in size. Data were expressed as the percent (\%) of death among each treatment groups across time; (C) Representative mice treated with AdGFP and AdUV were photographed at day 51. Boxes indicate the magnified $(\sim 3.2 \times$ total magnifications) right flanks of 2 
representative mice per treatment group; (D) Immunohistochemistry for hexon expression in A549 tumors harvested 7 days after the final injection. Slides were photographed at $200 \times$ and $400 \times$ total magnifications respectively. Differences in tumor growth were assessed by two-way ANOVA. Adjusted $p$-values were reported for multiple comparisons via Bonferroni's method at each time-point. Differences in murine survival were determined using the Kaplan-Meier log-rank sum test. * indicates $p$-value $<0.05, \dagger$ indicates $p$-value $<0.01, \ddagger$ indicates $p$ value $<0.001$ 


\section{4 - Discussion}

The goal of this study was to investigate which Ad genes may affect Ad oncolytic efficacy, and therefore, may be modified and combined with other approaches for the development of future oncolytic Ads. The Ad early genes in AdUV, E1a and E1b, E2, and E4, remained unchanged however, some critical Ad late genes were mutated and are worthy of additional study. These AdUV mutations likely enhanced Ad-mediated cancer cell lysis and cancer selectivity. Twelve of these mutations in the AdUV genome of interest were shown to alter the encoded amino acids, 5 of these mutations occurred within Ad capsid structural genes ( $p / I I$, Hexon, $p V I I I)$. Another 5 mutations occurred within genes encoding DNA binding or DNA packaging proteins (IVa2, pTP, 52K, $p \mathrm{~V}, 33 \mathrm{~K}$ ). Two mutations, E3A $10.5 k D$ and $E 3 C r 1-\alpha 0$, were not discussed in detail, which may have affected the receptor internalization and degradation (RID) pathways and immune cell-cell interactions, respectively.

The absence of mutations in the Ad early genes, E1 and E4, was surprising as these genes have important roles in an array of virus-host interactions. By far, the development of cancer selective Ads has focused upon the modification of the Ad early genes by the introduction of deletions to $E 1 b-19 \mathrm{~K}$ and $E 1 b-55 \mathrm{~K}$ or the regulation of E1a expression using cancer-selective promoters $[34,135]$. However, these data indicate that the late gene-encoded structural proteins may also influence Ad replication, release, and oncolysis [136]. This hypothesis agreed with a previous report showing that a mutation to 
Ad5 at 8350 was associated with large plaque formation in cancer cells due to the truncation of 21 amino acids in a gene called i-leader [60].

In this chapter, mutations in 6 different Ad proteins with known roles to package viral DNA during virion maturation are described. These Ad capsid proteins include IVa2, pTP, 33K, pV, 52K and pVIII. In particular, pV, IVa2, pVI and pVIII interact with and anchor Ad DNA onto the capsid [137]. The mutations in pVIII, pV and IVa2 are all on the interior of the Ad capsid and have been shown to cooperate to facilitate the packaging of DNA into the Ad capsid to produce mature virions. The mutations occurring within $\mathrm{pV}$, and its interaction partners IVa2 and $\mathrm{pVIII}$, indicate the importance of these proteins for DNA packaging which could support the rapid release of Ads.

AdUV was shown to rapidly transition from early to late phase gene expression as indicated in figure $4 \mathrm{~A}$ [82]. IVa2 and $33 \mathrm{~K}$ form a complex to stimulate the transcription of the major late Ad promoter $[110,125]$. It is possible these IVa2 and 33K mutations found in AdUV may have increased the formation of this complex to induce early to late phase transition during Ad replication. Furthermore, there exists indirect evidence that IVa2 and $33 \mathrm{~K}$ can also form a complex with DNA-binding protein (DBP) on one of the Ad capsid vertexes, facilitating Ad DNA packaging [110]. These mutations acting together may be associated with rapid AdUV virus assembly and release.

These results also indicate that AdUV can be safely used in animals and suppress tumor growth. AdUV is an E1b wild-type Ad. In early oncolytic studies in the 1950s, wild-type Ads were the first viruses used in clinical trials [138]. 
However, wild-type Ads are no longer used in clinical studies because of safety concerns and their limited cancer therapeutic efficacy. For this reason, AdUV, which is based on wild-type Ad5, is unlikely used in future clinical studies. Therefore, the goal of this limited animal study to investigate whether these novel AdUV mutations were toxic to animals. To study these mutations further, each mutation should be individually introduced into a well-characterized Ad vector background to understand their impact upon Ad replication and oncolytic therapy.

The expression of E1b by AdUV also likely enhanced its oncolytic potential. Several E1b wild-type oncolytic vectors have been described in the literature with increased cancer therapeutic efficacy containing other modes of cancer selectivity such as cancer selective promoters, or partial E1a deletions [81, 139]. Even though E1b expression is not essential for Ad replication in cancer cells [31], E1b may enhance the efficiency of Ad replication in cancer cells, likely via cyclin E induction [31]. Recently published data, shown in chapter II, indicates that E1b upregulates autophagy; however, the mechanism of autophagy induction by $E 1 b$ remains unknown [82]. Autophagy is known to degrade intracellular components, organelles and long-lived proteins [140-142]. It appears that E1b may drive Ad-mediated autophagy induction to promote virus replication by generating nutrient to build virus particles $[55,66]$. Therefore, the oncolytic effects and replication of AdUV was likely enhanced by E1b.

These findings taken together provide additional insight into the construction of oncolytic Ads. It appears that $E 1 b$ expression and mutations in the Ad late proteins, especially those associated with genome packaging, may 
augment Ad release and spread within tumor tissue, leading to enhanced oncolytic therapy efficacy. One of the limitations of this study is that the specific effects of these mutations upon oncolytic replication are unknown at this time. It is also possible that several of these mutations may cooperate to enhance oncolytic Ad efficacy. 


\section{CHAPTER IV}

\section{THE ROLE OF JNK PHOSPHORYLATION AS A MOLECULAR TARGET TO ENHANCE ADENOVIRUS REPLICATION, ONCOLYSIS AND CANCER THERAPEUTIC EFFICACY}

\section{1 - Introduction}

Oncolytic Ads represent an emerging class of lung cancer therapeutics with clear cancer selectivity in vitro $[33,55,90]$. E1b-deleted Ads selectively lyse cancer cells very efficiently in vitro; however, these viruses were ineffective during clinical trials $[19,53,143,144]$.

To overcome the limitations of Ad therapy, a more complete understanding of Ad-mediated cancer cell lysis or oncolysis is necessary. Among the programmed cell death pathways (apoptosis, necrosis, and autophagy), autophagy inducers have been reported to support Ad replication and oncolysis $[66,77]$. Therefore, autophagy is of significant interest as a potential driver of $\mathrm{Ad}$ oncolysis. Many viruses interact with autophagy signaling during infection, however autophagy can inhibit or promote virus replication. For example, autophagy inhibits HIV-1 [145], HSV [146] and influenza A infection [147]. However, Ads induce autophagy to promote their own replication and to lyse cancer cells [66], indicating that Ads induce autophagy to produce their antitumoral effects [77]. Furthermore, the autophagy inhibitors 3MA and Baf-A1 inhibited Ad replication and protect cancer cells from Ad oncolysis [66, 78]. Previously, E1b-deleted Ads were shown to induce less efficient production of 
the autophagy markers LC3-II and p62 [34, 66]. Therefore, E1b may play a role as an autophagy inducer.

The field of oncolytic adenovirology has not emphasized the investigation of autophagy and its induction by E1b. Therefore, the effect of various autophagy signaling pathways upon the replication or oncolytic effects of E1b-deleted Ads is unknown. Autophagy induction occurs predominantly via 2 mechanisms: 1) glucose starvation 2) phosphoinositide 3-kinase (PI3K) and MAP Kinase (MAPK) signal transduction. Autophagy induced via glucose starvation is driven by the energy-sensor AMP-activated protein kinase (AMPK) which promotes autophagy-mediated cellular catabolism [148, 149]. AMPK phosphorylates Ulk1 at serine 317 and 777 , activating Ulk1 leading to autophagy induction [148]. mTOR disrupted AMPK coordinated Ulk1 phosphorylation and phosphorylates Ulk1 at serine 757 to inhibit autophagy [74]. Furthermore, rapamycin treatment (an mTOR inhibitor) enhanced E1bdeleted Ad replication and oncolysis. Studies have indicated that mTOR activation is dependent upon the E4-ORF4 protein phosphatase 2A-binding domain and that mTOR supports the S-phase entry of G0-phase primary cells [150]. In this way, E4-ORF4 is thought to enhance Ad replication.

Interestingly, Ads do not appear to induce autophagy via the cell starvation AMPK pathway. Preliminary studies indicated that E1b wild-type Ads induce autophagy via c-JUN n-terminal kinase (JNK) phosphorylation, which occurs independently of the AMPK/mTOR-induced cell starvation autophagy induction pathway $[77,81,151]$. JNK induces autophagy via the phosphorylation 
of BCL-2, activating BECLIN-1 [36, 81, 152]. JNK and the map kinase (MAPK) pathway may play a crucial role to upregulate ATG5 expression [153]. The first report, to my knowledge, to demonstrate that Ads induced JNK phosphorylation via E1b was published by See and Shi in 1998; however, this report did not indicate if Ad induced p-JNK to enhance Ad replication or oncolysis [80]. Klein et al. reported that JNK expression was essential for the E1b wild-type Ad, $\triangle 24 R G D$, to induce autophagy in vitro and in vivo [81]. The goal of this chapter was to characterize the induction of $p$-JNK by $E 1 b$-deleted Ads and the role of $p$ JNK to stimulate Ad replication and cancer cell oncolysis.

Ads have been shown to manipulate both apoptosis and autophagy via the expression of E1a, E1b-19K, and E1b-55K to lyse cancer cells in a highlycoordinated manner. E1A is known to stabilize TP53 inducing apoptosis [96], while E1b-19K and E1b-55K counter act these effects by antagonizing BAK/BAX and TP53 respectively. Simultaneously, E1b-19K and E1b-55K also stimulate MKK7-mediated JNK phosphorylation to induce autophagy [80, 154]. Therefore, E1b expression appears to drive Ad oncolysis towards an autophagy-mediated mechanism; however, the effects of E1a upon JNK phosphorylation remains unknown. Interestingly, E1b-deletions are not sufficient to completely abolish JNK phosphorylation by oncolytic Ads, implicating the role of E1a as an inducer of both apoptosis and JNK phosphorylation.

In this chapter, the ability of oncolytic Ads to induce JNK phosphorylation via E1a or E1b was assessed using Ads which selectively over express E1a and Ads with selective E1b-deletions in lung cancer cells. These data indicated that 
both $E 1 b$ and $E 1 a$ were crucial for efficient JNK phosphorylation in A549 lung cancer cells. To determine in p-JNK inducers enhanced Ad replication and oncolysis, known chemical p-JNK inducers were screened to determine which drug was the most effect p-JNK inducer in A549 cells; this drug (etoposide) was then used in combination with the previously developed oncolytic Ad AdUV [82, 136]. These data indicated that etoposide enhanced AdUV oncolysis; however, etoposide was not shown to enhance AdUV replication using these conditions. It is expected that etoposide induced p-JNK production via a non-specific mechanism of action. Therefore, the selective effects of JNK activation upon oncolytic Ad replication and oncolysis was assessed using siRNA, targeting both JNK1 and JNK2 mRNAs sequences $[155,156]$. The suppression of JNK1/2 was shown to protect cancer cells from Ad-mediated A549 cell lysis. Ad replication was also significantly repressed in JNK1/2 siRNA-transfected cells infected by the E1b-19K wild-type Ads Ad5 and Adhz63, but not the E1b19K-deleted Ad Adhz60. These studies have demonstrated for the first time that $p-J N K$ is not only essential for Ad oncolysis, but also for Ad replication. These data suggest that JNK is an intriguing molecular target to enhance the therapeutic effects of oncolytic Ad therapy. 


\section{2 - Materials and Methods}

\section{Cell Lines and Culture Conditions}

HEK293 (ATCC no. CRL-1573) human embryonic kidney and A549 (ATCC no. CCL-185) human lung carcinoma cells were purchased from the ATCC (ATCC, Rockville, MD, USA). A549 and HEK293 cells were maintained in DMEM supplemented with $10 \%$ fetal bovine serum, L-glutamine, and penicillin/streptomycin $(100 \mathrm{U} / \mathrm{mL})$. All other cell culture reagents were obtained from VWR (VWR, Radnor, PA, USA). All cells were cultured and maintained in humidified $5 \% \mathrm{CO}_{2}$ incubators at $37^{\circ} \mathrm{C}$. 


\section{Adenoviral Vectors}

Ad5 d/309 is E1 wild-type E1 [95] and was used as a non-selective Ad control in these studies. Adhz63 is an E1b55K-deleted Ad similar to d/1520 and $\mathrm{H} 101$ and was used as a cancer selective control [96]. Adhz69 is an E1b55Kdeleted Ad that over-expresses E1A via the CMV promoter [157]. Adhz60 is an E1b55K, 19K-deleted vector used as a cancer selective control and E1b19Kdeleted Ad control for these studies [96]. AdUV is an E1b wild-type mutant oncolytic Ad based upon Ad5 as described previously [82, 136]. AdGFP is E1 (E1a and E1b) deleted, with green fluorescent protein (GFP) expression driven by the CMV promoter [55]. AdGFP, as a negative control, does not replicate nor induce CPE $[34,35]$. All Ads used in this study are based upon Ad5 backbone sequences (GENEID\# AC_000008.1). 


\section{Plasmid amplification and transfection}

To chemically transform a plasmid into chemically competent bacteria, the bacteria were mixed with between $200 \mathrm{ng}$ and $1 \mu \mathrm{gs}$ of plasmid DNA on ice for 30 min. The mixture was then transferred into a $42{ }^{\circ} \mathrm{C}$ water bath for $30 \mathrm{~s}$. After the heat shock, the bacteria/plasmid mixture was returned to the ice for $2 \mathrm{~min}$. $250 \mu \mathrm{L}$ of SOC media (Corning Cellgro, Tewksbury, MA) was then added to the mixture and placed at $37^{\circ} \mathrm{C}$ for $1 \mathrm{~h}$. This mixture was plated on LB agar plates containing $100 \mu \mathrm{g} / \mathrm{mL}$ of ampicillin. The plates were incubated at $37^{\circ} \mathrm{C}$ overnight. Colonies were selected the next day and grown in LB broth media, again supplemented with the proper antibiotic at the correct final concentrations listed above, and once again incubated overnight at $37^{\circ} \mathrm{C}$ in a shaker set at 300 RPM. After the colonies were expanded and grown in LB media, these cultures were then processed to isolate DNA plasmids using Qiagen Mini, or Maxi-scale kits (Qiagen, Hilden, Germany). Mini-scale cultures utilized 3-5 mL of $100 \mu \mathrm{g} / \mathrm{mL}$ ampicillin containing Luria-Bertani (LB) broth, while Maxi-scale cultures utilized 250-500 mL of $100 \mu \mathrm{g} / \mathrm{mL}$ ampicillin LB broth. The entire culture was then pelleted using an AvantiJ-26XPI centrifuge (Beckman Coulter, Brea, CA, USA) spun at $8000 \mathrm{xg}$ for 3 (Mini-scale) to 15 (Maxi-scale) min respectively. Following centrifugation, the media were decanted and the entire pellet was resuspended in RNAseA containing P1 buffer provided by the kit. The plasmid extraction and purification steps from this point forward were carried out in accordance with the manufacturer's protocol (Qiagen, Hilden, Germany). 
Two plasmids were used during the completion of these studies. The CMV-E1b19K plasmid was a generous gift from Dr. Eileen White at Rutgers University [158]. The pCycE-GFP plasmid was constructed by Dr. Heshan Zhou at the University and Louisville and was used as a negative control; pCycE-GFP was also used to determine plasmid transfection efficiency [31]. $2 \times 10^{5} \mathrm{~A} 549$ cells were seeded onto 6-well plates overnight for transfection. Cells were 60$70 \%$ confluent the next day; however, small gaps were present between those cells, ensuring maximal transfection efficiency. These cells were then transfected with $2 \mu \mathrm{g}$ of plasmid DNA using Jetprime according to the manufacturer's protocol for DNA transfection. The media of these transfected cells were changed after $4 \mathrm{~h}$. Using these conditions, a transfection efficiency of at least $85 \%$ was observed. 


\section{Drug preparation}

Etoposide, cytrabine, cycloheximide, and paclitaxel were all purchased from sigma (Sigma-Aldrich, St. Louis, MO, USA) and diluted into 100\% DMSO at a stock concentration of $10 \mathrm{mM}$. These stock solutions were then diluted in serum-containing media to $1 \mathrm{mM}$ for use at the indicated micromolar $(\mu \mathrm{M})$ concentrations indicated. Drug treatments were applied to the cells in culture briefly following cell seeding, but prior to Ad infection for the combination studies. 


\section{SiRNA transfection}

To ascertain the role of JNK expression upon Ad replication and oncolysis, siRNA transfection was utilized. Both JNK1 and JNK2 are phosphorylated by Ad5, therefore the suppression of both JNK1 and JNK2 was necessary [81]. The JNK1/2-siRNA utilized in this study: JNK1/2 5'- AAAGAAUGUCCUACCUUCU-3' was initially described by Dr. Li in 2004 and targets JNK1 and JNK2 at the mRNA positions 377 and 425 respectively [155]. JNK1/2-siRNA was ordered by email using the sequence from Dr. Li and its duplex complement from Thermo Fisher Scientific (Thermo Fisher Scientific, Waltham, MA, USA). The optimal siRNA concentration to suppress JNK1 and JNK2 was assessed by transfecting A549 cells with 10 to $400 \mathrm{nM}$ of JNK1/2-siRNA. These transfected cells were then lysed and studied by Western blot analysis to determine whether efficient JNK1

and JNK2 protein production was suppressed. $120 \mu \mathrm{g}$ of these protein isolates were electrophoresed on 10\% SDS-PAGE gels and JNK1 and JNK2 production was probed using JNK1 (1:100) and JNK2 (1:200) selective antibodies from Santa Cruz (Santa Cruz, Dallas, TX, USA). 


\section{Virus Titration and Release}

A549 cells were seeded onto 12-well plates at a density of $4 \times 10^{4}$ cells per well and allowed to adhere overnight. Cells were then treated as indicated and harvested with a cell scraper. These samples were then subjected to 3 freeze-thaw cycles to release all the Ads into solution for the determination of total Ad titer by the median tissue culture infective dose (TCID50) method as described in Chapter II. 


\section{Western Blot Analysis}

A549 cells were seeded onto $60 \mathrm{~mm}$ dishes overnight at a density of $3 \times$ $10^{5}$ cells per dish. Cells were collected and centrifuged at 1500 RPM (453 RCF) at $4{ }^{\circ} \mathrm{C}$ for 5 min using an Eppendorf 15 amp 5810R refrigerated centrifuge equipped with a A-4-62 rotor (Eppendorf, Hamburg, Germany). The cell pellets were then washed with PBS prior to lysis with RIPA buffer containing $50 \mathrm{mM}$ Tris- $\mathrm{HCl}, 150 \mathrm{mM} \mathrm{NaCl}, 1 \% \mathrm{NP}-40,0.5 \%$ sodium deoxycholate, and $0.1 \%$ SDS with PI containing 4-(2-aminoethyl)-benzenesulfonyl fluoride (AEBSF), pepstatin A, trans-epoxysuccinyl-L-leucylamido-(4-guanidino)butane (E-64), bestatin, leupeptin, and aprotinin (10 mL / $1 \times 10^{6}$ cells; Sigma, St. Louis, MO, USA). The cell lysates were then incubated on ice in PI containing RIPA buffer for $30 \mathrm{~min}$ and homogenized every 10 min using a vortex-genie 2 (Scientific Industries, Bohemia, NY, USA). These lysates were then centrifuged at 14,500 RPM $(196,000 \mathrm{RCF})$ at $4{ }^{\circ} \mathrm{C}$ for 10 min using a micromax RF microcentrifuge equipped with an IEC 851 rotor to pellet cell debris formed during lysate preparation (Thermo Fisher Scientific, Waltham, MA, USA). The pellet was discarded and the supernatant was stored at $-80{ }^{\circ} \mathrm{C}$ for further experimentation. Protein concentrations were determined using the Pierce BCA protein assay kit according to the manufacturer's instructions (Thermo Fisher Scientific, Waltham, MA, USA). Equal amounts of cellular protein were resolved by electrophoresis through $8 \%(E 1 A), 10 \%$ (JNK, p-JNK, JNK1, JNK2, E1b-19K, actin) or 12\% (LC3-I and LC3-II) SDS-polyacrylamide gels prior to transfer to methanol activated PVDF membranes (GE healthcare, Little Chalfont, UK) using a semi- 
dry transfer apparatus (BIO-RAD, Hercules, CA, USA). Membranes were then blocked using 5\% nonfat milk prepared in TBST for $1 \mathrm{~h}$ at room temperature. To detect protein expression, membranes were incubated with the following primary antibodies: rabbit-anti-human-LC3 (1:3000; Novus Biologicals, Littleton, CO, USA), rabbit-anti-human-actin (1:2000; Sigma, St. Louis, MO, USA), rabbit-antihuman p-JNK (1:1000; Cell Signaling, Danvers, MA, USA), rabbit-anti-humanJNK (1:1000; Cell signaling, Danvers, MA, USA), mouse-anti-human-JNK1 (1:100; Santa Cruz, Dallas, TX, USA), mouse-anti-human JNK2 (1:200; Santa Cruz, Dallas, TX), mouse-anti-Adenovirus2-E1b19K (1:150; Calbiochem, San Diego, CA, USA) or mouse-anti-adenovirus-E1A (1:1000; BD Pharmagen, San Jose, CA, USA) at $4{ }^{\circ} \mathrm{C}$ overnight on a lab-line thermal rocker (Thermo Fisher Scientific, Waltham, MA, USA). The mouse-anti-Adenovirus2-E1b19K antibody is cross-reactive with Ad serotype 5 (Ad5). Primary antibody binding was detected by the incubation with the horseradish peroxidase (HRP) linked anti-mouse or anti-rabbit immunoglobulin (lg) diluted 1:5000 for $1 \mathrm{~h}$ at room temperature (Amersham, Piscataway, NJ, USA). All antibodies were diluted in TBST. Enhanced chemiluminescence $(E C L)$ reagents were used to detect HRP-linked secondary antibody binding according to the manufacturer's instructions (Amersham, Piscataway, NJ, USA). 


\section{Cytotoxicity Assay}

A549 cells were seeded at a density of $2 \times 10^{4}$ cells per well onto 24 -well plates and allowed to adhere overnight. Cytotoxicity was assessed by crystal violet staining at the time-points indicated [97]. Suspended cells were aspirated, and the adherent cells were then fixed via incubation with $3.7 \%$ formaldehyde for 25 min at room temperature (RT). Excess formaldehyde was washed away using PBS. Cells were then stained using $1 \%$ crystal violet for 30 min at RT. Excess crystal violet was washed away with water. These crystal violet stained wells were then scanned using an HP Scanjet 4070 scanner (HP, Palo Alto, CA, USA). The remaining crystal violet was then solubilized with a $2 \%$ SDS solution, and the sample ODs were measured at $590 \mathrm{~nm}$ using a Synergy HT Multi-Mode Microplate Reader (Bio-Tek, Winooski, VT, USA). These OD values were then normalized to mock-treated cells, converting each sample OD into the percent (\%) cell viability by the formula, cell viability $\%=(\mathrm{OD}$ of treated cells $/ \mathrm{OD}$ of mocktreated cells) $\times 100$. 


\section{Statistical Analysis}

All experiments were repeated at least 3 times. Quantification of results was reported as means of 3 independent experiments plus or minus ( \pm ) the SD. Statistical significance was set at $p$-value less than 0.05 . Statistical significance was assessed using the two-way ANOVA test for the EC50 combination ratio study (Figure 18A) corrected for multiple comparisons via Bonferroni's test. All other statistical tests were conducted using one-way ANOVA with Tukey's posttest for multiple comparisons. However, the statistical analysis of the p-JNK fold changes induced by Ad5 treatment across time (Figure 13B,C) was conducted using one-way ANOVA with Dunnett's post-test. All statistical tests were conducted using GraphPad Prism 6 software (Microsoft, Redmond, WA, USA). 


\section{$\underline{4.3-\text { Results }}$}

\section{Adenovirus serotype 5 induces p-JNK expression in A549 cells}

To observe the effect of Ad infection upon JNK phosphorylation, A549 lung cancer cells were infected with the wild-type serotype $5 \mathrm{Ad}$ (Ad5) at an $\mathrm{MOI}$ of 10. Infected or non-infected (Mock) cells were then observed for CPE and for the production of $\mathrm{p}$-JNK via Western blot analysis from 18 to $72 \mathrm{~h}$ post-infection. These data indicated that E1b wild-type Ads, such as Ad5, led to a timedependent induction of CPE and p-JNK; induced p-JNK production was began at $18 \mathrm{~h}(4.1$ fold $)$ reaching the greatest p-JNK production at $72 \mathrm{~h}(18.4$ fold $)$ postinfection (Figure 13A-C). The highest levels of $p$-JNK production (48, and $72 \mathrm{~h}$ ) was associated with changes in A549 cell morphology consistent with CPE (Figure 13A,C). To quantify the effects of Ad5 upon CPE and oncolysis, A549 cells were stained with crystal violet at the time-points indicated. These data were expressed as a percentage of Ad5 treated cell viability relative to mock cells at each time-point (Figure 13C). By plotting these fold changes in p-JNK and LC3-II production overtime, the effects of Ad5 upon the induction of p-JNK (18 h) occurred first, prior to the induction of LC3-II (36 h), A549 oncolysis, and CPE induction by $\mathrm{Ad} 5$ at 48 and $72 \mathrm{~h}$ (Figure 13C). These data indicate that the $E 1 \mathrm{~b}$ wild-type Ad Ad5 induced JNK phosphorylation during A549 cell oncolysis. This was especially evident during the late phases of infection at 48 and $72 \mathrm{~h}$ postinfection respectively. 


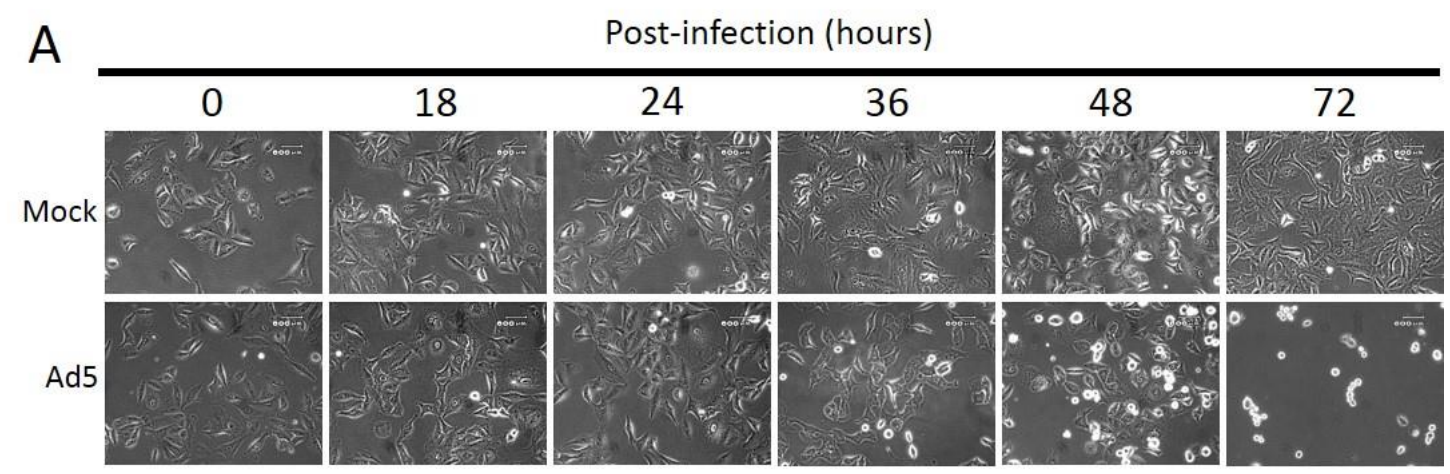

B

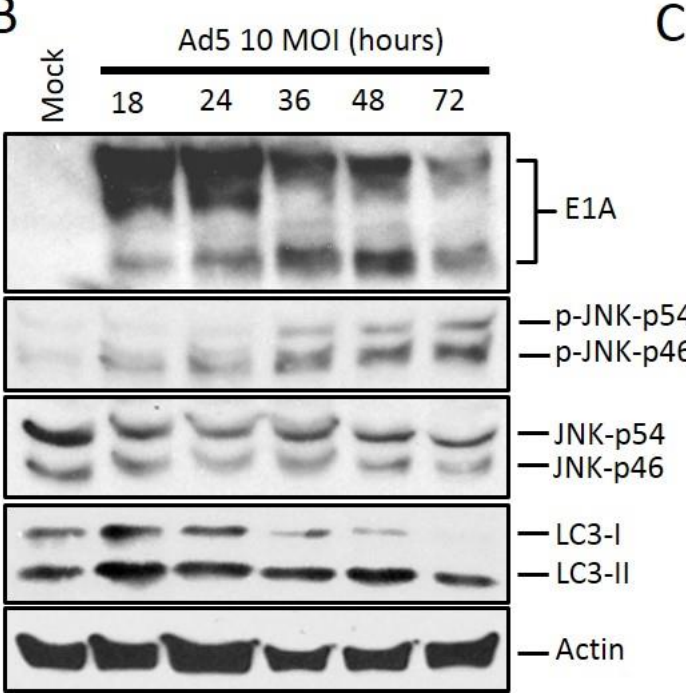

C

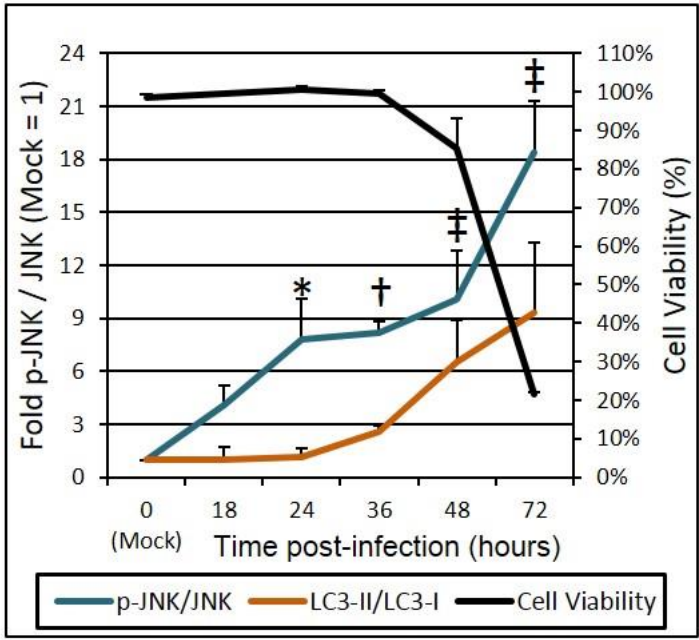

Figure 13. The effect of Ad5 upon JNK phosphorylation. A549 cells were mock treated or infected with Ad5 at an $\mathrm{MOI}$ of 10 and then observed from 0 to $72 \mathrm{~h}$ post-infection. (A) CPE induced by Mock or Ad5 treatment in A549 cells was observed at the indicated time-points. Pictures were taken using an inverted microscope at $200 x$ total magnification. $600 \mu \mathrm{m}$ scale bar is located in the top right corner. (B) A549 cell lysates were treated and harvested at the time-points indicated and observed for protein production via Western blot analysis. (C) Quantification of these Western blot data normalized to actin protein expression. Cell viability was determined by crystal violet staining and plotted on the secondary y-axis. Results are expressed as the average of 3 experiments plus or 
minus the standard deviation. Statistical analysis was performed using one-way ANOVA by Dunnett's test for multiple comparisons relative to the mock control ( 1 fold) column. ${ }^{*}$ indicates $p$-value $<0.05, \dagger$ indicates $p$-value $<0.01, \ddagger$ indicates $p$ value $<0.001$ 


\section{The effects of $E 1 b$ upon p-JNK activation}

To determine whether E1b-deleted Ads induced JNK phosphorylation, we infected A549 cells with the E1b wild-type Ad5, the E1b55K-deleted Adhz63 and the E1b55,19K-deleted Adhz60 at a MOI of 10 and observed for p-JNK production by Western blot analysis. Differences in p-JNK production were first assessed at $36 \mathrm{~h}$ post-infection prior to A549 cells lysis (Figure 14A). However, no differences in $\mathrm{p}$-JNK production were observed between E1b wild-type and E1b-deleted Ad treatments at any of the 3 MOls (1, 3, and 10) tested (Figure 14B,C). Therefore, the effects of Ad5, Adhz63 and Adhz60 upon p-JNK production at 48 and $72 \mathrm{~h}$ post-infection were assessed. These data indicated that p-JNK production by Ad5 (32.2 fold), Adhz63 (28.1 fold) and Adhz60 (10.9 fold) were significantly different at $72 \mathrm{~h}$ post-infection (Figure 15A-C).

Interestingly, Adhz63 was shown to induce similar p-JNK production to Ad5 (28.1 fold vs. 32.2 fold respectively), while Adhz63 induced similar oncolytic effects to Adhz60 at 72 hours (Figure 15C,D). These data indicate that E1b-19K expression, via Adhz63, may be critical for inducing p-JNK production. Therefore, a plasmid that expresses E1b-19K under control of the CMV promoter (CMVE1b19K) was utilized to selectively assess the role of E1b19K as a p-JNK inducer (Figure 15E). These data indicated that E1b-19K expression was sufficient to induce p-JNK production (22.7 fold) in A549 cells alone, demonstrating the potentially critical role of $E 1 b-19 \mathrm{~K}$ to activate JNK signally during Ad infection. 
A

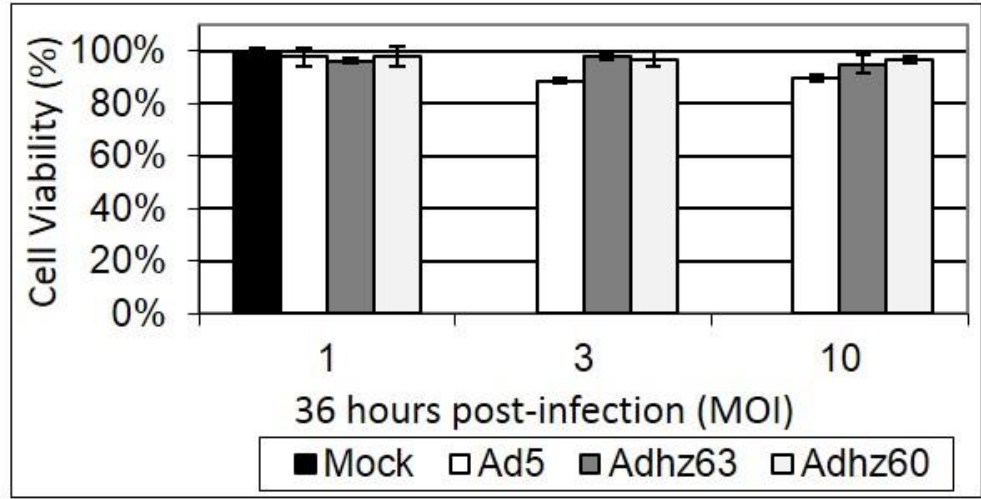

B

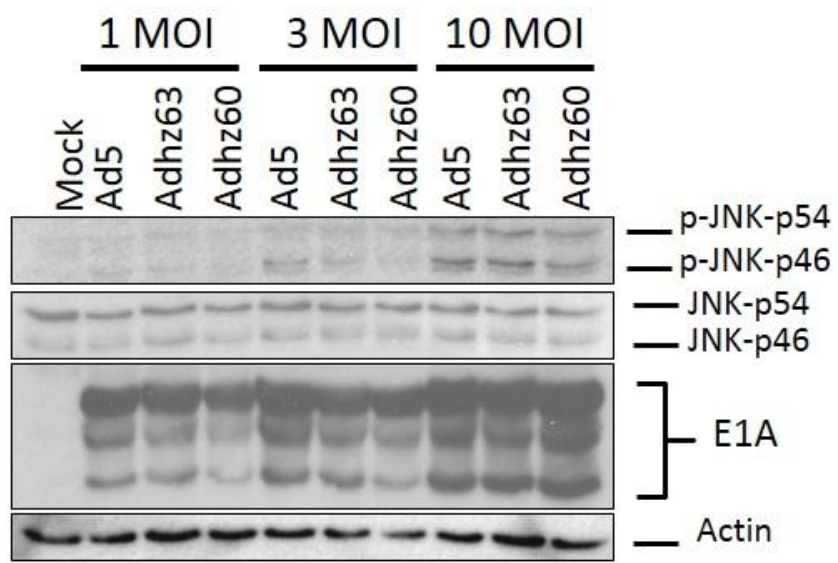

C

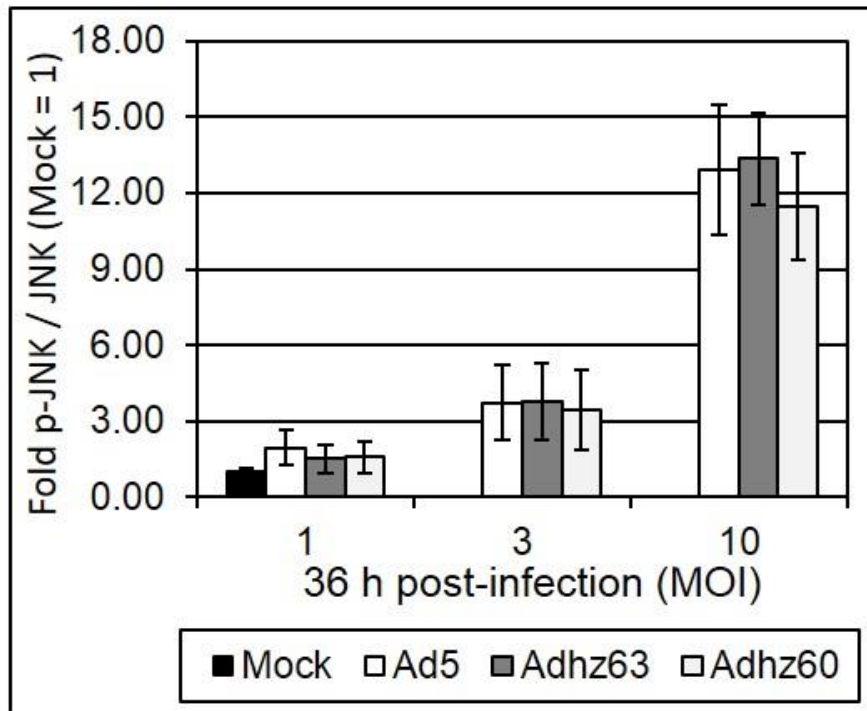


Figure 14. The effect of selective E1b-deleted Ads upon p-JNK at 36 h. A549 cells were mock-treated or infected with Ad5, Adhz63, and Adhz60 at an MOI of 1,3 and 10 respectively. (A) Crystal violet staining of A549 cells treated as indicated at $36 \mathrm{~h}$ post-infection. (B) A549 cell lysates were prepared at $36 \mathrm{~h}$ postinfection and observed for the production of the indicated proteins via Western blot analysis. (C) Quantification of these Western blot data was normalized to actin protein expression. Results were expressed as the average of 3 experiments plus or minus the standard deviation. 


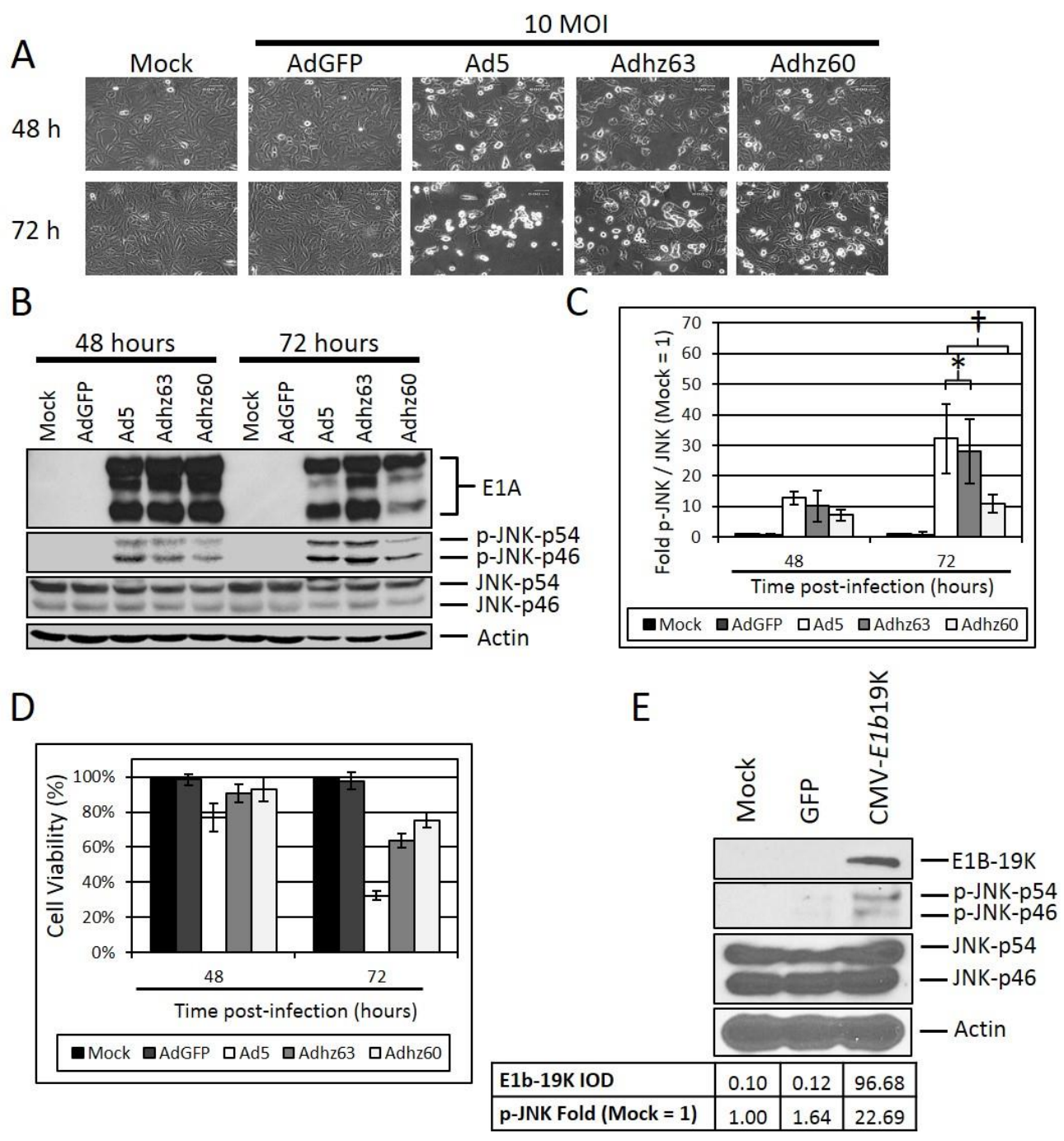

Figure 15. The effect of E1b-19K expression upon JNK phosphorylation. A549 cells were mock treated or infected with AdGFP, Ad5, Adhz63 and Adhz60 at an MOI of 10. (A) CPE induction in mock, AdGFP, Ad5, Adhz63 and Adhz60 treated cells. Pictures were taken using an inverted microscope at 200x total magnification at 48 and $72 \mathrm{~h}$ post-infection. $600 \mu \mathrm{m}$ scale bar is located in the top right corner. (B) A549 cell lysates were observed for the production of the indicated proteins via Western blot analysis. (C) Quantification of these Western 
blot data normalized to actin protein expression. (D) Cell viability was determined by crystal violet staining and expressed as the percent cell viability relative to non-treated cells. (E) A549 cells were mock transfected, or were transfected with GFP or CMV-E1b19K expressing plasmids as indicated. These cells were then lysed and observed for the production of the indicated proteins. IOD is an abbreviation for integrated optical density. IOD's were determined via densitometric analysis using Gel-pro analyzer 4.0 software. * indicates p-value < $0.05, \dagger$ indicates $p$-values $<0.01$ 


\section{The effect of E1a upon p-JNK production}

While extensive research has focused upon the role of $E 1 b$ as an inhibitor of apoptosis, recent reports indicate that E1b is also required for JNK phosphorylation; however, effects of other Ad genes upon JNK phosphorylation is unknown [159]. E1a has been shown to induce JNK phosphorylation in murine 3T3 fibroblasts; however, the effect of E1A upon p-JNK in cancer cells following oncolytic Ad infection remains unknown [159]. In this report, the total E1b-deleted Ad Adhz60 did not display totally ablated p-JNK production (10.9 fold), indicating that other Ad genes may also play a role to induce JNK phosphorylation (Figure 15C). Furthermore, E1b-deleted Ads have been shown to depend upon efficient E1a expression to lyse cancer cells [29], implicating the role of E1A as a potential inducer of p-JNK production during cancer cell oncolysis.

To assess the role of E1A as a p-JNK inducer, A549 cells were treated with Ad wild-type Ad5, the E1b55K-deleted E1a wild-type Adhz63, and the E1b55K-deleted CMV-E1a Adhz69. Therefore, by comparing between the Adhz63 and Adhz69 treatment groups, the effects of increased E1a production upon p-JNK is evident as both of these Ads have identical E1b55K-deleted

backgrounds. These data indicated that selective E1a over-expression by Adhz69 lead to increased E1A and p-JNK production (39.9 fold) relative to Ad5 (12.4 fold) and Adhz63 (3.8 fold) in the absence of E1b-55K expression (Figure 16B).

E1A is a well-known transactivator of many Ad and host cell genes [160]. One of the transcriptional targets of E1A is E1b-19K [40], E1b-19K induces p- 
JNK production in A549 cells as shown in Figure 15E. Therefore, the effects of E1A over-expression upon E1b-19K protein production was observed to determine if Adhz69 induced p-JNK production was due, at least in part, to enhanced E1b-19K expression (Figure 16C). Ad5 and Adhz60 were used as E1b-19K production positive and negative controls respectively for this experiment. These data have shown that markedly enhanced E1A production by Adhz69 is not significantly increase E1b-19K production relative to Adhz63 in A549 cells (31.0 IOD vs. 20.1 IOD; Figure 16C). Therefore, E1a likely drives pJNK production via an E1b19K independent mechanism of action. 
A
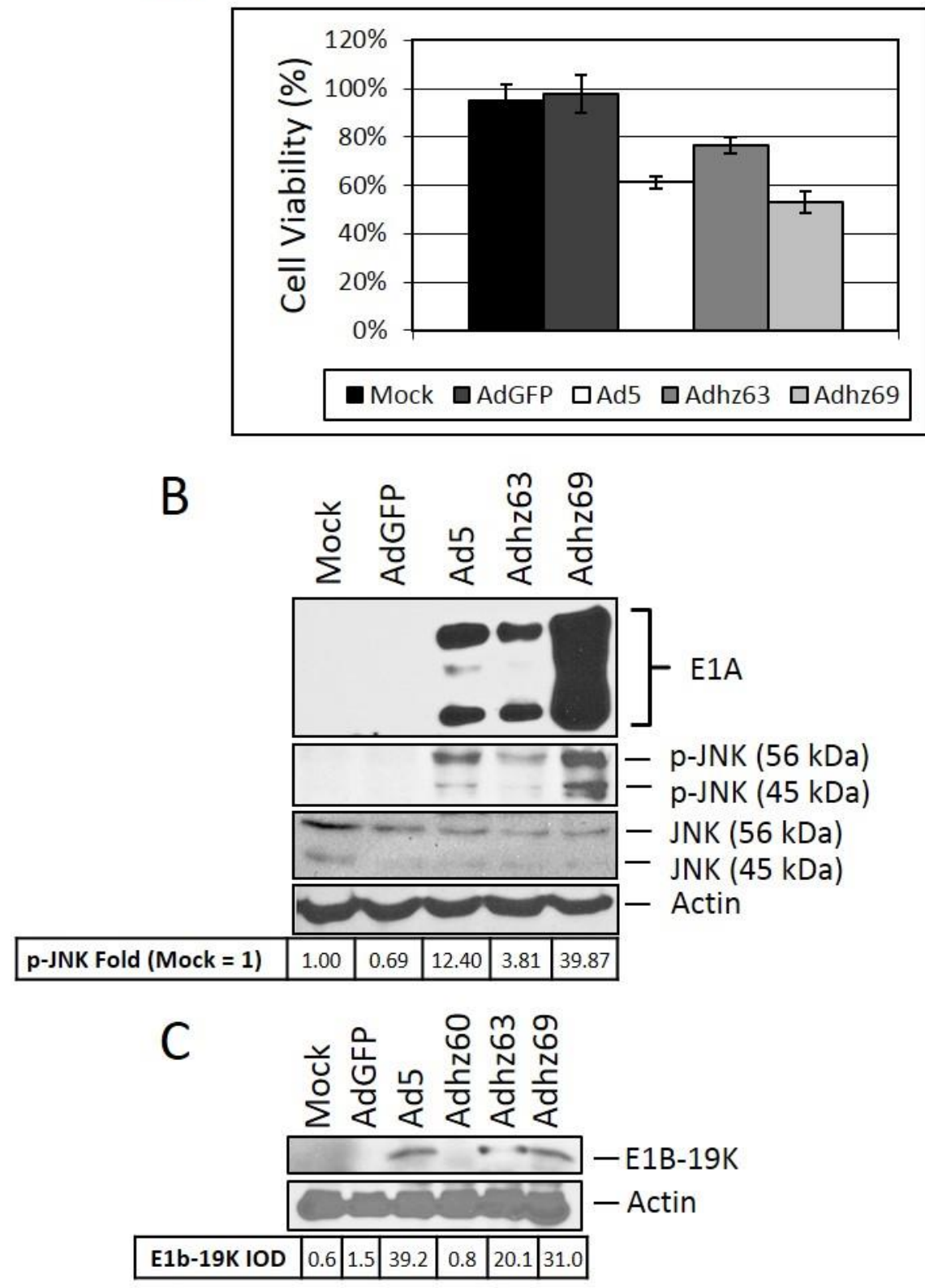

Figure 16. The effect of E1a expression upon JNK phosphorylation. A549 cells were mock-treated or infected with AdGFP, Ad5, Adhz63, and Adhz69 at an MOI of 10. (A) Cell viability was determined by crystal violet staining and expressed as the percent cell viability relative to non-treated cells at $48 \mathrm{~h}$ postinfection. (B) A549 cell lysates were treated as indicated at $48 \mathrm{~h}$ post-infection 
and observed for the protein production of the indicated proteins via Western blot analysis. (C) E1b-19K protein production was determined via Western blot analysis. Adhz60 is $E 1 b-19 \mathrm{~K}$ deleted and was used as a negative control. IOD is an abbreviation for integrated optical density. IOD's were determined via densitometric analysis using Gel-pro analyzer 4.0 software. 


\section{Evaluating known p-JNK inducers as enhancers of Ad oncolysis}

Four p-JNK inducing cancer chemotherapeutics (etoposide, cytarabine, cycloheximide and paclitaxel) were evaluated for their p-JNK induction in A549 cells [83-86]. First, the effective concentration 50\% (EC50) of each of these drugs to lyse A549 cells were determined (Figure 17A). To evaluate which drugs induced p-JNK production most efficiently, A549 cells were treated at their EC50s for $24 \mathrm{~h}$ and then their effects upon p-JNK production were assessed via Western blot analysis. These data indicated that etoposide and cycloheximide induced p-JNK production; while cytarabine and paclitaxel did not induce p-JNK using these conditions (Figure 17B).

These data led to additional studies to determine if etoposide or cyclohexamide enhanced Ad replication and oncolysis. Using the median-effect method of Chou and Talalay [161], the effect of etoposide and cyclohexamide upon AdUV oncolysis was determined $[82,136]$. Among these two drugs, the oncolytic effects of AdUV was only enhanced following etoposide treatment in A549 cells ( $p$-value $<0.001$ ) using the combination ratio of $0.5 \mathrm{MOI}$ and $0.7 \mu \mathrm{M}$ respectively (Figure 17C). Upon further dose-escalation of this combination ratio, the greatest differences in AdUV oncolysis were observed between AdUV alone at an $\mathrm{MOI}$ of $1(70 \%)$ and AdUV $(1 \mathrm{MOI})$ in combination with etoposide at $1.4 \mu \mathrm{M}$ (54\%; Figure 18A). Using these conditions, however, etoposide was not shown to enhance AdUV replication (Figure 18B). These data indicated that the p-JNK inducer, etoposide, was sufficient to enhance AdUV oncolysis but not AdUV replication. 
A

\begin{tabular}{|c|c|}
\hline Drugs & EC50 $(\mu \mathrm{M})$ \\
\hline Etoposide & 3.5 \\
\hline Cytrabine & 3 \\
\hline Cycloheximide & 0.5 \\
\hline Paclitaxel & 0.05 \\
\hline
\end{tabular}

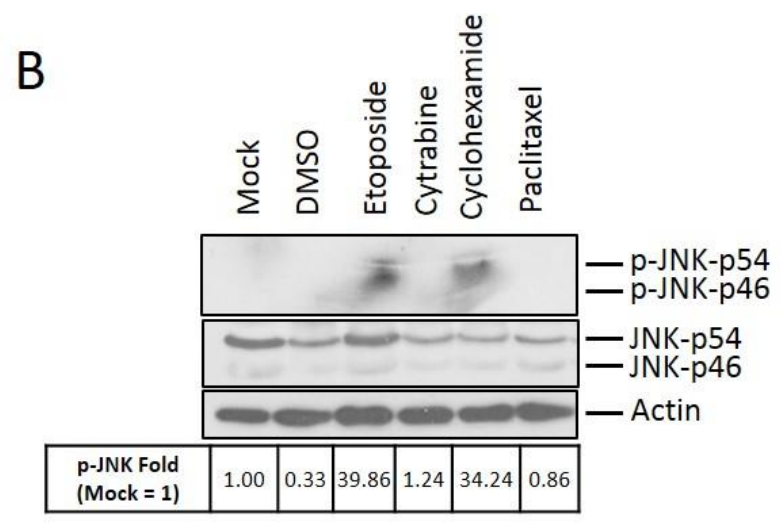

C

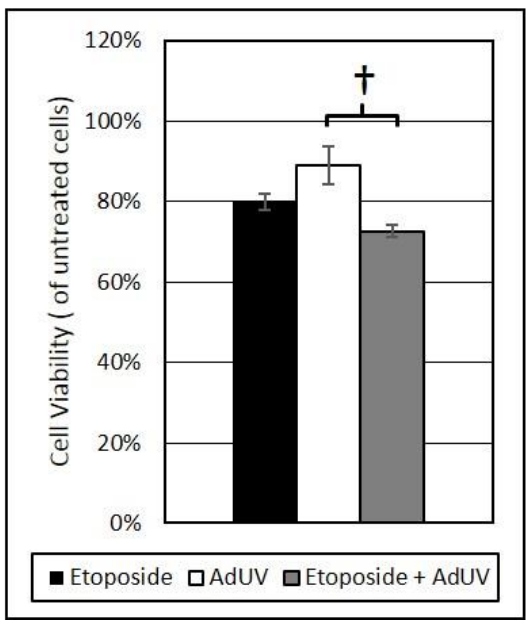

Figure 17. The effect of etoposide upon p-JNK and Ad oncolysis. A549 cells were treated with etoposide, cytrabine, cycloheximide and paclitaxel to determine their EC50s in A549 cells. (A) EC50 values as determined using crystal violet staining and prism statistical analysis. (B) The effect of these drugs at their 
EC50's upon JNK phosphorylation was determined by Western blot analysis. (C) Crystal violet staining for A549 cells treated with AdUV at $0.5 \mathrm{MOI}$ alone, $0.7 \mu \mathrm{M}$ etoposide or in combination. Significance was assessed via one-way ANOVA with Tukey's post-test analysis for multiple comparisons. † indicates p-value < 0.01 
A

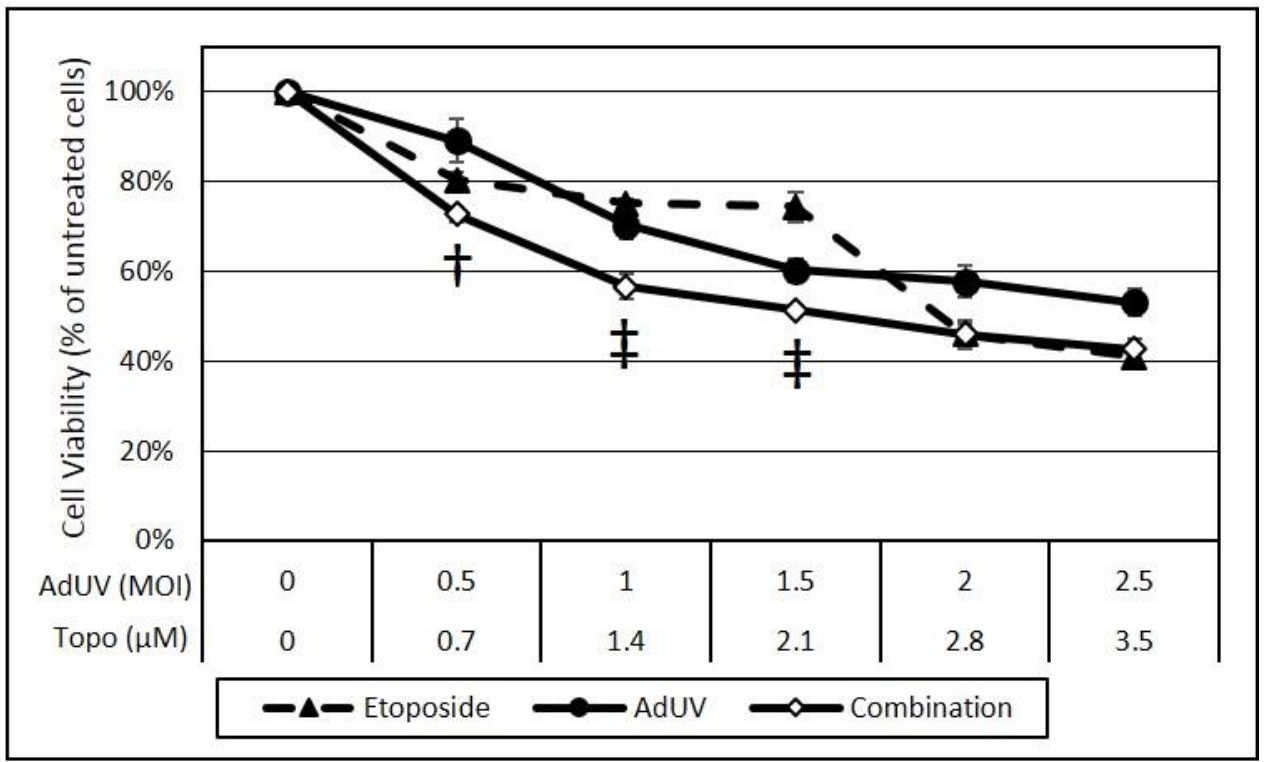

B

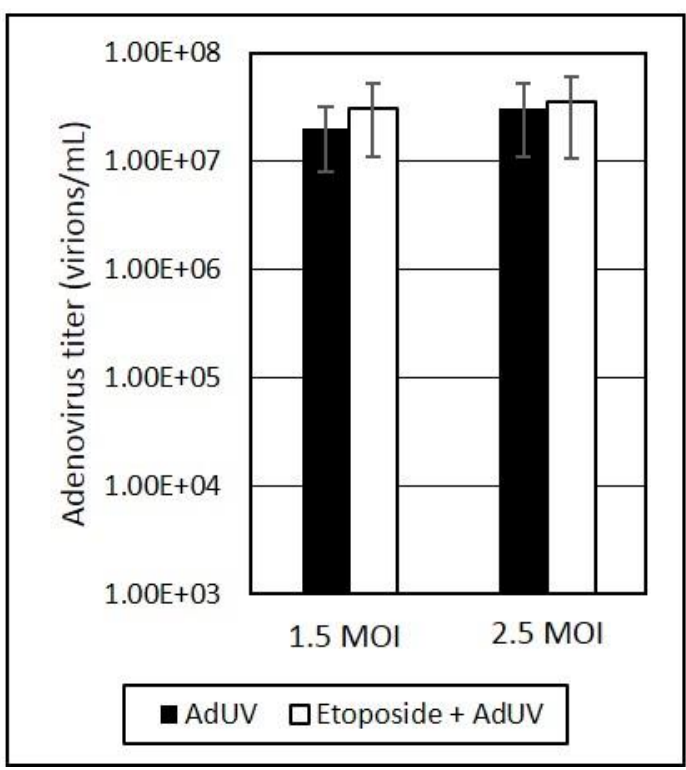

Figure 18. The effect of etoposide upon Ad replication and oncolysis. A549 cells were treated with etoposide and AdUV at a constant ratio of $0.5 \mathrm{MOI}$ AdUV to $0.7 \mu \mathrm{M}$ etoposide, respectively. (A) Crystal violet staining of A549 cells treated with the increasing combination ratios ( 1 to 5 fold) to determine if etoposide 
enhanced AdUV oncolysis. Significance was assessed via two-way ANOVA with Bonferroni's post-test analysis for multiple comparisons. (B) AdUV titer as determined by the TCID50 method. Significance was assessed via one-way ANOVA with Tukey's post-test analysis for multiple comparisons. $\dagger$ indicates $p$ value $<0.01, \ddagger$ indicates $p$-value $<0.001$ 


\section{The selective effects of JNK upon Ad replication and A549 cell oncolysis}

Wild-type Ad infection has been shown to induce JNK1 and JNK2 phosphorylation [80, 81]. Therefore, the suppression of both JNK1 and 2 using siRNA was necessary to elucidate effects of JNK upon Ad replication and oncolysis.

First, A549 cells were either mock treated or transfected with 10 to $400 \mathrm{nM}$ of JNK1/2-siRNA. Cells were screened for efficient JNK1/2 suppression via Western blot analysis with JNK1 and JNK2 selective antibodies. Using this approach, JNK1/2-siRNA selectively inhibited JNK1 and JNK2 expression at 200 and $400 \mathrm{nM}$ respectively; the $400 \mathrm{nM}$ transfection condition was selected as this condition displayed the most efficient suppression of both JNK1 and 2 (Figure 19A). JNK1/2-siRNA transfection protected A549 cells against oncolysis relative to scramble-siRNA transfected cells (Figure 19B). This protective effect was observed for Ad5, Adhz63 and Adhz60. The greatest differences, however, were seen in Ad5-infected cells (cell viability $29 \%$ vs. $61 \%$ scramble-siRNA vs. JNK1/2-siRNA, respectively) and Adhz63-infected cells (cell viability $45 \%$ vs. $77 \%$ scramble-siRNA vs. JNK1/2-siRNA, respectively; Figure 19B). Using the same siRNA transfection approach, JNK1/2 suppression was also shown to inhibit the replication of all 3 Ads studied (Figure 19C). These differences were observed for all 3 Ads however, only Ad5- and Adhz63- infected cells displayed statistically significant differences between siRNA transfection groups. We found that $1.45 \times 10^{8}$ and $6.6 \times 10^{7}$ titers when transfected with scramble-siRNA, compared to $1.43 \times 10^{7}$ and $1 \times 10^{7}$ titers when transfected with the JNK1/2- 
siRNA, respectively (Figure 19C). These data indicated that JNK expression supports both the Ad replication and oncolytic effects of Ads in A549 cancer cells. 
A

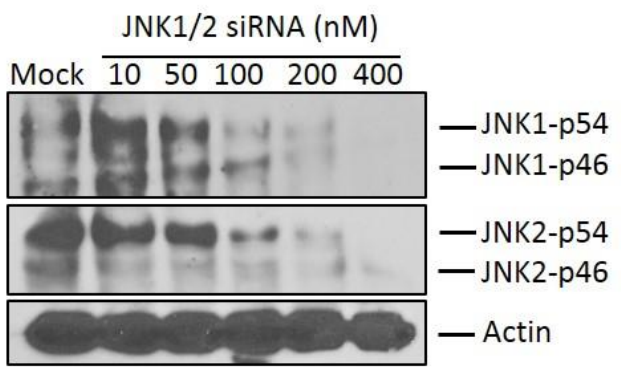

B

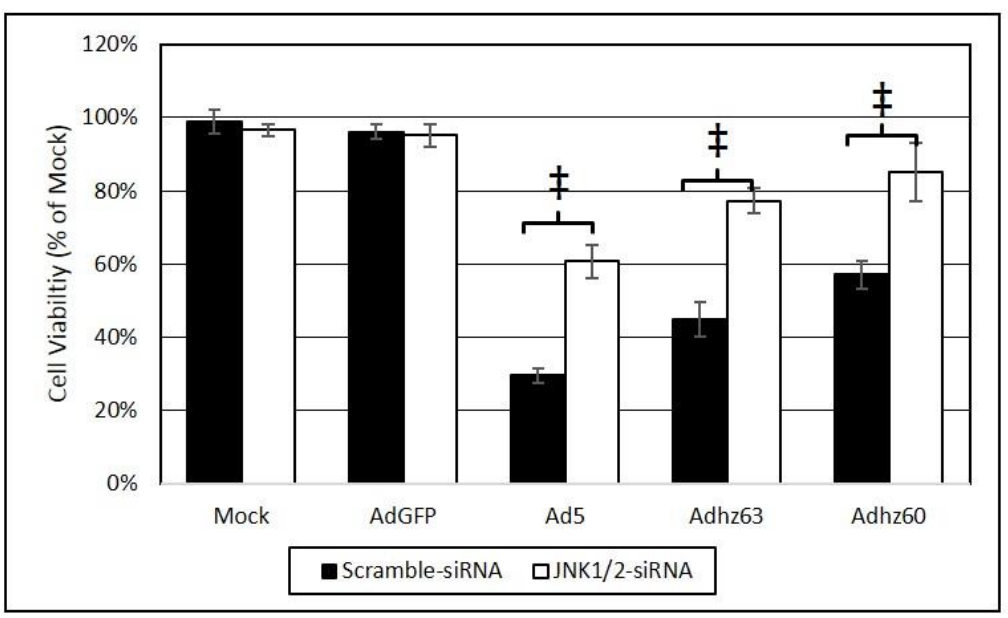

C

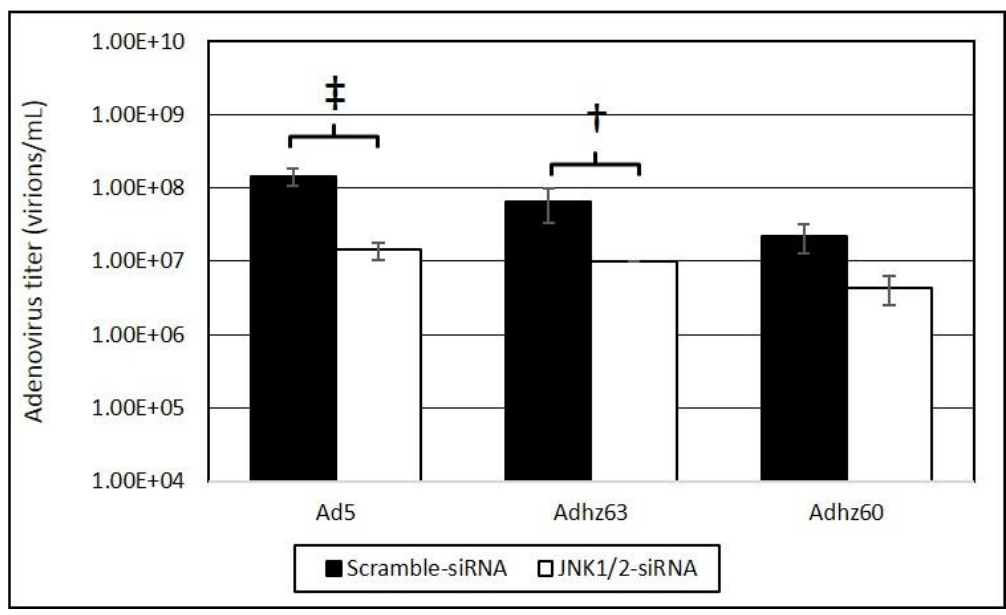

Figure. 19 The effect of JNK expression upon A549 cell oncolysis and oncolytic Ad replication. (A) The concentration of JNK1/2-siRNA that efficiently repressed JNK1 and JNK2 expression was determined at $48 \mathrm{~h}$ by Western blot analysis using JNK1 and JNK2 selective antibodies. (B) The effect of JNK1/2- 
siRNA upon cell viability was assessed using crystal violet staining. Statistical analysis was performed by one-way ANOVA using Tukey's post-test for multiple comparisons. (C) The effect of JNK1/2-siRNA upon Ad replication was assessed via the TCID50 method. Statistical analysis was performed by one-way ANOVA using Tukey's post-test for multiple comparisons. $\dagger$ indicates $p$-value $<0.01$, $\ddagger$ indicates p-value $<0.001$. 


\section{4 - Discussion}

The goal of the studies in this chapter was to ascertain the relationship between Ads, p-JNK, Ad replication and oncolysis. Other laboratories have reported the requirement of JNK expression for the oncolytic effects of the E1bwild-type oncolytic Ad, $\triangle 24 R G D$ [81]. These findings were studied further by observing the effect of E1b upon JNK, specifically to understand why E1bdeleted Ads produced disappointing results during clinical trials and to determine if $\mathrm{p}-\mathrm{JNK}$ inducers can enhance the efficacy of Ad therapy. To my knowledge, this is the first report demonstrating the role of JNK to promote both Ad replication and oncolysis.

During Ad infection, many cell death pathways are induced. However, several reports agree that autophagy is the predominant mechanism of cancer cell death induced following oncolytic Ad infection [55, 66, 78, 162-164]. In this report, significant induction of the autophagy marker LC3-II in A549 cells was observed following wild-type Ad5 infection beginning at $36 \mathrm{~h}$ post-infection (Figure 13C). The expression of p-JNK is known to induce autophagy via the phosphorylation of BCL-2, releasing BECLIN-1, which then initiates autophagosome formation [88, 151, 164]. Attenuated p-JNK induction by E1bdeleted Ads was most pronounced following E1b55,19K-deleted Ad Adhz60 infection relative to the E1b55K-deleted Ad Adhz63; indicating the importance of E1b-19K as a p-JNK inducer (Figure 15B). This finding is consistent with the only other known report describing E1b-mediated JNK phosphorylation [80]. In this study, E1b-19K was shown to be the main driver of JNK phosphorylation [80]. 
This finding was confirmed using a selective $E 1 b-19 \mathrm{~K}$ expressing plasmid known as CMV-E1b19K [158]. These data indicated E1b-19K alone was sufficient to induce p-JNK production in A549 cells (Figure 15E).

However, the E1b55,19K-deleted Ad Adhz60 induced p-JNK during Ad infection despite the loss of $E 1 b$, implicating the role of other non-E1b genes such as E1a to induce JNK phosphorylation (Figure 15B). Therefore, the E1b55K-deleted, CMV-E1a Ad Adhz69 [157] which overexpresses E1A was used to determine if increased E1A production stimulates greater JNK phosphorylation. These data indicated that E1a overexpression led to a marked increase in p-JNK production in A549 cells (Figure 16B). This is the first report, to my knowledge, to indicate that E1A induces JNK phosphorylation in cancer cells. To test if increased E1A production indirectly enhanced the expression of E1b19K, A549 cells were infected with Ad5, Adhz63, Adhz60, and Adhz69 and observed for the production of E1b-19K by Western blot analysis. These data indicated that Adhz69 displayed slightly greater levels of E1b-19K production (31.0 IOD) than the E1b55K-deleted Adhz63 (20.1 IOD; Figure 16B,C). Considering the subtle differences shown in E1b-19K expression, it is likely that the markedly enhanced p-JNK induction following Adhz69 treatment was due to increased E1A and not E1b-19K production. E1A, much like E1b-19K, does not have any endogenous kinase activity therefore it is likely that E1A induces JNK phosphorylation by the stimulation of the MAPK cascade or another family of kinases during infection. The effect of E1A upon JNK phosphorylation will be the subject of future studies. 
Due to the important role of $\mathrm{p}$-JNK during Ad oncolysis, cancer chemotherapeutics were screened for p-JNK production and observed their effects upon AdUV replication and oncolysis; AdUV was developed and characterized as described previously $[82,136]$. These data indicated that etoposide was the greatest inducer of p-JNK production and was also shown to significantly enhance Ad oncolysis ( $p$-value $<0.001$; Figure 17C). For the first time, these data indicated that cancer chemotherapeutic drugs inducing p-JNK could enhance the therapeutic efficacy of oncolytic Ads.

The use of pharmacological JNK phosphorylation inducers likely stimulated an array of other signaling pathways in addition to JNK, therefore additional approaches were necessary to further elucidate the effects of JNK upon Ad replication and oncolysis. To determine the effect of JNK upon Ad replication and oncolysis selectively, A549 cells were transfected with siRNA targeting identical mRNA sequences contained in both JNK1 and JNK2 mRNA $[155,156]$. JNK1/2-siRNA transfected cells were shown to be partially protected against Ad-mediated A549 cell lysis (Figure 19B). These effects were more pronounced in the Ad5 and Adhz63 treatment groups. Ad5, Adhz63 and Adhz60 replication was also suppressed in JNK1/2-siRNA relative to scramble-siRNAtransfected cells. These data indicate the critical role of JNK to enhance Ad oncolysis and replication.

In addition to inducing autophagic cancer cell death, p-JNK can also induce cancer cell growth. For example, A549 cells treated with the JNK1/2/3 inhibitor, sp600125, were shown to form significantly smaller tumors in nude mice 
[165]. A549 cells are known to express k-RAS; the RAS pathway phosphorylates JNK indirectly via MKK7 of the MAPK cascade [166]. Unfortunately, there are very limited molecular tools to observe the selective effects of p-JNK upon autophagy without disrupting other important cellular processes such as cancer cell growth which play a significant role during Ad replication. Ads induce the cyclin E/CDK2 axis to induce an S-phase-like state in G0 cells during infection, increasing DNA synthesis in order to replicate Ad DNA [31, 33]. It is possible, therefore, that the inhibition of oncolytic Ad efficacy following JNK1/2-siRNA transfection could be the result of A549 cell cycle repression and not a direct effect of JNK upon Ad oncolysis.

These studies indicated for the first time that JNK not only supports Ad oncolysis, but also Ad replication. These data also indicate that Adhz69, an E1b19K wild-type E1a over-expressing Ad, was a highly efficient inducer of p-JNK production, implicating that E1A may play a significant role to induce JNK phosphorylation (Figure 16B). Cancer chemotherapeutics inducing p-JNK were also shown to enhance Ad oncolysis, supporting the role of $p$-JNK to enhance Ad oncolytic therapy (Figure $17 \mathrm{C}$ and $18 \mathrm{~A}$ ). The role of JNK to support Ad oncolysis were confirmed using JNK1/2-targeting siRNA; JNK suppression was also shown to inhibit Ad replication (Figure 19B,C). Previous reports indicate that autophagy inducers supported Ad oncolysis and replication $[55,66]$. I have extended upon these studies and these data implicate p-JNK as an intriguing molecular target to enhance the cancer therapeutic efficacy of oncolytic Ads. 


\section{CHAPTER V}

\section{SUMMARY AND FUTURE PERSPECTIVES}

All clinical studies conducted to date have shown that the efficacy of Ad oncolytic virotherapy has remained low $[15,17,18,57,58,98-100]$. The disappointing efficacy of oncolytic Ads tested clinically appears to be due to many factors, including limited cancer cell lysis, inefficient Ad release from cancer cells, and spread in tumors [101-103]. Progress to improve the antitumoral effects of Ads has been hampered by a lack of knowledge pertaining to which gene and mutations lead to enhanced Ad release and spread. Furthermore, the molecular mechanisms by which E1b-deleted oncolytic Ads induce oncolysis, specifically via autophagy and JNK phosphorylation are unknown. My goal was to fill these gaps and to obtain valuable information to enhance the cancer therapeutic efficacy of oncolytic Ads.

Previously, oncolytic Ad spread was shown to be limited in solid tumors [35]; oncolytic Ads were shown to only infect of 5-20 tumor cells around the injection site following intratumoral injection [103]. In this dissertation, the oncolytic Ad mutant (AdUV) was developed. AdUV displayed enhanced release and spread. Upon DNA analysis, mutations which may have been responsible for enhanced AdUV release and spread may have been identified. These DNA mutations will be the subject of future experimentation. This dissertation also presents data extending the mechanistic understanding by which $E 1 b$-deleted 
Ads phosphorylate JNK. Additionally the p-JNK inducer, etoposide, was shown to enhance the oncolytic effects of AdUV in vitro.

Initial studies, shown in Chapter II, focused upon the development and characterization of the novel oncolytic Ad AdUV. Most Ads used in clinical studies have been subjected to E1 gene modifications to produce cancer selective Ad vectors. E1b-deleted Ads were shown to display attenuated oncolytic Ad replication, suppressing their therapeutic efficacy [96]. An alternative strategy to develop oncolytic Ads is to use random DNA mutagenesis and then select for Ad mutants with the desired therapeutic properties. In this dissertation, the E1 wild-type Ad, dl309 (Ad5) was repeatedly UV irradiated and selected in Soas- 2 cells for 72 cycles. AdUV was then isolated from a large plaque clone formed on Soas-2 cells. After the characterization of 6 Ad large plaque forming clones, AdUV was shown to lyse cancer cells with the greatest efficiency and was studied further. AdUV was characterized and shown to lead to more efficient oncolysis compared to Ad5. This appeared to be related to enhanced autophagy induction and viral spread in vitro. (This paper has been published in Viruses 2016, 8(6), 167; doi: 10.3390/v8060167).

The work presented in Chapter III focused upon the investigation of those mutated genes in the AdUV genome. These mutations were thought to alter Ad oncolytic efficacy and therefore may be integrated into novel Ad vectors or combined with other approaches to develop next generation novel oncolytic Ads with enhanced cancer therapeutic efficacy. The Ad early genes in AdUV, E1a and $E 1 b, E 2$, and $E 4$, remained unchanged, however, the Ad late genes were 
mutated. The mutations occurring within $\mathrm{pV}$ and its interaction partners IVa2 and pVIII, indicating the importance of these DNA packaging proteins for Ad oncolysis. Indirect evidence suggests that IVa2 and 33K can also form a complex with DNA-binding protein (DBP) on the 12 Ad capsid vertexes, facilitating Ad DNA packaging [110]. Additional mutations to $\mathrm{pV}$ and 52K also appear to have enhanced Ad DNA packaging via increasing the number of positively charged amino acids in these DNA binding proteins. To characterize the impact(s) of these mutations upon Ad replication and oncolysis, furher studies are needed to $\mid$ incorporate them into an Ad vector with well-characterized cancer selectivity.

Additionally, the work presented in Chapter III indicated that AdUV suppressed A549 xenograft tumor growth and was non-lethal in nude mice. AdUV is an E1b wild-type Ad. E1b wild-type Ads displayed limited cancer therapeutic efficacy previously [138]. Therefore, the goal of this limited animal study to investigate whether these novel AdUV mutations were toxic to A549xenograft-bearing athymic nude mice $(\mathrm{NCr}-\mathrm{nu} / \mathrm{nu})$. It is possible that the expression of $E 1 b$ by AdUV could have also contributed to its enhanced oncolytic effects. Several other E1b wild-type oncolytic Ad vectors have been reported to display increased cancer therapeutic efficacy $[81,130]$. Even though E1b expression is not essential for Ad replication in cancer cells [31], E1b may enhance Ad replication efficiency in cancer cells, likely via the induction of cyclinE [31] and autophagy [66]. Previously, E1b was shown to induce autophagy to provide the necessary macromolecules to promote Ad replication and oncolysis $[55,66]$. Therefore the effects of these mutations upon autophagy, as 
well as the investigation of the interactions of Ads with autophagy mediators, may reveal additional therapeutic approaches to enhance oncolytic Ad therapy (This paper has been published in Viruses 2016, 8(12), 333; doi: 10.3390/v8120333).

Chapter IV built upon the initial studies shown in Chapters II and III by evaluating p-JNK induction by E1b-deleted Ads in A549 cells. These studies also investigate the impact of p-JNK upon Ad replication and oncolysis. Previously pJNK was reported as an essential cellular factor for the oncolysis of E1b wildtype Ads [88]; therefore the effect of JNK expression upon the replication and oncolysis of E1b wild-type and E1b-deleted Ads in A549 cells was evaluated via JNK1/2-siRNA suppression. These siRNA-JNK1/2 suppression studies indicated that JNK enhanced Ad replication and oncolysis in A549 cells. E1b-deleted Ads also displayed less p-JNK production in A549 cells. These differences were most pronounced between the E1b55K-deleted Adhz63 and the E1b55,19K-deleted Adhz60, indicating the importance of $E 1 b-19 \mathrm{~K}$ as a p-JNK inducer. This finding was validated using an E1b-19K plasmid expression vector. It also appears that the expression of E1A led to JNK phosphorylation. Increased E1a-mediated E1b$19 \mathrm{k}$ transactivation may also play a minor role to induce $\mathrm{p}$-JNK production as observed by Western blot analysis (This manuscript is in preparation).

The work presented in this dissertation has addressed the question, "How can oncolytic Ad virotherapy be enhanced?" by generating a novel oncolytic Ad (AdUV) with enhanced anticancer efficacy, revealed DNA mutations which potentially could be utilized to create the next generation of oncolytic Ads, and provided a deeper understanding of how Ads induce the JNK pathway with 
implications for novel combinatorial cancer therapeutic development. This work also raises a number of interesting directions for future research in the field of oncolytic virotherapy.

First, there is still much more to learn about the mutations and oncolytic properties of AdUV. These data indicate that AdUV contained several DNA mutations which may have contributed to its enhanced oncolytic efficiency, enhanced autophagy induction and release from A549 cells in vitro. DNA sequence analysis indicated that most of these mutations occurred in the Ad late genes, implicating their significance for the development of future oncolytic Ads. To determine which mutation(s), or combination of mutations, have the greatest effect upon oncolysis, additional in vitro and in vivo studies are necessary.

Second, AdUV effectively suppressed A549 xenograft tumor growth while remaining non-lethal to athymic nude mice (NCr-nu/nu). Twelve of these mutations were shown to alter their respective encoded amino acid sequences. Six of these mutations were shown to occur in genes associated with Ad DNA packaging (Iva2, pTP, 33K, pV, 52K and pVIII). Two of these mutations, 52K and $p V$, replaced their encoded amino acids for positively charged residues. Therefore, I hypothesized that these mutations increased the ability of $52 K$ and $p V$ to bind the negatively charged DNA sugar-phosphate backbone more efficiently, leading to more rapid Ad release from infected cancer cells. I propose to incorporate these $52 \mathrm{~K}$ and $p V$ mutations into the $E 1 b$-deleted, cyclin $\mathrm{E}$ promoter driven E1A Ad, Ad-cycE as described previously [34, 35, 55]. These mutations must be incorporated into an E1b-deleted background because the 
wild-type Ad5 was shown to be in-effective during clinical trials for cervical cancer in the 1950's [138]. In addition to their limited anti-cancer efficacy, E1 wild-type Ads are no longer used in clinical studies due to their safety concerns and potential for cancer non-selective replication. For these reasons, E1 wild-type Ads such as AdUV are unlikely to be used in future clinical studies; however by the inclusion of these mutations into E1b-deleted vectors, such as Ad-cycE, the effects of these mutations can be further characterized and potentially be translated clinically.

Third, the role of $E 1 b-19 \mathrm{~K}$ and $E 1 a$ as inducers of $\mathrm{JNK}$ phosphorylation was elucidated in A549 cells. Interestingly, E1a-induced p-JNK may also be related to E1b19K via E1a-mediated, E1b-19K transactivation [40, 160]. Previous reports indicated that E1a alone was not sufficient to induce p-JNK production [80]. Therefore, the effects of E1a upon p-JNK in the absence of E1b-19K as well as the effects of E1a and E1b-19K plasmid co-transfection will be the subject of future studies.

E1A effects many cellular pathways, however one of its most crucial roles is as a master regulator of viral and host cell gene transactivation. In this manner, E1A manipulates many cellular pathways to enhance Ad replication. It is also possible that E1A induces $p-J N K$ by binding retinoblastoma protein $(p R b)$, displacing the transcription factor E2F-1 from its $\mathrm{pRb}$ binding pocket, which then transactivates the expression of many autophagy-related genes including LC3 and BECLIN-1 [167-169]. Another transcription factor modulated by E1a is p300. 
p300 has been shown to form a multiprotein complex with CREB binding protein (CBP) and cyclic AMP dependent transcription factor (ATF2) protein to specifically bind the JUN2 element [170]. E1b wild-type Ads also induce autophagy independently of c-JUN expression [88]. This observation may be reconciled by the observation that JNK target sites on ATF2 were not required for the formation of the p300/CBP-ATF2 multi-protein complexes, indicating that $p$ JNK and p300 act independently to induce c-JUN and autophagy [170]. JNK also participates in c-JUN-induced gene transactivation [171]. Therefore, it is also possible that $\mathrm{p}$-JNK can enhance Ad gene transactivation in cooperation with cJNK to enhance Ad replication. In future studies, microarray and Ad serotype 5 genomic analyses could identify novel c-JUN DNA binding sites to predict which Ad genes are affected by increased p-JNK production in cancer cells.

To further understand the effect of p-JNK upon Ad replication and oncolysis, the use of chemical p-JNK inducers and siRNA mediated JNK suppression were utilizied. Etoposide was shown to induce p-JNK and enhance oncolysis, while inhibiting Ad replication. Another p-JNK inducer cycloheximide, was inhibited Ad oncolysis or replication of AdUV. I hypothesize these effects upon Ad replication may be related to the apoptosis induction by etoposide and the inhibition of protein synthesis by cycloheximide respectively [172]. These cancer chemotherapeutic drugs therefore may act upon p-JNK via a nonselective mechanism of action. Therefore A549 cells were subjected to JNK1/2 siRNA-mediated suppression. These data indicated that JNK enhanced AdUV oncolysis and replication. It is clear that p-JNK expression supports Ad 
replication and oncolysis, but the effects of JNK upon c-JUN, the transactivation of Ad genes and the licensing DNA replication machinery remains an interesting area for future research.

These data indicate that $\mathrm{p}-\mathrm{JNK}$ inducers are attractive molecular targets to enhance the anti-cancer therapeutic efficacy of oncolytic Ads. Another intriguing molecular target which has not been studied is the JNK phosphatase M3/6. M3/6 selectively de-phosphorylates JNK; therefore, the inhibition of M3/6 would likely significantly enhance p-JNK production in a much more selective manner than cancer chemotherapeutics utilized in this study. The Dr. McMasters laboratory has confirmed that autophagy inducers acting via the cell starvation pathway enhanced oncolytic Ad replication and oncolysis. However these studies shown in Chapter IV indicate that autophagy inducers acting upon the p-JNK/BECLIN-1 axis would produce greater synergistic cancer cell killing effects in combination with E1b-deleted oncolytic Ads than drugs targeting cell starvation induced autophagy $[55,66]$.

These studies taken together have characterized the novel oncolytic Ad, AdUV, which displayed the therapeutic properties of enhanced oncolysis, release, spread and autophagy induction. Following DNA sequence analysis, the ability of AdUV to induce its enhanced cancer therapeutic effects appears related to mutations in the Ad late genes, specifically genes associated with Ad DNA packaging. This dissertation also provided a more complete description of the interaction between the $\mathrm{E} 1$ genes, JNK and Ad oncolysis. For the first time, a link between JNK expression and Ad replication in cancer cells using JNK1/2- 
targeting siRNA. There are many exciting future directions of these studies, including: the incorporation of AdUV DNA packaging gene mutations into well characterized oncolytic Ad vectors, the effect of JNK upon cyclin E, determining whether JNK is required for Ad-mediated DNA replication licensing, and finally, whether selective JNK induction enhances E1b-deleted Ad oncolysis. I believe that future progress in oncolytic adenovirology, along with various improvements in targeted therapeutic strategies, should pave the way for the next generation of oncolytic virotherapy. 


\section{REFERENCES}

1. Onaitis, M.W., R.P. Petersen, S.S. Balderson, E. Toloza, W.R. Burfeind, D.H. Harpole, Jr., and T.A. D'Amico, Thoracoscopic lobectomy is a safe and versatile procedure: experience with 500 consecutive patients. Ann Surg, 2006. 244(3): p. 420-5.

2. Zarogoulidis, K., P. Zarogoulidis, K. Darwiche, E. Boutsikou, N. Machairiotis, K. Tsakiridis, N. Katsikogiannis, I. Kougioumtzi, I. Karapantzos, H. Huang, and D. Spyratos, Treatment of non-small cell lung cancer (NSCLC). J Thorac Dis, 2013. 5 Suppl 4: p. S389-96.

3. Wang, E.H., C.D. Corso, C.E. Rutter, H.S. Park, A.B. Chen, A.W. Kim, L.D. Wilson, R.H. Decker, and J.B. Yu, Postoperative Radiation Therapy Is Associated With Improved Overall Survival in Incompletely Resected Stage II and III Non-Small-Cell Lung Cancer. J Clin Oncol, 2015.

4. Einhorn, L.H., First-line chemotherapy for non-small-cell lung cancer: is there a superior regimen based on histology? J Clin Oncol, 2008. 26(21): p. 3485-6.

5. Ramalingam, S. and C. Belani, Systemic chemotherapy for advanced nonsmall cell lung cancer: recent advances and future directions. Oncologist, 2008. 13 Suppl 1: p. 5-13.

6. Tanoue, L.T. and F.C. Detterbeck, New TNM classification for non-smallcell lung cancer. Expert Rev Anticancer Ther, 2009. 9(4): p. 413-23.

7. Schuchert, M.J. and J.D. Luketich, Solitary sites of metastatic disease in non-small cell lung cancer. Curr Treat Options Oncol, 2003. 4(1): p. 65-79.

8. Quint, L.E., S. Tummala, L.J. Brisson, I.R. Francis, A.S. Krupnick, E.A. Kazerooni, M.D. Iannettoni, R.I. Whyte, and M.B. Orringer, Distribution of distant metastases from newly diagnosed non-small cell lung cancer. Ann Thorac Surg, 1996. 62(1): p. 246-50.

9. Schiller, J.H., D. Harrington, C.P. Belani, C. Langer, A. Sandler, J. Krook, J. Zhu, D.H. Johnson, and G. Eastern Cooperative Oncology, Comparison of four chemotherapy regimens for advanced non-small-cell lung cancer. N Engl J Med, 2002. 346(2): p. 92-8. 
10. Heuvers, M.E., J.P. Hegmans, B.H. Stricker, and J.G. Aerts, Improving lung cancer survival; time to move on. BMC Pulm Med, 2012. 12: p. 77.

11. Pollock, J. and E.B. Garon, Management of small-cell lung cancer: time to move forward. Oncology (Williston Park), 2010. 24(11): p. 1043, 1046-7.

12. Parker, J.N., D.F. Bauer, J.J. Cody, and J.M. Markert, Oncolytic viral therapy of malignant glioma. Neurotherapeutics, 2009. 6(3): p. 558-69.

13. Vijayalingam, S., M. Kuppuswamy, T. Subramanian, F.F. Strebeck, C.L. West, M. Varvares, and G. Chinnadurai, Evaluation of apoptogenic adenovirus type 5 oncolytic vectors in a Syrian hamster head and neck cancer model. Cancer Gene Ther, 2014. 21(6): p. 228-37.

14. Nettelbeck, D.M., Cellular genetic tools to control oncolytic adenoviruses for virotherapy of cancer. J Mol Med (Berl), 2008. 86(4): p. 363-77.

15. Kirn, D., Oncolytic virotherapy for cancer with the adenovirus dl1520 (Onyx-015): results of phase I and II trials. Expert Opin Biol Ther, 2001. 1(3): p. 525-38.

16. Heise, C., A. Sampson-Johannes, A. Williams, F. McCormick, D.D. Von Hoff, and D.H. Kirn, ONYX-015, an E1B gene-attenuated adenovirus, causes tumor-specific cytolysis and antitumoral efficacy that can be augmented by standard chemotherapeutic agents. Nat Med, 1997. 3(6): p. $639-45$.

17. Makower, D., A. Rozenblit, H. Kaufman, M. Edelman, M.E. Lane, J. Zwiebel, H. Haynes, and S. Wadler, Phase Il clinical trial of intralesional administration of the oncolytic adenovirus ONYX-015 in patients with hepatobiliary tumors with correlative p53 studies. Clin Cancer Res, 2003. 9(2): p. 693-702.

18. $\mathrm{Yu}, \mathrm{W}$. and $\mathrm{H}$. Fang, Clinical trials with oncolytic adenovirus in China. Curr Cancer Drug Targets, 2007. 7(2): p. 141-8.

19. Xia, Z.J., J.H. Chang, L. Zhang, W.Q. Jiang, Z.Z. Guan, J.W. Liu, Y. Zhang, X.H. Hu, G.H. Wu, H.Q. Wang, Z.C. Chen, J.C. Chen, Q.H. Zhou, J.W. Lu, Q.X. Fan, J.J. Huang, and X. Zheng, [Phase III randomized clinical trial of intratumoral injection of E1B gene-deleted adenovirus (H101) combined with cisplatin-based chemotherapy in treating squamous cell cancer of head and neck or esophagus]. Ai Zheng, 2004. 23(12): p. 1666-70. 
20. Pol, J., G. Kroemer, and L. Galluzzi, First oncolytic virus approved for melanoma immunotherapy. Oncoimmunology, 2016. 5(1): p. e1115641.

21. Bauzon, M., F. Jin, P. Kretschmer, and T. Hermiston, In vitro analysis of cidofovir and genetically engineered TK expression as potential approaches for the intervention of ColoAd1-based treatment of cancer. Gene Ther, 2009. 16(9): p. 1169-74.

22. $\mathrm{Di}, \mathrm{Y}$., L. Seymour, and K. Fisher, Activity of a group B oncolytic adenovirus (ColoAd1) in whole human blood. Gene Ther, 2014. 21(4): p. 440-3.

23. Berk, A.J., Adenoviridae: the viruses and their replication. In: HowleyDMKP (ed) Fields virology. . 2006: Lippincott Williams \& Wilkins, Philadelphia, pp 2354-2394.

24. Seth, P. and J. Higginbotham, Advantages and disadvantages of multiple different methods of adenoviral vector construction. Methods Mol Med, 2000. 45: p. 189-98.

25. Ben-Israel, H. and T. Kleinberger, Adenovirus and cell cycle control. Front Biosci, 2002. 7: p. d1369-95.

26. Barker, D.D. and A.J. Berk, Adenovirus proteins from both E1B reading frames are required for transformation of rodent cells by viral infection and DNA transfection. Virology, 1987. 156(1): p. 107-21.

27. Stillman, B., Functions of the adenovirus E1B tumour antigens. Cancer Surv, 1986. 5(2): p. 389-404.

28. Lowe, S.W. and H.E. Ruley, Stabilization of the p53 tumor suppressor is induced by adenovirus 5 E1A and accompanies apoptosis. Genes Dev, 1993. 7(4): p. 535-45.

29. Zheng, X., X.M. Rao, C.L. Snodgrass, K.M. McMasters, and H.S. Zhou, Selective replication of E1B55K-deleted adenoviruses depends on enhanced E1A expression in cancer cells. Cancer Gene Ther, 2006. 13(6): p. 572-83.

30. Rao, X.M., X. Zheng, S. Waigel, W. Zacharias, K.M. McMasters, and H.S. Zhou, Gene expression profiles of normal human lung cells affected by adenoviral E1B. Virology, 2006. 350(2): p. 418-28.

31. Zheng, X., X.M. Rao, J.G. Gomez-Gutierrez, H. Hao, K.M. McMasters, and H.S. Zhou, Adenovirus E1B55K region is required to enhance cyclin $E$ 
expression for efficient viral DNA replication. J Virol, 2008. 82(7): p. 341527.

32. Cheng, P.H., S.L. Wechman, K.M. McMasters, and H.S. Zhou, Oncolytic Replication of E1b-Deleted Adenoviruses. Viruses, 2015. 7(11): p. 576779.

33. Cheng, P.H., X.M. Rao, K.M. McMasters, and H.S. Zhou, Molecular basis for viral selective replication in cancer cells: activation of CDK2 by adenovirus-induced cyclin E. PLoS One, 2013. 8(2): p. e57340.

34. Cheng, P.H., X.M. Rao, X. Duan, X.F. Li, M.E. Egger, K.M. McMasters, and H.S. Zhou, Virotherapy targeting cyclin E overexpression in tumors with adenovirus-enhanced cancer-selective promoter. J Mol Med (Berl), 2015. 93(2): p. 211-23.

35. Cheng, P.H., X.M. Rao, S.L. Wechman, X.F. Li, K.M. McMasters, and H.S. Zhou, Oncolytic adenovirus targeting cyclin $E$ overexpression repressed tumor growth in syngeneic immunocompetent mice. BMC Cancer, 2015. 15: p. 716.

36. Debbas, M. and E. White, Wild-type $p 53$ mediates apoptosis by E1A, which is inhibited by E1B. Genes Dev, 1993. 7(4): p. 546-54.

37. Rao, L., M. Debbas, P. Sabbatini, D. Hockenbery, S. Korsmeyer, and E. White, The adenovirus E1A proteins induce apoptosis, which is inhibited by the E1B 19-kDa and Bcl-2 proteins. Proc Natl Acad Sci U S A, 1992. 89(16): p. 7742-6.

38. White, E., P. Sabbatini, M. Debbas, W.S. Wold, D.I. Kusher, and L.R. Gooding, The 19-kilodalton adenovirus E1B transforming protein inhibits programmed cell death and prevents cytolysis by tumor necrosis factor alpha. Mol Cell Biol, 1992. 12(6): p. 2570-80.

39. Cuconati, A., K. Degenhardt, R. Sundararajan, A. Anschel, and E. White, Bak and Bax function to limit adenovirus replication through apoptosis induction. J Virol, 2002. 76(9): p. 4547-58.

40. Herrmann, C.H., C.V. Dery, and M.B. Mathews, Transactivation of host and viral genes by the adenovirus E1B 19K tumor antigen. Oncogene, 1987. 2(1): p. 25-35.

41. Schreiner, S., P. Wimmer, H. Sirma, R.D. Everett, P. Blanchette, P. Groitl, and T. Dobner, Proteasome-dependent degradation of Daxx by the viral E1B-55K protein in human adenovirus-infected cells. J Virol, 2010. 84(14): p. 7029-38. 
42. Pennella, M.A., Y. Liu, J.L. Woo, C.A. Kim, and A.J. Berk, Adenovirus E1B 55-kilodalton protein is a p53-SUMO1 E3 ligase that represses p53 and stimulates its nuclear export through interactions with promyelocytic leukemia nuclear bodies. J Virol, 2010. 84(23): p. 12210-25.

43. Liu, Y., A. Shevchenko, A. Shevchenko, and A.J. Berk, Adenovirus exploits the cellular aggresome response to accelerate inactivation of the MRN complex. J Virol, 2005. 79(22): p. 14004-16.

44. Muller, S. and T. Dobner, The adenovirus E1B-55K oncoprotein induces SUMO modification of p53. Cell Cycle, 2008. 7(6): p. 754-8.

45. Dix, B.R., S.J. Edwards, and A.W. Braithwaite, Does the antitumor adenovirus ONYX-015/dl1520 selectively target cells defective in the p53 pathway? J Virol, 2001. 75(12): p. 5443-7.

46. Rivlin, N., R. Brosh, M. Oren, and V. Rotter, Mutations in the p53 Tumor Suppressor Gene: Important Milestones at the Various Steps of Tumorigenesis. Genes Cancer, 2011. 2(4): p. 466-74.

47. Harada, J.N. and A.J. Berk, p53-Independent and-dependent requirements for E1B-55K in adenovirus type 5 replication. J Virol, 1999. 73(7): p. 5333-44.

48. Malumbres, M. and M. Barbacid, To cycle or not to cycle: a critical decision in cancer. Nat Rev Cancer, 2001. 1(3): p. 222-31.

49. Kirn, D., Clinical research results with dl1520 (Onyx-015), a replicationselective adenovirus for the treatment of cancer: what have we learned? Gene Ther, 2001. 8(2): p. 89-98.

50. Waszak, P., M.L. Franco-Montoya, M.P. Jacob, I. Deprez, M. Levame, C. Lafuma, A. Harf, and C. Delacourt, Effect of intratracheal adenoviral vector administration on lung development in newborn rats. Hum Gene Ther, 2002. 13(15): p. 1873-85.

51. Keedy, V., W. Wang, J. Schiller, S. Chada, B. Slovis, K. Coffee, J. Worrell, L.A. Thet, D.H. Johnson, and D.P. Carbone, Phase I study of adenovirus p53 administered by bronchoalveolar lavage in patients with bronchioloalveolar cell lung carcinoma: ECOG 6597. J Clin Oncol, 2008. 26(25): p. 4166-71.

52. Nemunaitis, J., T. Meyers, N. Senzer, C. Cunningham, H. West, E. Vallieres, S. Anthony, S. Vukelja, B. Berman, H. Tully, B. Pappen, S. Sarmiento, R. Arzaga, S. Duniho, S. Engardt, M. Meagher, and M.A. 
Cheever, Phase I Trial of sequential administration of recombinant DNA and adenovirus expressing L523S protein in early stage non-small-cell lung cancer. Mol Ther, 2006. 13(6): p. 1185-91.

53. Nemunaitis, J., C. Cunningham, A. Buchanan, A. Blackburn, G. Edelman, P. Maples, G. Netto, A. Tong, B. Randlev, S. Olson, and D. Kirn, Intravenous infusion of a replication-selective adenovirus (ONYX-015) in cancer patients: safety, feasibility and biological activity. Gene Ther, 2001. 8(10): p. 746-59.

54. You, L., C.T. Yang, and D.M. Jablons, ONYX-015 works synergistically with chemotherapy in lung cancer cell lines and primary cultures freshly made from lung cancer patients. Cancer Res, 2000. 60(4): p. 1009-13.

55. Cheng, P.H., S. Lian, R. Zhao, X.M. Rao, K.M. McMasters, and H.S. Zhou, Combination of autophagy inducer rapamycin and oncolytic adenovirus improves antitumor effect in cancer cells. Virol J, 2013. 10: p. 293.

56. Chan, L., P.H. Cheng, X.M. Rao, K.M. McMasters, and H.S. Zhou, Indole3-carbinol (I3C) increases apoptosis, represses growth of cancer cells, and enhances adenovirus-mediated oncolysis. Cancer Biol Ther, 2014. 15(9).

57. Yamamoto, M. and D.T. Curiel, Current issues and future directions of oncolytic adenoviruses. Mol Ther, 2010. 18(2): p. 243-50.

58. McCormick, F., Cancer-specific viruses and the development of ONYX015. Cancer Biol Ther, 2003. 2(4 Suppl 1): p. S157-60.

59. Zhao, T., X.M. Rao, X. Xie, L. Li, T.C. Thompson, K.M. McMasters, and H.S. Zhou, Adenovirus with insertion-mutated E1A selectively propagates in liver cancer cells and destroys tumors in vivo. Cancer Res, 2003. 63(12): p. 3073-8.

60. Yan, W., G. Kitzes, F. Dormishian, L. Hawkins, A. Sampson-Johannes, J. Watanabe, J. Holt, V. Lee, T. Dubensky, A. Fattaey, T. Hermiston, A. Balmain, and Y. Shen, Developing novel oncolytic adenoviruses through bioselection. J Virol, 2003. 77(4): p. 2640-50.

61. Gros, A., J. Martinez-Quintanilla, C. Puig, S. Guedan, D.G. Mollevi, R. Alemany, and M. Cascallo, Bioselection of a gain of function mutation that enhances adenovirus 5 release and improves its antitumoral potency. Cancer Res, 2008. 68(21): p. 8928-37. 
62. Beier, R., T. Hermiston, and D. Mumberg, Isolation of more potent oncolytic paramyxovirus by bioselection. Gene Ther, 2013. 20(1): p. 10211.

63. Sugimoto, T., C. Bartholomeusz, A.M. Tari, and N.T. Ueno, Adenovirus type 5 E1A-induced apoptosis in COX-2-overexpressing breast cancer cells. Breast Cancer Res, 2007. 9(4): p. R41.

64. Abou El Hassan, M.A., I. van der Meulen-Muileman, S. Abbas, and F.A. Kruyt, Conditionally replicating adenoviruses kill tumor cells via a basic apoptotic machinery-independent mechanism that resembles necrosis-like programmed cell death. J Virol, 2004. 78(22): p. 12243-51.

65. Zeng, X. and C.R. Carlin, Host cell autophagy modulates early stages of adenovirus infections in airway epithelial cells. J Virol, 2013. 87(4): p. 2307-19.

66. Rodriguez-Rocha, H., J.G. Gomez-Gutierrez, A. Garcia-Garcia, X.M. Rao, L. Chen, K.M. McMasters, and H.S. Zhou, Adenoviruses induce autophagy to promote virus replication and oncolysis. Virology, 2011. 416(1-2): p. 9-15.

67. Liu, Y. and B. Levine, Autosis and autophagic cell death: the dark side of autophagy. Cell Death Differ, 2015. 22(3): p. 367-76.

68. Peter, M.E., Programmed cell death: Apoptosis meets necrosis. Nature, 2011. 471(7338): p. 310-2.

69. Ren, J. and H. Taegtmeyer, Too much or not enough of a good thing--The Janus faces of autophagy in cardiac fuel and protein homeostasis. $\mathrm{J}$ Mol Cell Cardiol, 2015. 84: p. 223-6.

70. Davison, A.J., M. Benko, and B. Harrach, Genetic content and evolution of adenoviruses. J Gen Virol, 2003. 84(Pt 11): p. 2895-908.

71. Shi, J.H., D.H. Hu, Z.F. Zhang, X.Z. Bai, H.T. Wang, X.X. Zhu, Y.J. Su, and C.W. Tang, Reduced expression of microtubule-associated protein 1 light chain 3 in hypertrophic scars. Arch Dermatol Res, 2012. 304(3): p. 209-15.

72. Kabeya, Y., N. Mizushima, T. Ueno, A. Yamamoto, T. Kirisako, T. Noda, E. Kominami, Y. Ohsumi, and T. Yoshimori, LC3, a mammalian homologue of yeast Apg8p, is localized in autophagosome membranes after processing. EMBO J, 2000. 19(21): p. 5720-8. 
73. Barth, S., D. Glick, and K.F. Macleod, Autophagy: assays and artifacts. J Pathol, 2010. 221(2): p. 117-24.

74. Kim, J., M. Kundu, B. Viollet, and K.L. Guan, AMPK and mTOR regulate autophagy through direct phosphorylation of Ulk1. Nat Cell Biol, 2011. 13(2): p. 132-41.

75. Roos, W.P., A.D. Thomas, and B. Kaina, DNA damage and the balance between survival and death in cancer biology. Nat Rev Cancer, 2016. 16(1): p. 20-33.

76. Yousefi, S. and H.U. Simon, Autophagy in cancer and chemotherapy. Results Probl Cell Differ, 2009. 49: p. 183-90.

77. Ito, H., H. Aoki, F. Kuhnel, Y. Kondo, S. Kubicka, T. Wirth, E. Iwado, A. Iwamaru, K. Fujiwara, K.R. Hess, F.F. Lang, R. Sawaya, and S. Kondo, Autophagic cell death of malignant glioma cells induced by a conditionally replicating adenovirus. J Natl Cancer Inst, 2006. 98(9): p. 625-36.

78. Jiang, H., E.J. White, C.I. Rios-Vicil, J. Xu, C. Gomez-Manzano, and J. Fueyo, Human adenovirus type 5 induces cell lysis through autophagy and autophagy-triggered caspase activity. J Virol, 2011 . 85(10): p. 4720-9.

79. Bogoyevitch, M.A., The isoform-specific functions of the $c$-Jun N-terminal Kinases (JNKs): differences revealed by gene targeting. Bioessays, 2006. 28(9): p. 923-34.

80. See, R.H. and Y. Shi, Adenovirus E1B 19,000-molecular-weight protein activates $c$-Jun $\mathrm{N}$-terminal kinase and c-Jun-mediated transcription. Mol Cell Biol, 1998. 18(7): p. 4012-22.

81. Klein, S.R., S. Piya, Z. Lu, Y. Xia, M.M. Alonso, E.J. White, J. Wei, C. Gomez-Manzano, H. Jiang, and J. Fueyo, C-Jun N-terminal kinases are required for oncolytic adenovirus-mediated autophagy. Oncogene, 2015.

82. Wechman, S.L., X.M. Rao, P.H. Cheng, J.G. Gomez-Gutierrez, K.M. McMasters, and H.S. Zhou, Development of an Oncolytic Adenovirus with Enhanced Spread Ability through Repeated UV Irradiation and Cancer Selection. Viruses, 2016. 8(6).

83. Anderson, S.M., M.E. Reyland, S. Hunter, L.M. Deisher, K.A. Barzen, and D.O. Quissell, Etoposide-induced activation of c-jun N-terminal kinase (JNK) correlates with drug-induced apoptosis in salivary gland acinar cells. Cell Death Differ, 1999. 6(5): p. 454-62. 
84. Sampath, D., J. Cortes, Z. Estrov, M. Du, Z. Shi, M. Andreeff, V. Gandhi, and W. Plunkett, Pharmacodynamics of cytarabine alone and in combination with 7-hydroxystaurosporine (UCN-01) in AML blasts in vitro and during a clinical trial. Blood, 2006. 107(6): p. 2517-24.

85. Guo, Y.L., K. Baysal, B. Kang, L.J. Yang, and J.R. Williamson, Correlation between sustained c-Jun $\mathrm{N}$-terminal protein kinase activation and apoptosis induced by tumor necrosis factor-alpha in rat mesangial cells. $\mathrm{J}$ Biol Chem, 1998. 273(7): p. 4027-34.

86. Peng, Z.G., D.C. Liu, Y.B. Yao, X.L. Feng, X. Huang, Y.L. Tang, J. Yang, and X.X. Wang, Paclitaxel induces apoptosis in leukemia cells through a JNK activation-dependent pathway. Genet Mol Res, 2016. 15(1): $p$. 15013904.

87. Garber, K., China approves world's first oncolytic virus therapy for cancer treatment. J Natl Cancer Inst, 2006. 98(5): p. 298-300.

88. Klein, S.R., S. Piya, Z. Lu, Y. Xia, M.M. Alonso, E.J. White, J. Wei, C. Gomez-Manzano, H. Jiang, and J. Fueyo, C-Jun N-terminal kinases are required for oncolytic adenovirus-mediated autophagy. Oncogene, 2015. 34(41): p. 5295-301.

89. Mulvihill, S., R. Warren, A. Venook, A. Adler, B. Randlev, C. Heise, and D. Kirn, Safety and feasibility of injection with an E1B-55 kDa gene-deleted, replication-selective adenovirus (ONYX-015) into primary carcinomas of the pancreas: a phase I trial. Gene Ther, 2001. 8(4): p. 308-15.

90. Bischoff, J.R., D.H. Kim, A. Williams, C. Heise, S. Horn, M. Muna, L. Ng, J.A. Nye, A. SampsonJohannes, A. Fattaey, and F. McCormick, An adenovirus mutant that replicates selectively in p53-deficient human tumor cells. Science, 1996. 274(5286): p. 373-376.

91. Cafferata, E.G., D.R. Maccio, M.V. Lopez, D.L. Viale, C. Carbone, G. Mazzolini, and O.L. Podhajcer, A novel A33 promoter-based conditionally replicative adenovirus suppresses tumor growth and eradicates hepatic metastases in human colon cancer models. Clin Cancer Res, 2009. 15(9): p. 3037-49.

92. Nemunaitis, J., A.W. Tong, M. Nemunaitis, N. Senzer, A.P. Phadke, C. Bedell, N. Adams, Y.A. Zhang, P.B. Maples, S. Chen, B. Pappen, J. Burke, D. Ichimaru, Y. Urata, and T. Fujiwara, A phase I study of telomerase-specific replication competent oncolytic adenovirus (telomelysin) for various solid tumors. Mol Ther, 2010. 18(2): p. 429-34. 
93. DeWeese, T.L., H. van der Poel, S. Li, B. Mikhak, R. Drew, M. Goemann, U. Hamper, R. DeJong, N. Detorie, R. Rodriguez, T. Haulk, A.M. DeMarzo, S. Piantadosi, D.C. Yu, Y. Chen, D.R. Henderson, M.A. Carducci, W.G. Nelson, and J.W. Simons, A phase I trial of CV706, a replication-competent, PSA selective oncolytic adenovirus, for the treatment of locally recurrent prostate cancer following radiation therapy. Cancer Res, 2001. 61(20): p. 7464-72.

94. Russell, S.J., K.W. Peng, and J.C. Bell, Oncolytic virotherapy. Nat Biotechnol, 2012. 30(7): p. 658-70.

95. Jones, N. and T. Shenk, Isolation of adenovirus type 5 host range deletion mutants defective for transformation of rat embryo cells. Cell, 1979. 17(3): p. 683-9.

96. Rao, X.M., M.T. Tseng, X. Zheng, Y. Dong, A. Jamshidi-Parsian, T.C. Thompson, M.K. Brenner, K.M. McMasters, and H.S. Zhou, E1A-induced apoptosis does not prevent replication of adenoviruses with deletion of E1b in majority of infected cancer cells. Cancer Gene Ther, 2004. 11(9): p. 585-93.

97. Ishiyama, M., H. Tominaga, M. Shiga, K. Sasamoto, Y. Ohkura, and K. Ueno, A combined assay of cell viability and in vitro cytotoxicity with a highly water-soluble tetrazolium salt, neutral red and crystal violet. Biol Pharm Bull, 1996. 19(11): p. 1518-20.

98. Opyrchal, M., I. Aderca, and E. Galanis, Phase I clinical trial of locoregional administration of the oncolytic adenovirus ONYX-015 in combination with mitomycin- $C$, doxorubicin, and cisplatin chemotherapy in patients with advanced sarcomas. Methods Mol Biol, 2009. 542: p. 70517.

99. Lu, W., S. Zheng, X.F. Li, J.J. Huang, X. Zheng, and Z. Li, Intra-tumor injection of H101, a recombinant adenovirus, in combination with chemotherapy in patients with advanced cancers: a pilot phase II clinical trial. World J Gastroenterol, 2004. 10(24): p. 3634-8.

100. Xu, R.H., Z.Y. Yuan, Z.Z. Guan, Y. Cao, H.Q. Wang, X.H. Hu, J.F. Feng, Y. Zhang, F. Li, Z.T. Chen, J.J. Wang, J.J. Huang, Q.H. Zhou, and S.T. Song, [Phase II clinical study of intratumoral H101, an E1B deleted adenovirus, in combination with chemotherapy in patients with cancer]. Ai Zheng, 2003. 22(12): p. 1307-10.

101. Parato, K.A., D. Senger, P.A. Forsyth, and J.C. Bell, Recent progress in the battle between oncolytic viruses and tumours. Nat Rev Cancer, 2005. 5(12): p. 965-76. 
102. Smith, E., J. Breznik, and B.D. Lichty, Strategies to enhance viral penetration of solid tumors. Hum Gene Ther, 2011. 22(9): p. 1053-60.

103. Galanis, E., S.H. Okuno, A.G. Nascimento, B.D. Lewis, R.A. Lee, A.M. Oliveira, J.A. Sloan, P. Atherton, J.H. Edmonson, C. Erlichman, B. Randlev, Q. Wang, S. Freeman, and J. Rubin, Phase I-II trial of ONYX015 in combination with MAP chemotherapy in patients with advanced sarcomas. Gene Ther, 2005. 12(5): p. 437-45.

104. Gros, A., C. Puig, S. Guedan, J.J. Rojas, R. Alemany, and M. Cascallo, Verapamil enhances the antitumoral efficacy of oncolytic adenoviruses. Mol Ther, 2010. 18(5): p. 903-11.

105. Baird, S.K., J.L. Aerts, A. Eddaoudi, M. Lockley, N.R. Lemoine, and I.A. McNeish, Oncolytic adenoviral mutants induce a novel mode of programmed cell death in ovarian cancer. Oncogene, 2008. 27(22): $p$. 3081-3090.

106. Sandig, V., R. Youil, A.J. Bett, L.L. Franlin, M. Oshima, D. Maione, F. Wang, M.L. Metzker, R. Savino, and C.T. Caskey, Optimization of the helper-dependent adenovirus system for production and potency in vivo. Proc Natl Acad Sci U S A, 2000. 97(3): p. 1002-7.

107. Graham, F.L., J. Rudy, and P. Brinkley, Infectious circular DNA of human adenovirus type 5: regeneration of viral DNA termini from molecules lacking terminal sequences. EMBO J, 1989. 8(7): p. 2077-85.

108. Bett, A.J., W. Haddara, L. Prevec, and F.L. Graham, An efficient and flexible system for construction of adenovirus vectors with insertions or deletions in early regions 1 and 3. Proc Natl Acad Sci U S A, 1994. 91(19): p. 8802-6.

109. Zhang, W., J.A. Low, J.B. Christensen, and M.J. Imperiale, Role for the adenovirus IVa2 protein in packaging of viral DNA. J Virol, 2001. 75(21): p. $10446-54$.

110. Pardo-Mateos, A. and C.S. Young, Adenovirus IVa2 protein plays an important role in transcription from the major late promoter in vivo. Virology, 2004. 327(1): p. 50-9.

111. Webster, A., I.R. Leith, and R.T. Hay, Domain organization of the adenovirus preterminal protein. J Virol, 1997. 71(1): p. 539-47. 
112. Tamanoi, F. and B.W. Stillman, Function of adenovirus terminal protein in the initiation of DNA replication. Proc Natl Acad Sci U S A, 1982. 79(7): p. 2221-5.

113. van Breukelen, B., A.B. Brenkman, P.E. Holthuizen, and P.C. van der Vliet, Adenovirus type 5 DNA binding protein stimulates binding of DNA polymerase to the replication origin. J Virol, 2003. 77(2): p. 915-22.

114. Gustin, K.E. and M.J. Imperiale, Encapsidation of viral DNA requires the adenovirus L1 52/55-kilodalton protein. J Virol, 1998. 72(10): p. 7860-70.

115. Hasson, T.B., D.A. Ornelles, and T. Shenk, Adenovirus L1 52- and 55kilodalton proteins are present within assembling virions and colocalize with nuclear structures distinct from replication centers. J Virol, 1992. 66(10): p. 6133-42.

116. Paterson, C.P., L.E. Ayalew, and S.K. Tikoo, Mapping of nuclear import signal and importin alpha3 binding regions of 52K protein of bovine adenovirus-3. Virology, 2012. 432(1): p. 63-72.

117. Chatterjee, P.K., M.E. Vayda, and S.J. Flint, Identification of proteins and protein domains that contact DNA within adenovirus nucleoprotein cores by ultraviolet light crosslinking of oligonucleotides 32P-labelled in vivo. $\mathrm{J}$ Mol Biol, 1986. 188(1): p. 23-37.

118. Chatterjee, P.K., M.E. Vayda, and S.J. Flint, Interactions among the three adenovirus core proteins. J Virol, 1985. 55(2): p. 379-86.

119. Matthews, D.A. and W.C. Russell, Adenovirus core protein V interacts with p32--a protein which is associated with both the mitochondria and the nucleus. J Gen Virol, 1998. 79 ( Pt 7): p. 1677-85.

120. Alva, V., M. Ammelburg, J. Soding, and A.N. Lupas, On the origin of the histone fold. BMC Struct Biol, 2007. 7: p. 17.

121. Perez-Vargas, J., R.C. Vaughan, C. Houser, K.M. Hastie, C.C. Kao, and G.R. Nemerow, Isolation and characterization of the DNA and protein binding activities of adenovirus core protein V. J Virol, 2014. 88(16): p. 9287-96.

122. Xue, B., R.L. Dunbrack, R.W. Williams, A.K. Dunker, and V.N. Uversky, PONDR-FIT: a meta-predictor of intrinsically disordered amino acids. Biochim Biophys Acta, 2010. 1804(4): p. 996-1010. 
123. Tormanen, H., E. Backstrom, A. Carlsson, and G. Akusjarvi, L4-33K, an adenovirus-encoded alternative RNA splicing factor. J Biol Chem, 2006. 281(48): p. 36510-7.

124. Wu, K., D. Guimet, and P. Hearing, The adenovirus L4-33K protein regulates both late gene expression patterns and viral DNA packaging. $\mathrm{J}$ Virol, 2013. 87(12): p. 6739-47.

125. Ali, H., G. LeRoy, G. Bridge, and S.J. Flint, The adenovirus L4 33kilodalton protein binds to intragenic sequences of the major late promoter required for late phase-specific stimulation of transcription. J Virol, 2007. 81(3): p. 1327-38.

126. Ma, H.C. and P. Hearing, Adenovirus structural protein Illa is involved in the serotype specificity of viral DNA packaging. J Virol, 2011. 85(15): $p$. 7849-55.

127. Shenk, T.J., Adenoviridae: the viruses and their replication. In: HowleyDMKP (ed) Fields virology. 1996, Lippincott-Raven, Philadelphia (1996),. p. pp. 2111 - 2148.

128. Bergstrom Lind, S., K.A. Artemenko, L. Elfineh, Y. Zhao, J. Bergquist, and U. Pettersson, Post translational modifications in adenovirus type 2. Virology, 2013. 447(1-2): p. 104-11.

129. Mangel, W.F. and C. San Martin, Structure, function and dynamics in adenovirus maturation. Viruses, 2014. 6(11): p. 4536-70.

130. Vellinga, J., S. Van der Heijdt, and R.C. Hoeben, The adenovirus capsid: major progress in minor proteins. J Gen Virol, 2005. 86(Pt 6): p. 1581-8.

131. Molinier-Frenkel, V., R. Lengagne, F. Gaden, S.S. Hong, J. Choppin, H. Gahery-Segard, P. Boulanger, and J.G. Guillet, Adenovirus hexon protein is a potent adjuvant for activation of a cellular immune response. J Virol, 2002. 76(1): p. 127-35.

132. Bruder, J.T., E. Semenova, P. Chen, K. Limbach, N.B. Patterson, M.E. Stefaniak, S. Konovalova, C. Thomas, M. Hamilton, C.R. King, T.L. Richie, and D.L. Doolan, Modification of Ad5 hexon hypervariable regions circumvents pre-existing Ad5 neutralizing antibodies and induces protective immune responses. PLoS One, 2012. 7(4): p. e33920.

133. Arnold, U. and R.T. Raines, Replacing a single atom accelerates the folding of a protein and increases its thermostability. Org Biomol Chem, 2016. 14(28): p. 6780-5. 
134. Reddy, V.S. and G.R. Nemerow, Structures and organization of adenovirus cement proteins provide insights into the role of capsid maturation in virus entry and infection. Proc Natl Acad Sci U S A, 2014. 111(32): p. 11715-20.

135. Nettelbeck, D.M., V. Jerome, and R. Muller, Gene therapy: designer promoters for tumour targeting. Trends Genet, 2000. 16(4): p. 174-81.

136. Wechman, S.L., X.M. Rao, K.M. McMasters, and H.S. Zhou, Adenovirus with DNA Packaging Gene Mutations Increased Virus Release. Viruses, 2016. 8(12).

137. Yang, Z., Z. Zhu, L. Tang, L. Wang, X. Tan, P. Yu, Y. Zhang, X. Tian, J. Wang, Y. Zhang, D. Li, and W. Xu, Genomic analyses of recombinant adenovirus type 11a in China. J Clin Microbiol, 2009. 47(10): p. 3082-90.

138. Huebner, R.J., W.P. Rowe, W.E. Schatten, R.R. Smith, and L.B. Thomas, Studies on the use of viruses in the treatment of carcinoma of the cervix. Cancer, 1956. 9(6): p. 1211-8.

139. Jiang, H., C. Gomez-Manzano, R. Alemany, D. Medrano, M. Alonso, B.N. Bekele, E. Lin, C.C. Conrad, W.K. Yung, and J. Fueyo, Comparative effect of oncolytic adenoviruses with E1A-55 kDa or E1B-55 kDa deletions in malignant gliomas. Neoplasia, 2005. 7(1): p. 48-56.

140. Baehrecke, E.H., Autophagy: dual roles in life and death? Nat Rev Mol Cell Biol, 2005. 6(6): p. 505-10.

141. Klionsky, D.J., H. Abeliovich, P. Agostinis, D.K. Agrawal, G. Aliev, D.S. Askew, M. Baba, E.H. Baehrecke, B.A. Bahr, A. Ballabio, B.A. Bamber, D.C. Bassham, E. Bergamini, X. Bi, M. Biard-Piechaczyk, J.S. Blum, D.E. Bredesen, J.L. Brodsky, J.H. Brumell, U.T. Brunk, et al., Guidelines for the use and interpretation of assays for monitoring autophagy in higher eukaryotes. Autophagy, 2008. 4(2): p. 151-75.

142. Klionsky, D.J. and S.D. Emr, Autophagy as a regulated pathway of cellular degradation. Science, 2000. 290(5497): p. 1717-21.

143. Khuri, F.R., J. Nemunaitis, I. Ganly, J. Arseneau, I.F. Tannock, L. Romel, M. Gore, J. Ironside, R.H. MacDougall, C. Heise, B. Randlev, A.M. Gillenwater, P. Bruso, S.B. Kaye, W.K. Hong, and D.H. Kirn, a controlled trial of intratumoral ONYX-015, a selectively-replicating adenovirus, in combination with cisplatin and 5-fluorouracil in patients with recurrent head and neck cancer. Nat Med, 2000. 6(8): p. 879-85. 
144. Kimball, K.J., M.A. Preuss, M.N. Barnes, M. Wang, G.P. Siegal, W. Wan, H. Kuo, S. Saddekni, C.R. Stockard, W.E. Grizzle, R.D. Harris, R. Aurigemma, D.T. Curiel, and R.D. Alvarez, A phase I study of a tropismmodified conditionally replicative adenovirus for recurrent malignant gynecologic diseases. Clin Cancer Res, 2010. 16(21): p. 5277-87.

145. Campbell, G.R., R.S. Bruckman, Y.L. Chu, and S.A. Spector, Autophagy induction by histone deacetylase inhibitors inhibits HIV type 1. J Biol Chem, 2015. 290(8): p. 5028-40.

146. Yakoub, A.M. and D. Shukla, Autophagy stimulation abrogates herpes simplex virus-1 infection. Sci Rep, 2015. 5: p. 9730.

147. Zhang, R., X. Chi, S. Wang, B. Qi, X. Yu, and J.L. Chen, The regulation of autophagy by influenza A virus. Biomed Res Int, 2014. 2014: p. 498083.

148. Alers, S., A.S. Loffler, S. Wesselborg, and B. Stork, Role of AMPK-mTORUlk1/2 in the regulation of autophagy: cross talk, shortcuts, and feedbacks. Mol Cell Biol, 2012. 32(1): p. 2-11.

149. Meley, D., C. Bauvy, J.H. Houben-Weerts, P.F. Dubbelhuis, M.T. Helmond, P. Codogno, and A.J. Meijer, AMP-activated protein kinase and the regulation of autophagic proteolysis. J Biol Chem, 2006. 281(46): $p$. 34870-9.

150. O'Shea, C., K. Klupsch, S. Choi, B. Bagus, C. Soria, J. Shen, F. McCormick, and D. Stokoe, Adenoviral proteins mimic nutrient/growth signals to activate the mTOR pathway for viral replication. EMBO J, 2005. 24(6): p. 1211-21.

151. Cheng, X., H. Liu, C.C. Jiang, L. Fang, C. Chen, X.D. Zhang, and Z.W. Jiang, Connecting endoplasmic reticulum stress to autophagy through IRE1/JNK/beclin-1 in breast cancer cells. Int J Mol Med, 2014. 34(3): p. $772-81$.

152. Pattingre, S., A. Tassa, X. Qu, R. Garuti, X.H. Liang, N. Mizushima, M. Packer, M.D. Schneider, and B. Levine, Bcl-2 antiapoptotic proteins inhibit Beclin 1-dependent autophagy. Cell, 2005. 122(6): p. 927-39.

153. Zhou, Y.Y., Y. Li, W.Q. Jiang, and L.F. Zhou, MAPK/JNK signalling: a potential autophagy regulation pathway. Biosci Rep, 2015. 35(3).

154. Han, J., P. Sabbatini, D. Perez, L. Rao, D. Modha, and E. White, The E1B $19 \mathrm{~K}$ protein blocks apoptosis by interacting with and inhibiting the p53inducible and death-promoting Bax protein. Genes Dev, 1996. 10(4): p. 461-77. 
155. Li, G., Y. Xiang, K. Sabapathy, and R.H. Silverman, An apoptotic signaling pathway in the interferon antiviral response mediated by RNase $L$ and $c$ Jun NH2-terminal kinase. J Biol Chem, 2004. 279(2): p. 1123-31.

156. Oleinik, N.V., N.I. Krupenko, and S.A. Krupenko, Cooperation between JNK1 and JNK2 in activation of p53 apoptotic pathway. Oncogene, 2007. 26(51): p. 7222-30.

157. Zheng, X., X.M. Rao, C. Snodgrass, M. Wang, Y. Dong, K.M. McMasters, and H.S. Zhou, Adenoviral E1a expression levels affect virus-selective replication in human cancer cells. Cancer Biol Ther, 2005. 4(11): p. 125562.

158. White, E. and R. Cipriani, Specific disruption of intermediate filaments and the nuclear lamina by the 19-kDa product of the adenovirus E1B oncogene. Proc Natl Acad Sci U S A, 1989. 86(24): p. 9886-90.

159. Romanov, V.S., A.I. Brichkina, H. Morrison, T.V. Pospelova, V.A. Pospelov, and P. Herrlich, Novel mechanism of JNK pathway activation by adenoviral E1A. Oncotarget, 2014. 5(8): p. 2176-86.

160. Berk, A.J., Adenovirus promoters and E1A transactivation. Annu Rev Genet, 1986. 20: p. 45-79.

161. Chou, T.C. and P. Talalay, Quantitative analysis of dose-effect relationships: the combined effects of multiple drugs or enzyme inhibitors. Adv Enzyme Regul, 1984. 22: p. 27-55.

162. Klein, S.R., H. Jiang, M.B. Hossain, X. Fan, J. Gumin, A. Dong, M.M. Alonso, C. Gomez-Manzano, and J. Fueyo, Critical Role of Autophagy in the Processing of Adenovirus Capsid-Incorporated Cancer-Specific Antigens. PLoS One, 2016. 11(4): p. e0153814.

163. Gomez-Gutierrez, J.G., J. Nitz, R. Sharma, S.L. Wechman, E. Riedinger, E. Martinez-Jaramillo, H. Sam Zhou, and K.M. McMasters, Combined therapy of oncolytic adenovirus and temozolomide enhances lung cancer virotherapy in vitro and in vivo. Virology, 2016. 487: p. 249-59.

164. Piya, S., E.J. White, S.R. Klein, H. Jiang, T.J. McDonnell, C. GomezManzano, and J. Fueyo, The E1B19K oncoprotein complexes with Beclin 1 to regulate autophagy in adenovirus-infected cells. PLoS One, 2011. 6(12): p. e29467.

165. Okada, M., K. Shibuya, A. Sato, S. Seino, E. Watanabe, S. Suzuki, M. Seino, and C. Kitanaka, Specific role of JNK in the maintenance of the 
tumor-initiating capacity of A549 human non-small cell lung cancer cells. Oncol Rep, 2013. 30(4): p. 1957-64.

166. He, X.Y., J.X. Chen, X. Ou-Yang, Z. Zhang, and H.M. Peng, [Construction of let-7a expression plasmid and its inhibitory effect on $k$-Ras protein in A549 lung cancer cells]. Nan Fang Yi Ke Da Xue Xue Bao, 2010. 30(11): p. 2427-31.

167. Jiang, H., V. Martin, C. Gomez-Manzano, D.G. Johnson, M. Alonso, E. White, J. Xu, T.J. McDonnell, N. Shinojima, and J. Fueyo, The RB-E2F1 pathway regulates autophagy. Cancer Res, 2010. 70(20): p. 7882-93.

168. Wang, B., S. Ling, and W.C. Lin, 14-3-3Tau regulates Beclin 1 and is required for autophagy. PLoS One, 2010. 5(4): p. e10409.

169. Johnson, D.G. and J. Degregori, Putting the Oncogenic and Tumor Suppressive Activities of E2F into Context. Curr Mol Med, 2006. 6(7): p. 731-8.

170. Duyndam, M.C., H. van Dam, P.H. Smits, M. Verlaan, A.J. van der Eb, and A. Zantema, The N-terminal transactivation domain of ATF2 is a target for the co-operative activation of the c-jun promoter by $p 300$ and 12S E1A. Oncogene, 1999. 18(14): p. 2311-21.

171. McDonough, P.M., D.S. Hanford, A.B. Sprenkle, N.R. Mellon, and C.C. Glembotski, Collaborative roles for c-Jun N-terminal kinase, $c$-Jun, serum response factor, and Sp1 in calcium-regulated myocardial gene expression. J Biol Chem, 1997. 272(38): p. 24046-53.

172. Schneider-Poetsch, T., J. Ju, D.E. Eyler, Y. Dang, S. Bhat, W.C. Merrick, R. Green, B. Shen, and J.O. Liu, Inhibition of eukaryotic translation elongation by cycloheximide and lactimidomycin. Nat Chem Biol, 2010. 6(3): p. 209-217. 


\section{APPENDIX}

List of Abbreviations

3MA 3-methyladenine

Ad $\quad$ Adenovirus

Ad2 Adenovirus serotype 2

Ad5 Adenovirus serotype 5

Ads $\quad$ Adenoviruses

AEBSF 4-(2-aminoethyl)-benzenesulfonyl fluoride

AMPK AMP-activated protein kinase

ANOVA Analysis of Variance

AKT Protein Kinase B

ATF2 Cyclic AMP Dependent Transcription Factor

Atg Autophagy related

BAL Bronchoalveolar Lavage

CFDA China Food and Drug Administration

$\mathrm{ddH}_{2} \mathrm{O} \quad$ Double Distilled Water

DMEM Dulbecco's Modified Eagle Medium

E1A Early gene $1 \mathrm{~A}$ 


\begin{tabular}{|c|c|}
\hline E1B & Early gene $1 \mathrm{~B}$ \\
\hline EC50 & Effective Concentration $50 \%$ \\
\hline ECL & Enhanced Chemiluminescence \\
\hline FBS & Fetal Bovine Serum \\
\hline FDA & Food and Drug Administration \\
\hline GFP & Green Fluorescent Protien \\
\hline HRP & Horse Radish Peroxidase \\
\hline IFU & Infectious Viral Unit \\
\hline $\lg$ & Immunoglobin \\
\hline IGV & Integrated Genomics Viewer \\
\hline IT & Intratumoral injection \\
\hline IV & Intravenous injection \\
\hline LB & Luria-Bertani broth \\
\hline LC3 & Light Chain 3 \\
\hline MAPK & Mitogen Activated Protein Kinase \\
\hline $\mathrm{MOI}$ & Multiplicity of Infection \\
\hline OD & Opitical Density or absorbance \\
\hline IOD & Integrated Optical Density \\
\hline PBS & Phosphate Buffered Saline \\
\hline
\end{tabular}




$\begin{array}{ll}\text { PFU } & \text { Plaque Forming Units } \\ \text { PI3K } & \text { Phosphoinositide 3-Kinase } \\ \text { PI } & \text { Protease Inhibitor } \\ \text { PML-nb } & \text { Promyelocytic Leukemia ProteinNuclear Bodies } \\ \text { RCF } & \text { Relative Centrifugal Force } \\ \text { RIPA } & \text { Radioimmunoprecipitation Assay Buffer } \\ \text { RPM } & \text { Revolutions Per Minute } \\ \text { RPMI } & \text { Roswell Park Memorial Institute } \\ \text { SC } & \text { Subcutaneous injection } \\ \text { SDS } & \text { Sodium Dodecyl Sulfate } \\ \text { SEER } & \text { Surveillance Epidemiology and End Results } \\ \text { Ser } & \text { Serine } \\ \text { TBST } & \text { Tris-Buffered saline with Tween 20 } \\ \text { TNM } & \text { Tumor Nodes Metastatsis } \\ \text { Wt } & \text { Wild-type }\end{array}$




\author{
CURRICULUM VITAE \\ Stephen Lindsey Wechman, Ph.D. \\ Postdoctoral Fellow \\ 1220 E. Broad St. \\ MMRB, rm 4003h \\ Richmond, VA, 23298 \\ Phone \#: (502) 316-0370 \\ Fax \# : (804) 827-1124 \\ e-mail: Stephen.Wechman@vcuhealth.org \\ Last updated: 4/6/2017
}

\section{EDUCATION}

$2011-2017$

$2011-2015$

$2007-2011$
Ph.D. in Pharmacology and Toxicology, University of Louisville, Louisville, KY M.S. in Pharmacology and Toxicology, University of Louisville, Louisville, KY

B.S. in Biology, Georgetown College, Georgetown, KY

\title{
ACADEMIC APPOINTMENTS
}

2017 - Postdoctoral Fellow, NIH-sponsored

Department of Human and Molecular Genetics

Virginia Commonwealth University, Richmond, VA

Supervisor: Dr. Paul Fisher

Projects: MDA-7 and MDA-9 were discovered by the Fisher lab following subtraction hybridization melanoma cells which were induced to terminally differentiate. MDA-7 (IL-24) is a potent immuno-stimulatory cytokine capable of destroying metastatic lesions in vivo. MDA-9 is associated with cancer cell metastasis, invasion, virus infection and intracellular membrane trafficking. 1) The effects of MDA-7 and MDA-9 upon Ad replication. 2) Elucidating the interaction partners of MDA-9 associated with its oncogenic effects and the utility of PDZ1,2-domain specific MDA-9 inhibitors for their cancer therapeutic efficacy.

2011 - 2017 Graduate Research Assistant

Department of Pharmacology and Toxicology

University of Louisville, Louisville, KY

Supervisors: Dr. Kelly McMasters and Dr. Heshan Zhou

Masters Thesis Title: Improved Oncolytic Virotherapy By Increasing Virus Spread Within tumors.

Doctoral Dissertation Title: Characterization of a Mutant Oncolytic Adenovirus and the Role of JNK in Enhancing Virotherapy.

Oncolytic adenoviruses: studied oncolytic Ad therapy with emphasis upon autophagy, JNK using cell culture, Western blot, expression vectors, murine xenograft, and DNA sequencing technologies. 
2013 - 2014 Teaching Assistant, Introduction to Pharmacology (BIOL-395-01)

Department of Pharmacology and Toxicology

University of Louisville, Louisville, KY

Course Director: Dr. Steven Myers

Tasks: I was responsible for the instruction of two cancer chemotherapy lectures.

Dr. Myers and I actively discussed student performance and how to teach more effectively. Dr. Myers also provided insight into the challenges and rewards of being a professor who lectures to undergraduate and medical students.

\title{
OTHER APPOINTMENTS
}

2011

\author{
Fellowship, Research Assistant, Howard Hughes Medical Institute (HHMI) \\ Undergraduate Summer Research Assistant \\ Department of Biology \\ University of Kentucky, Lexington, KY \\ Supervisor: Dr. Gisela Garcia-Ramos \\ Modeling HIV-1 therapy: Mathematically modeled the effects of therapeutic HIV-1 \\ particles to inhibit the infection of CD4+ helper t cells and by pathogenic HIV-1 \\ virus particles using differential equations and MATLAB simulations.
}

\section{PROFESSIONAL MEMBERSHIPS AND ACTIVITIES}

2012 - Member, KAS, Kentucky Academy of Science

2014 - Member, AACR, American Association for Cancer Research

2015 - Member, AAAS, American Association for the Advancement of Science

2016 - Member, NPA, National Postdoctoral Association

2017 - Member, IRACDA, Institutional Research and Academic Career Development Award

2017 - Member, NRMN, National Research Mentoring Network

\section{HONORS AND AWARDS}

2003 Eagle Scout Award, Boy Scouts of America

2010 Fellowship, Georgetown College Program for the Accelerated Learning in Sciences (GCPALS) fellowship awarded via the Howard Hughes medical institute, Georgetown College, Georgetown, KY

2011 Top 15\% Worldwide, Mathematical Competition in Modeling (MCM), Georgetown College, Georgetown, KY

2011 Fellowship, Integrated Programs in Biomedical Sciences (IPIBS), University of Louisville, Louisville, KY

2013 Fellowship, Surgery chairmen scholarship, University of Louisville, Louisville, KY

2013 Featured in "College to Career" publication, Georgetown College, Georgetown, KY

$20133^{\text {rd }}$ place, Research Louisville!, University of Louisville, Louisville, KY

$20131^{\text {st }}$ place, Kentucky Academy of Science, Morehead University, Morehead, KY

$201422^{\text {nd }}$ place, Research Louisville!, University of Louisville, Louisville, KY

$20142^{\text {nd }}$ place, 'Condict Moore research prize', James Graham Brown Cancer Center Retreat, University of Louisville, Louisville, KY

$20142^{\text {nd }}$ place, Kentucky Academy of Sciences, University of Kentucky, Lexington, KY

$2016 \mathrm{NIH}$ fellowship, Institutional Research and Academic Career Development Awards (IRACDA), Virginia Commonwealth University, Richmond, VA

2017 Dean's citation for Ph.D. degree, top 10\% of Ph.D. Graduates from the department of Pharmacology and Toxicology, University of Louisville, Louisville, KY

\section{INVITED REVIEWER}

Virology Journal 
TEACHING ACTIVITIES

University of Louisville (2013 to 2016; all courses were team taught.)

$\underline{2013}$

- 11/18 Instructor, DHED-402-01 “Dental Pharmacology: Cancer Chemotherapy Lecture"

- 9/9 Instructor, Patient SIM session "Pharmacology SIM Session on Autonomics"

- 4/16 Instructor, BIOL-395-01 "Cancer Chemotherapy: part 2 chemotherapy drugs"

- 4/11 Instructor, BIOL-395-01 "Cancer Chemotherapy: cancer and the cell cycle"

- Spring Teaching assistant to Dr. Steven Myers, BIOL-395 Introduction to pharmacology

2014

- 8/29 Instructor, Patient SIM session "Pharmacology SIM Session on Autonomics"

- 4/12 Instructor, BIOL-395-01 "Cancer Chemotherapy: cancer chemotherapeutics"

- 4/10 Instructor, BIOL-395-01 "Cancer Chemotherapy: cancer and the cell cycle"

- 3/18 Instructor, BIOL-395-01 "Hormone Pharmacology: Androgens and Estrogens"

$\underline{2015}$

- 11/17 Instructor, DHED-402-01 “Dental Pharmacology: Cancer Chemotherapy Lecture"

$\underline{2016}$

- 4/7 Instructor, BIOL-395-01 "Cancer Chemotherapy: cancer chemotherapeutics"

- 4/5 Instructor, BIOL-395-01 "Cancer Chemotherapy: cancer and the cell cycle"

- 11/15 Instructor, DHED-402-01 "Dental Pharmacology: Cancer Chemotherapy Lecture"

\section{GRANTS AND CONTRACTS}

\section{Current}

Fellowship, Institutional Research and Academic Career Development Awards (VCU-IRACDA)

Role in Project: Postdoctoral Fellow

Principal Investigator: Dr. Paul Fisher

Co-Principal Investigator: Dr. Joyce Lloyd

Funding Agency: National institute of Health

Project Period: $2 / 27 / 2017$ to 2/25/2020

Project Award: $\$ 162,631$ (total, over three years)

Past

Fellowship, Surgery Chairmen Scholarship

Role in Project: Graduate Student Researcher, University of Louisville

Principal Investigator: Dr. Kelly McMasters

Funding Agency: Department of Surgery, University of Louisville

Project Period: June 1, 2013 to present

Project Award: $\$ 60,489$ (total)

Fellowship, Georgetown College Program for accelerated learning in the sciences (GCPALS)

Role in Project: Undergraduate Researcher, Georgetown College

Principal Investigator: Mark Christensen (Georgetown College)

Funding Agency: Howard Hughes Medical Institute

Project Period: May 3, 2010 to August 6, 2010

Project Award: $\$ 4,000$ (total) 
Fellowship, Integrated Programs in Biomedical Sciences (IPIBS)

Role in Project: Graduate Student Researcher, University of Louisville

Principal Investigator: Thomas Geoghegan (University of Louisville)

Funding Agency: University of Louisville

Project Period: August 1, 2011 to June 1, 2013

Project Award: $\$ 40,326$ (total)

\section{ORAL PRESENTATIONS}

\section{Invited talks}

1. Wechman SL. 2016. Oncolytic Ads, Autophagy, and E1b. Dr. Charkavarti Lab Research Retreat. Ohio State University, Columbus, Ohio. (Inviter: Dr. Arnab Charkarvarti, Professor)

2. Wechman SL. 2016. Oncolytic Ads, Autophagy, and E1b. Translational Head and Neck Cancer Research Seminar. Ohio State University, Columbus, Ohio. (Inviter: Dr. Quintin Pan, Professor)

3. Wechman SL. 2016. Oncolytic Ads, Autophagy, and E1b. Seminar for Dr. Byrd's lab. Ohio State University, Columbus, Ohio. (Inviter: Dr. John Byrd, Professor)

4. Wechman SL. 2016. Oncolytic Ads, Autophagy, and E1b. Seminar for Dr. Fisher's lab. Virginia Commonwealth University, Richmond, Virginia. (Inviter: Dr. Paul Fisher, Professor)

5. Wechman, SL. 2016. Lessons Learned From: My work, UofL, Teaching and Job hunting. Howard Hughes medical institute sponsored GCPAL seminar series. Georgetown College, Georgetown, Kentucky. (Inviter: Dr. Tim Griffith, Associate Professor)

\section{Local/Regional Meetings}

1. Wechman SL, Rao XM, Zhou HS, McMasters KM. 2013. AdUV has greater potency, replication, and spread within lung cancer cells. Kentucky Academy of Science, Health Sciences section, Moorhead University, Moorhead, Kentucky.

2. Wechman SL, Rao XM, McMasters KM, Zhou HS. 2014. Next generation oncolytic therapy is highly active against lung cancer. OVSOT Summer Meeting, University of Louisville, Louisville, Kentucky.

3. Wechman SL, Rao XM, Gao H, McMasters KM, Zhou HS. 2014. Viability of losartan and other anti-fibrotics in combination with oncolytic adenovirus therapy. Kentucky Academy of Science, Health Sciences section, University of Kentucky, Lexington, Kentucky.

\section{POSTERS}

\section{National/international Meetings}

1. Wechman SL, Rao XM, Cheng PH, McMasters KM, Zhou HS. 2016. Improved Oncolytic Virotherapy by Increasing Adenovirus Spread. Poster \# 3753, American Association for Cancer Research, Gene and Vector-Based Therapy section, New Orleans, Louisiana .

\section{Local/Regional Meetings}


1. Wechman SL, and Garcia-Ramos G. 2011. Comparisons of inhibitory techniques against HIV-1 using recombinant viruses. Kentucky Academy of Sciences, Cellular and Molecular Biology section, Murray, Kentucky.

2. Wechman SL, Rao XM, Cheng PH, Hao H, Gomez-Gutierrez JG, McMasters KM, Zhou HS. 2012. Insights from novel UV mutant oncolytic E1b-deleted adenoviruses for cancer gene therapy. Research! Louisville, Louisville, Kentucky.

3. Wechman SL, Rao XM, McMasters KM, Zhou HS. 2013. AdUV has greater potency, replication, and spread within lung cancer cells. Research! Louisville, Louisville, Kentucky.

4. Wechman SL, Rao XM, McMasters KM, Zhou HS. 2013. AdUV has greater potency, replication, and spread within lung cancer cells. Brown Cancer Center Retreat, Louisville, Louisville, KY.

5. Wechman SL, Rao XM, McMasters KM, Zhou HS. 2014. AdUV has greater potency, replication, and spread within lung cancer cells. Research! Louisville, University of Louisville, Louisville, Kentucky.

6. Gao H, Rao XM, Wechman SL, McMasters KM, Zhou HS 2014. Viability of losartan and other anti-fibrotics in combination with oncolytic adenovirus therapy. Research! Louisville, University of Louisville, Louisville, Kentucky.

7. Wechman SL, Rao XM, McMasters KM, Zhao HS 2014. AdUV has greater potency, replication, and spread within lung cancer cells. James Graham Brown Cancer Center Retreat, University of Louisville, Louisville, Kentucky.

8. Gao H, Rao XM, Wechman SL, McMasters KM, Zhao, HS. 2014. Viability of losartan and other anti-fibrotics in combination with oncolytic adenovirus therapy. James Graham Brown Cancer Center Retreat, University of Louisville, Louisville, Kentucky.

9. Wechman SL, Rao XM, Cheng PH, McMasters KM, Zhou HS. 2015. Improvement of Oncolytic Adenovirus efficacy via bioselection. Research Louisville, University of Louisville, Louisville, Kentucky.

10. Nitz J, Wechman SL, Reidinger E, Sharma R, Zhou HS, McMasters KM, GomezGutierrez JG. 2015. Combined Therapy of Oncolytic Adenovirus and Temozoloamide Enhances Lung cancer virotherapy in vitro and in vivo. Research! Louisville, University of Louisville, Louisville, Kentucky.

11. Kemper N, Rao XM, Wechman SL, Zhou HS, McMasters KM. 2015. I3C Decreases Cyclin E expression and represses cancer cell growth. Research! Louisville, University of Louisville, Louisville, Kentucky.

12. Wechman SL, Rao XM, Zhou HS, McMasters KM. 2016. Improvement of Oncolytic Adenovirus Efficacy via Repeated UV-Irradiation and Cancer Selection. Research! Louisville, University of Louisville, Louisville, Kentucky.

13. Wechman SL, Rao XM, Zhou HS, McMasters KM. 2016. Improvement of Oncolytic Adenovirus Efficacy via Repeated UV-Irradiation and Cancer Selection. Kentucky Lung Cancer Research Program (KLCR). University of Kentucky, Lexington, Kentucky. 


\section{Published manuscripts}

1. Cheng PH, Wechman SL, McMasters KM, Zhou HS. 2015. Review. Oncolytic replication of E1b-deleted Adenoviruses. Viruses. 7(11):5767-5779. DOI: 10.3390/v7112905

2. Gomez-Gutierrez JG, Nitz J, Sharma R, Wechman SL, Riedinger E, Martinez-Jaramillo E, Zhao HS, McMasters KM. 2015. Combined Therapy of Oncolytic Adenovirus and Temozolomide Enhances Lung Cancer Therapy in vitro and in vivo. Virology. 487:249259. DOI: 10.1016

3. Cheng PH, Rao XM, Wechman SL, McMasters KM, Zhou HS. 2015. Oncolytic Adenovirus Targeting Cyclin E Overexpression Repressed Tumor Growth in Syngeneic Immunocompetent Mice. BMC Cancer. 15(1):716-727. DOI: 10.1186/s12885-015-1731-x

4. Wechman SL, Rao XM, Cheng PH, Gomez-Gutierrez JG, McMasters KM, Zhou HS. 2016. Development of an Oncolytic Adenovirus with Enhanced Spread Ability Through Repeated UV Irradiation and Cancer Selection. Viruses. 8(6):167-181. DOI:10.3390/v8060167

5. Wechman SL, Rao XM, McMasters KM, Zhou HS. Adenovirus with DNA Packaging Gene Mutations Increased Virus Release. Viruses 2016, 8(12), 333 doi:10.3390/v812033

\section{Submitted Manuscripts}

1. Martinez-Jaramillo $E^{*}$, Wechman $S^{*}$, Shirwan $H$, Montes-de-Oca-Luna R, Zhou HS, McMasters KM, Gomez-Gutierrez JG. Adenovirus lacking E1b efficiently induces cytopathic effect in HPV-16-positive murine cancer cells via virus replication and apoptosis. Submitted to Cancer Investigation.

(Note: * denotes equal contribution to the manuscript)

\section{Manuscripts in progress}

1. Wechman SL, Rao XM, McMasters KM, Zhou HS. DNA sequence analysis of a mutant oncolytic adenovirus displaying enhanced cancer cell lysis.

2. Wechman SL, Rao XM, McMasters KM, Zhou HS. The Role of JNK Phosphorylation as a Molecular Target to Enhanced Adenovirus Replication, Oncolysis and Cancer Therapeutic Efficacy.

\section{PANEL DISCUSSIONS}

1. Invited speaker, "Interested in graduate school?" a panel discussion for current Georgetown College Students. Georgetown College, Georgetown, KY, September 27, 2012. (Inviter: Dr. Tim Griffith, Associate Professor)

2. Inviter speaker, Panel discussion about the transition between Undergraduate and Graduate school for current Virginia State University Students. Virginia State University, Richmond, VA, April, 5, 2017. (Inviter: Dr. Leslie Whiteman, Associate Professor)

\section{COMMUNITY SERVICE}

Member, Newtown Christian Church, Choir (2005-2011)

Deacon, Newtown Christian Church (2010-2011)

Head Deacon, Newtown Christian Church (2010)

Judge, Louisville Regional Science \& Engineering fair, Junior Biomedical sciences division (2016)

Volunteer, Splat Out Cancer, University of Louisville James Graham Brown Cancer Center (2016) 


\section{SKILLS}

\section{Lab skills:}

Cell culture, western blot analysis, DNA transfection, bacterial transformation, DNA digestion, level 2 animal training (mice), intratumoral injection, subcutaneous injection, intraparenteral injection, tail vein injection, microtome based frozen tissue sectioning, H\&E staining, immunohistochemistry, handling and propagation adenoviruses, DNA sequence analysis, cancer cell cloning, CRISPR/Cas9 gene editing technology and statistical analysis (trained by Dr. Shesh N. Rai, director of biostatistics at UofL).

\section{Computer skills:}

Advanced knowledge of excel spreadsheet and forumula manipulation, word, powerpoint, western blot densitometry, Graphpad Prism, Integrated genomics viewer (IGV), ImageJ, Gelpro 3.2, calcusyn, Gel pro analyzer 4.0, and math models using differential equations and MATLAB.

\section{Soft skills:}

Skilled presenter ( 5 awards / 8 attempts $=62.5 \%$ ), excellent interpersonal verbal communication skills, lecturer (12 lectures), and experienced student mentor (11 summer students).

\section{REFERENCES}

Dr. Kelly McMasters

Phone \#: (502) 852-5447

e-mail: kelly.mcmasters@louisville.edu

Dr. McMasters is my primary research advisor and chairman of my $\mathrm{PhD}$ dissertation committee since 11 / 2011. He has paid my stipend and provided critical insight and direction to the completion of my PhD project.

Dr. Heshan Sam Zhou

Phone \#: (502) 852-5745

e-mail: hszhou01@louisville.edu

My primary supervisor since 11 / 2011. Dr. Zhou focuses upon the study of cancer gene therapy and has directed my research and served on my Ph.D. dissertation committee.

Dr. Jorge Gomez-Gutierrez

Phone \#: (502) 852-8464

e-mail: jgguti01@louisville.edu

Assistant professor and co-author, we have worked together closely since 11 / 2011. 